\title{
Molecular cytogenetic analysis in the study of brain tumors: findings and applications
}

\author{
Jane Bayani, M.H.Sc., Ajay Pandita, D.V.M., Ph.D., and Jeremy A. Squire, Ph.D. \\ Department of Applied Molecular Oncology, Ontario Cancer Institute, Princess Margaret Hospital, \\ University Health Network; Arthur and Sonia Labatt Brain Tumor Research Centre, Hospital for Sick \\ Children; and Departments of Laboratory Medicine and Pathobiology and Medical Biophysics, \\ University of Toronto, Ontario, Canada
}

\begin{abstract}
Classic cytogenetics has evolved from black and white to technicolor images of chromosomes as a result of advances in fluorescence in situ hybridization (FISH) techniques, and is now called molecular cytogenetics. Improvements in the quality and diversity of probes suitable for FISH, coupled with advances in computerized image analysis, now permit the genome or tissue of interest to be analyzed in detail on a glass slide. It is evident that the growing list of options for cytogenetic analysis has improved the understanding of chromosomal changes in disease initiation, progression, and response to treatment. The contributions of classic and molecular cytogenetics to the study of brain tumors have provided scientists and clinicians alike with new avenues for investigation. In this review the authors summarize the contributions of molecular cytogenetics to the study of brain tumors, encompassing the findings of classic cytogenetics, interphase- and metaphase-based FISH studies, spectral karyotyping, and metaphase- and array-based comparative genomic hybridization. In addition, this review also details the role of molecular cytogenetic techniques in other aspects of understanding the pathogenesis of brain tumors, including xenograft, cancer stem cell, and telomere length studies.
\end{abstract}

\section{KEY WORDS - fluorescence in situ hybridization • comparative genomic hybridization • spectral karyotyping • chromosome • microarray $\bullet$ gene amplification}

\section{A BRIEF HISTORY OF HUMAN CYTOGENETICS}

The science of human cytogenetics (see review by Smeets ${ }^{25}$ ) is attributed to the Austrian cytologist Walther Flemming, who published the first illustration of the human chromosome in 1882. Six years later, in 1888, Waldeyer introduced the term "chromosome." Sutton later

\footnotetext{
Abbreviations used in this paper: $\mathrm{ACTH}=$ adrenocorticotropic hormone; $\mathrm{BAC}=$ bacterial artificial chromosome CGAP $=$ Cancer Genome Anatomy Project; $\mathrm{CGH}=$ comparative genomic hybridization; $\mathrm{CI}=$ confidence interval; $\mathrm{CNS}=$ central nervous system; DAPI = 4,6'-diamino-2-phenylindole-dihydrochloride; DNET = dysembryoplastic neuroepithelial tumor; EGFR = epidermal growth factor receptor; FISH = fluorescence in situ hybridization; G-banding = Giemsa banding; GBM = glioblastoma multiforme; $\mathrm{GH}=$ growth hormone; $\mathrm{LOH}=$ loss of heterozygosity; NF1, NF2 = neurofibromatosis Types 1 and 2; PCR = polymerase chain reaction; $\mathrm{PNET}=$ primitive neuroectodermal tumor; $\mathrm{PNST}=$ peripheral nerve sheath tumor; PRL = prolactin; $\mathrm{SKY}=$ spectral karyotyping; TMA = tissue microarray; $\mathrm{TSH}=$ thyroid-stimulating hormone; $\mathrm{WHO}=$ World Health Organization.
}

combined the disciplines of cytology and genetics to coin the term cytogenetics: the study of chromosomes. The classic work of Theodor Boveri in the 1880 s provided the foundation for understanding chromosomes as the units of inheritance, their involvement in embryonic development, and later, their role in disease. He postulated that chromosomal changes could lead to the development of cancer. In 1959, the first human karyotypes prepared from peripheral lymphocytes were visualized by Hungerford and colleagues. ${ }^{109}$ The ability to visualize numerical and structural chromosomal abnormalities helped reveal the genetics of Down syndrome (trisomy 21), Turner syndrome $(45, \mathrm{X})$, and Klinefelter syndrome $(47, \mathrm{XXY}) .^{255}$

Cancer cytogenetics took a major leap in the late 1960s with studies of hematological malignancies, which finally led to the discovery of the Philadelphia chromosome $(\mathrm{Ph}),{ }^{180}$ which was later found to be a consistent chromosomal change among chronic myelogenous leukemias. ${ }^{230}$ These findings provided the impetus to identify consistent/ recurrent/nonrandom chromosomal changes in various disease conditions, yielding a plethora of simple and complex structural and numerical cytogenetic aberrations. 
The development of reliable cloning strategies in the 1980s facilitated the genomic analysis and sequencing of specific DNA fragments. In addition, improvements in fluorescence microscopy permitted the visualization of these cloned DNA fragments to the chromosomal target. The emergence of FISH in the late 1980s and early 1990s paved the way for an effective and direct means of mapping specific DNA fragments to their chromosomal locations. ${ }^{275} \mathrm{Be}-$ sides being used as an important tool for gene mapping, FISH was also applied to ascertain the presence, absence, copy number, or location(s) of a particular chromosomal locus/gene in cancer cells. The FISH analysis could be applied not only to chromosomes (metaphase-based FISH), but to the interphase nuclei (interphase-based FISH) of cultured specimens, as well as to cells from tissues embedded in paraffin, touch preparations, or smears.

The complexities and heterogeneity of karyotypes in some cancers forced investigators to find means of determining the overall genomic changes in a given tissue. The difficulty in obtaining good cytogenetic preparations from the majority of solid tumors led to the development of the two types of CGH assays: metaphase- and (micro)arraybased CGH. Comparative genomic hybridization is a twocolor FISH-based ${ }^{125}$ or array-based ${ }^{3}$ method used to identify the net gains and losses of genomic material in a given DNA sample. Equal amounts of tumor and normal DNA are differentially labeled, denatured, and hybridized to a normal metaphase spread or cloned DNA arrayed on glass slides. Any deviation in the ratio from 1 denotes gains or losses of those regions in the tumor DNA. This technique, which has enabled researchers to identify common regions of gain, loss, or high-level amplification without the need for actively dividing cells to provide metaphase spreads, is usefully applied to DNAs retrieved from archived material.

Although these methods proved to be useful in revealing patterns of genomic alterations among different tumors, the information regarding the way in which these genomic changes were exhibited (that is, simple deletions/balanced translocations compared with complex rearrangements/unbalanced translocations) in the karyotype was lost. The structural configurations in which amplifications, gains, and deletions were occurring could provide clues to the mechanisms influencing or causing these chromosomal alterations. In the past, the numerical and structural complexities of certain cancers made G-banding descriptions often incomplete and prone to errors. In the late 1990s SKY, a multicolor FISH assay, was developed; ${ }^{247}$ this technique permitted the visualization of the entire genome in one experiment (for review see Bayani and Squire ${ }^{12,14}$ ). It was now possible to identify the chromosomes involved in complex structural aberrations and to reveal subtle chromosomal translocations that otherwise would have been missed or incorrectly annotated.

Due to the large body of literature and space constraints, the citation of all findings will not be possible, and we apologize in advance to those authors for the omission of their contributions. In recent years, a number of online resources have become useful tools for cataloging molecular cytogenetic findings. In this review we refer mostly to the data accumulated in the CGAP website, which is properly known as the Mitelman Database of Chromosome Aberrations in Cancer (2005). Mitelman F, Johansson B and Mertens F (eds.) (http://cgap.nci.nih.gov/Chromosomes/Mitelman).
We also refer to the NCI and NCBI's SKY/M-FISH and CGH Database (2001) (http://www.ncbi.nlm.nih.gov/sky/ skyweb.cgi); the Progenetix CGH online database (http:// www.progenetix.net/); and PubMed/Medline (http://www. ncbi.nlm.nih.gov/entrez/query.fcgi). Readers are encouraged to visit these websites regularly for updates.

\section{CYTOGENETIC FINDINGS IN BRAIN NEOPLASMS}

\section{Neuroepithelial Tumors of the CNS: Glial Tumors}

Astrocytic Tumors. Astrocytic tumors comprise the largest and most common group of brain tumors. The subcategories of astrocytic tumors included in this review are as follows: astrocytomas, anaplastic astrocytomas, GBM, pilocytic astrocytomas, subependymal giant cell astrocytomas, and pleomorphic xanthoastrocytomas.

Astrocytomas, Anaplastic Astrocytomas, and GBMs. This group of glial tumors illustrates the potential for lowgrade astrocytomas to progress to a more malignant phenotype, and corresponds to the WHO grading of CNS tumors based on their histological features. Astrocytomas (WHO Grade II) are also known as low-grade diffuse astrocytomas and are characterized by slow growth and infiltration of neighboring brain structures. Anaplastic astrocytomas (WHO Grade III), also known as malignant and high-grade astrocytomas, may arise from a diffuse astrocytoma or de novo with no indication of a less malignant precursor. Glioblastomas or GBM (WHO Grade IV) may develop from a diffuse or an anaplastic astrocytoma (termed secondary GBM), but more commonly present de novo with no evidence of a less malignant precursor (termed primary GBM). The major genetic determinants that distinguish these two types of GBMs are EGFR amplification and TP53 mutation, ${ }^{110}$ with the first being predominantly associated with the spontaneous variant, and the latter being primarily associated with GBMs arising from malignant progression. Because progression toward malignancy typically arises from a precursor lesion, low- and high-grade astrocytomas share similar changes. Classic cytogenetic analyses have revealed that karyotypes range from being karyotypically normal to grossly abnormal in structure and chromosome number. A general observation has been that the progression in malignancy is concomitant with an increase in complexity, both in structure and ploidy. ${ }^{25}$

A survey of the CGAP site (http://cgap.nci.nih.gov/ Chromosomes/Mitelman) yields 102 low-grade astrocytomas $1,26,50,51,58,62,85,92,94,98,126,154,175,182,209,214,232,236,249,270,271,278,280,295,296$, ${ }_{298}$ (astrocytoma not otherwise specified/astrocytoma I and II) that possess normal or abnormal karyotypes with neardiploid chromosomal counts (45-53), most commonly with the loss of one of the sex chromosomes. The most common whole chromosomal gains and losses are as follows: $+7,-9,-10,+19$, and -22 . Tetraploid karyotypes represent approximately 25 to $30 \%$ of the karyotypes and recapitulate the findings in their diploid counterparts of whole chromosomal gains and losses. Structural chromosomal abnormalities present as partial deletions and translocations with the presence of structural changes including ring chromosomes. No specific, recurrent chromosomal translocation has been reported. 
In 410 cases of astrocytomas Grades II and IV found at

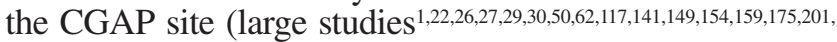
$207,211,249,270,295,298$ ), karyotypes similar to those among the lowgrade astrocytomas persist, namely normal karyotypes or those only missing a sex chromosome, as well as karyotypes with copy number changes from chromosomes 7, 9, 10,19 , and 22, as described earlier. As with the low-grade tumors, these karyotypes typically possess gains and losses of the entire chromosome. Karyotypes with tetraploid and triploid chromosomal counts occur more frequently, suggesting increasing genomic instability and errors in the mitotic machinery. ${ }^{176}$ Complex structural aberrations, including unbalanced translocations, insertions, the presence of double minute chromosomes, ring chromosomes, and unidentifiable "marker chromosomes" present more frequently, and contribute to the amplification of chromosomal regions that are believed to harbor oncogenes.

These gross findings from the conventional cytogenetic studies have been confirmed by $\mathrm{CGH}$ studies. In a survey of published results in 509 gliomas analyzed using $\mathrm{CGH}$ before 2001, ${ }^{134}$ common changes between the three astrocytic tumor types include partial or whole gains of chromosome 7 , loss of chromosome 10, loss of chromosome 22, and loss of $9 p$ and $13 q$, confirming the cytogenetic findings from the previous two decades. The $\mathrm{CGH}$ assay also has been used to identify novel regions of change, including gains at 1p34-p36, 12p13, and 20q13. When present, amplifications were characteristically found at $1 \mathrm{p} 36.2,3 \mathrm{q} 26.3-$ q27, 7p12, 7q21-q31, 8q24.1, 12p13, 12q13-q15, 17q24, $19 \mathrm{q} 13.2$, and $20 \mathrm{q} 13.1$, and net genomic losses at $1 \mathrm{p} 22$, 4q33-q35, 6q16, 6q23-q27, 9p21, 10q25-q26, 13q21.1, and $22 \mathrm{q} 13$. Examination of the Progenetix database reveals $\mathrm{CGH}$ profiles from 78 astrocytomas not otherwise specified, 60 anaplastic astrocytomas, and 108 glioblastomas. A majority of the cases referenced at this site have been reviewed by Koschny, et al., ${ }^{134}$ and the reader may also refer to the website for a listing of these cases and their references.

The composite genomic profiles show that the 78 astrocytomas not otherwise specified have overall net losses at chromosomes 1p (16.7\%), $2(20 \%), 3 p(3.9 \%), 4(7.7 \%), 9 p$ $(7.7 \%), 10 q(3 \%), 13 q 21(6.4 \%), 18(3.9 \%), 19 q(16.7 \%)$, and $\mathrm{X}(10 \%)$. Gains are primarily identified on chromosomes $5(7.7 \%), 7(16.7 \%)$ or $7 q(15 \%), 8 q(5.1 \%), 9(6 \%)$, $10 \mathrm{p}(7.7 \%), 12 \mathrm{p}(6.4 \%)$, and 19p (7.7\%). Amplifications are restricted to the region spanning $8 \mathrm{q} 21-8 \mathrm{qter}(2.6 \%)$. Among the 60 anaplastic astrocytomas, similar trends can be seen and the effects of changes in ploidy are apparent in the increase of whole chromosomal gains and losses across the genome. For anaplastic astrocytomas, losses were identified at $1 \mathrm{p}(20 \%), 3(10 \%), 8 \mathrm{p}(8 \%), 9 \mathrm{p}(21.7 \%), 10(26.7 \%)$, 12q21-qter (16.6\%), 13q11-q32 (20\%), $14(13.3 \%), 17 \mathrm{p}$ $(13.3 \%), 19 \mathrm{q}(22 \%)$, and $22(23.3 \%)$. Gains were identified at $1 \mathrm{q}(15 \%), 2 \mathrm{q}(13.3 \%), 5(5 \%)$ and $5 \mathrm{q} 11-\mathrm{q} 23(13.8 \%), 7$ $(35 \%), 8 \mathrm{q}(10 \%), 12 \mathrm{q} 11-\mathrm{q} 21(11.7 \%), 17 \mathrm{q}(8.3 \%)$, and 20 $(11.7 \%)$. Amplifications are present at 1p31 and 1p32 (10\% each), 7p11.2 (8.3\%), 7q21 (1.7\%), 7q22-q33 (3.3\%), 8q13$\mathrm{q} 23.3(3.3 \%), 12 \mathrm{q} 13-\mathrm{q} 21(1.7 \%), 15 \mathrm{q} 26(1.7 \%)$, and $20 \mathrm{p} 12$ (1.7\%). Among 108 glioblastomas, the affected chromosomes and overall frequency of gains and losses were found to be similar to those in the anaplastic group. In addition, the frequency of amplifications at the same chromosomal loci revealed some increases. Based on $\mathrm{CGH}$ studies, regions of amplification, gains, and loss have allowed identification of new candidate tumor suppressor genes and oncogenes as well as confirmation of the status of other genes previously identified using other molecular techniques. The roles of these and other putative tumor suppressor and oncogenes is reviewed in Ichimura, et al. ${ }^{110}$

Identification of the chromosomal changes associated with tumor progression was the subject of investigation in many early CGH studies. Weber, et al., ${ }^{291}$ identified alterations in primary astrocytomas (Grade II) to include losses on Xp and 5p, gains on $8 \mathrm{q}$ and $19 \mathrm{p}$, and gain/amplification on 12p. Common progression-associated changes found in anaplastic astrocytoma (Grade III) or GBM included losses on 4q, 9p, 10q, 11p, and 13q, and gains on 1q, 6p, and 20q. The most frequent amplification site in all tumors was located on $12 \mathrm{p} 13 .{ }^{291}$

In a similar study by Nishizaki and colleagues ${ }^{179}$ lowgrade astrocytomas were characterized by gains at $8 \mathrm{q}, 9 \mathrm{q}$, $12 q, 15 q$, and 20q; anaplastic astrocytomas were characterized by loss of 10q, 9p, and 13q, and gains of 1q, 7, 11q, and $\mathrm{Xq}$; and GBMs were characterized primarily by losses of $9 \mathrm{p}$, loss of all or part of chromosome 10, and loss of $13 \mathrm{q}$, $22 \mathrm{q}$, and $\mathrm{Xq}$. More recently, Wiltshire, et al., ${ }^{297}$ examined 102 astrocytomas by using $\mathrm{CGH}$ to identify the genomic changes associated with each histological subtype and its clinical findings. Low-grade astrocytomas (Grade I) showed losses of chromosome 19p. In Grades II and III, losses of $9 p$ and $10 q$ with gains of $19 p$ and $19 q$ were identified. Grade IV tumors obtained in patients younger than 45 years of age showed changes including the loss of $9 p$ and/or 9q, 10p and/or 10q, and chromosome 22, and gains of $7 p$ and/or $7 q$ and $19 p$. Tumors resected in patients older than 45 years of age had changes including the loss of $9 p$ and $10 p$ and/or $10 q$, and gains of $7 p$ and/or $7 q, 19 p$ and/or $19 \mathrm{q}$, and 20p and/or 20q. Cox proportional hazards statistical modeling showed that the presence of $+7 q$ and $10 q$ $\mathrm{CGH}$ alterations significantly increased a patient's risk of dying, independent of histological grade.

The information provided by these $\mathrm{CGH}$ studies has enabled investigators to validate these findings, both retrospectively and prospectively, by using conventional molecular assays; however, many have preferred to "FISH" the gene/chromosomal locus of interest directly to a cytogenetic specimen or tissue section. ${ }^{150,248}$ The "FISH-ing" of specific probes directly to tissue or cytogenetic specimens has since revealed the heterogeneity of the tumor genome. The FISH examinations of EGFR amplification have revealed that cells within a given tumor specimen possess different levels of gene amplification, ${ }^{185}$ information that is lost during the bulk DNA extraction of the specimen.

The technological improvements in microdissection methods in recent years have permitted investigators to select specific cells for extraction and study. This has helped researchers overcome the shortcomings of early CGH studies that were conducted using DNA contaminated with surrounding normal and abnormal cells. Proper and careful microdissection reduced or eliminated the "diluting" effects of contaminating cells with normal or questionable histological features. In a study by Hirose and associates, ${ }^{105} \mathrm{mi}-$ crodissection was used to extract small regions of pure tumor from the paraffin-embedded sections of Grade II astrocytomas for CGH analysis. Thirty cases of Grade II astrocytoma were analyzed, and copy number changes were 
detected in $83 \%$ of cases. The most frequent aberrations were gains on 7q, 5p, 9, and 19p. Losses were detected at $19 q, 1 p$, and Xp. As a result, two subgroups of Grade II astrocytomas were identified: those with a gain on $7 q$ and those with losses on $1 \mathrm{p} / 19 \mathrm{q}$. Because only the microdissected cells were shown to be purely astrocytic, not oligodendritic, the authors of this study suggest that genetic differences exist within the grade, and may be influenced by the patient's age and tumor location.

In addition to advancing researchers' ability to select specific cells for analysis, the increased resolution of arraybased CGH (see Albertson and Pinkel ${ }^{3}$ ) has resulted in refinements of genomic signatures to a $1-\mathrm{Mb}$ level, a significant improvement over the 5- to $10-\mathrm{Mb}$ resolution for metaphase-based CGH. Recently, Misra and coworkers ${ }^{171}$ used array-based CGH to identify subgroups among 50 primary Grade IV astrocytomas (GBMs). A 2246 BAC array with a mean $1.5-\mathrm{Mb}$ resolution was used. Thirty-three candidate sites for amplification and homozygous deletion were detected, and three major genetic subgroups within the GBM tumors were identified, including those with chromosome 7 gain and chromosome 10 loss; tumors with only chromosome 10 loss in the absence of chromosome 7 gain; and tumors without a copy number change in chromosomes 7 or 10. Correlation to clinical data suggested that there was no overall difference in survival between the groups; however, the group showing the loss of chromosome 10 and gain of chromosome 7 showed characteristics typical of GBM survivors, whereas the group without chromosome 10 loss or chromosome 7 gain showed characteristics of typical and long-term survivors.

The benefit of BAC array-based CGH is the ability to identify genes contained within the BAC contig, making validation possible by using FISH on cytogenetic or tissue specimens. Amplification of EGFR appeared to occur primarily in the group with chromosome 10 loss and chromosome 7 gain, and the authors postulated that this was associated with the primary form of GBM rather than the secondary form, which is associated with the group lacking chromosome 10 loss or chromosome 7 gain. The benefit from the increased resolution of array-based CGH is clear, and has led to much finer analysis beyond the level of individual chromosomes. De Stahl, et al., ${ }^{61}$ used a tiling-path array for chromosome 22 in a CGH experiment in 50 patients with GBM to identify germ-line and tumor-specific aberrations. Hemizygous deletions were detected in $28 \%$ of the tumors, with a predominant pattern of monosomy 22 in $20 \%$ of cases. The tiling nature of the array revealed the distribution of overlapping hemizygous deletions to delineate two putative tumor suppressor loci across 22q. Two distinct loci were affected by regional gains; both were of germ-line origin and were identified as TOP $3 B$ and TAFA, whose gene functions show promise for further investigation.

The advantage of CGH-based assays is the requirement of only small amounts of tumor DNA; thus, the need for mitotically active cells is not required, as it is in metaphase preparations of tumors. Nevertheless, invaluable information regarding the mechanism of genomic change/instability at the chromosomal level has been lost. The advent of whole-genome FISH assays provided the means for revealing the information classified as unidentifiable in classic cytogenetic studies (see Bayani and Squire ${ }^{14}$ ) and revealed the true complexity of the karyotypes. Furthermore, these studies provided clues to the nature of epigenetic changes. Several SKY studies revealed complex chromosomal

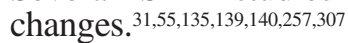

A study by our group ${ }^{257}$ examined glial tumors derived from short-term cultures by conventional cytogenetics, CGH, and SKY (http://www.ncbi.nlm.nih.gov/sky/). The combination of different molecular cytogenetic techniques allowed us to identify the frequent involvement of chromosomes 1 and 10, which were affected by translocations, in addition to chromosomes $3,5,7$, and 11 . No specific recurrent chromosomal translocation was identified; however, the resulting breakpoint analysis and the identification of chromosomal origins in complex aberrations and "marker" chromosomes, together with net genomic changes, provided a more comprehensive cytogenetic description of the tumors. An example of the SKY analysis of the glioma cell line SF549 is shown in Fig. 1. Breakpoint analysis also provided a chromosomal basis for disruption of gene function and expression, because breakpoints were found to occur near regions of gains/amplification and deletion detected using CGH analysis.

A larger study by Krupp and colleagues ${ }^{139}$ investigated 23 diffuse astrocytomas by combinations of either SKY, metaphase-based CGH, or metaphase-based FISH. According to their findings, most of the identified structural rearrangements were localized on chromosome arms $2 p$ and $7 \mathrm{q}$, with numerical changes most frequently involving chromosomes 7, Y, X, 10, and 17. A review of interphasebased FISH data indicated that cells with polysomy 7 were found in $75 \%$ of Grade II astrocytomas as well as in $100 \%$ of Grade III astrocytomas and GBM cases. Monosomy 10 was found in 75\% of Grades II and III astrocytomas as well as in $100 \%$ of GBM cases. More recently, Cowell, et al., ${ }^{55}$ examined four GBM cell lines derived from primary tumors by SKY and array-based CGH, with FISH and PCR validation experiments. Their findings confirmed previous molecular cytogenetic observations of GBMs: karyotypes with chromosomal counts near normal or in the triploid, tetraploid, or hexaploid range as well as complex structural changes. Using a 6000 BAC array, CGH enabled the identification of deletions at the 9p13 p21 region harboring the $C D K N 2 A$ gene (seen in all four tumors), which were confirmed with FISH assays. Amplifications of EGFR (7p12.3) were also identified and confirmed using PCR analysis.

Pilocytic Astrocytomas. Pilocytic astrocytomas, tumors classified as Grade I by WHO, typically occur in children and have a relatively good prognosis. ${ }^{110}$ These tumors can maintain their Grade I status over a long period of time and rarely become more malignant in phenotype. Results of classic cytogenetic analysis of pilocytic astrocytomas are characterized by normal karyotypes or abnormal karyotypes in the near-diploid range. As in the Grade II astrocytomas, whole chromosomal gains and losses characterized the tumors (particularly the loss of sex chromosomes) as well as the gains of chromosome 7, loss of 10, and loss of 22. The CGAP database describes 31 cases of pilocytic/juvenile astrocytomas. $22,30,62,117,207,225,295,306$

The Progenetix site currently reports nine cases ${ }^{250}$ of pilocytic (juvenile) astrocytomas, showing predominately losses for all of $1 \mathrm{p}(11 \%)$ or at 1p31-p36 (22\%), 3 (11\%), 14q11q24 (11\%), $15(11 \%)$, and 19, 20, 21, and 22 (each at 11\%). Gains occur predominately for chromosomes $4(22 \%)$ or 

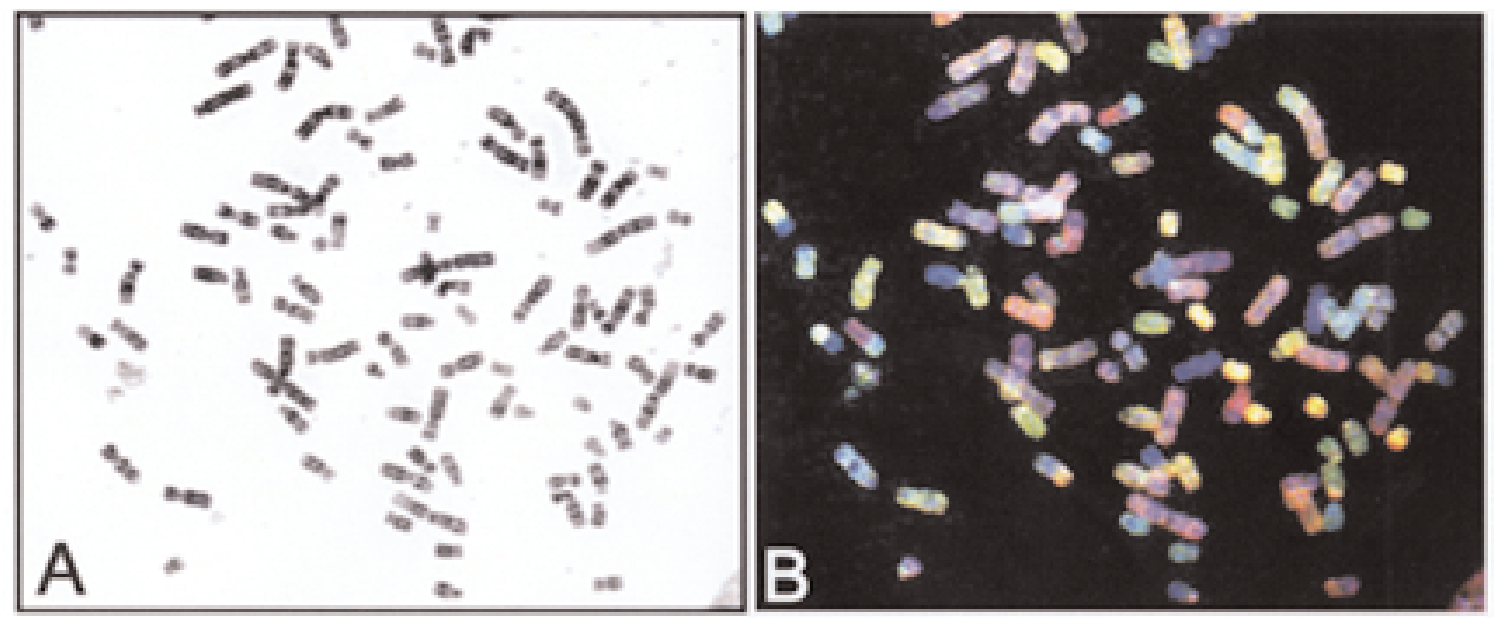

Fig. 1. A SKY hybridization study revealing a partial metaphase spread from the astrocytoma cell line SF549. A: Inverted DAPI staining emphasizes the complexity in chromosomal structure and banding patterns. B: Hybridization of the SKY paints to the metaphase spread is shown. Translocations can be easily identified by the change in color along the length of the chromosome. Software analysis identifies subtle shifts in spectral output, to reveal the presence of different chromosomal contributions to a given chromosomal structure. Original magnification $\times 60$.

4q21-q32 (33\%), 5q14-q31 (11\%), 6q14-q23 (33\%), 7 $(11 \%)$ or $7 \mathrm{q} 31(33 \%), 10(10 \%), 11(10 \%)$ or $11 \mathrm{q} 14$-qter (22\%), and 13q21-q31 (22\%). Other CGH studies ${ }^{233,297}$ confirm the low frequency of net genomic changes stemming from either the normal or near-diploid karyotypic changes. Wiltshire and coworkers ${ }^{297}$ however, identified the loss of $19 \mathrm{p}$ in a subset of pilocytic astrocytomas as the only significant numerical alteration. To date, no SKY or multicolor FISH analysis of pilocytic astrocytomas has been reported in the literature.

Subependymal Giant Cell Astrocytoma. Subependymal giant cell astrocytoma (WHO Grade I) is a benign, slowgrowing tumor. This lesion occurs almost exclusively in patients with tuberous sclerosis complex. ${ }^{251}$ Genetic linkage studies have tied tuberous sclerosis complex to two different loci, one on chromosome 9q34 (TSC1) and another on chromosome 16q13.3 (TSC2). ${ }^{198}$ Only one study of the cytogenetic basis for subependymal giant cell astrocytoma has been identified. Debiec-Rychter, et al. ${ }^{65}$ published two cases of this tumor that were identified using conventional cytogenetics. One of the tumors had a complex, near-diploid karyotype with a translocation involving chromosome 22 at band q12, whereas the second one showed chromosome 1 loss and chromosome 22 deletion at band q12. Both lesions also had normal karyotypes.

Pleomorphic Xanthoastrocytoma. Pleomorphic xanthoastrocytoma is a low-grade glioma corresponding to $\mathrm{WHO}$ Grade II. It is uncommon and accounts for less than $1 \%$ of all astrocytic tumors. Most patients have a relatively favorable prognosis; however, tumors that have undergone progressive anaplastic transformation to high-grade gliomas or GBM have also been reported. ${ }^{110,299}$ Few cytogenetic studies have been conducted on pleomorphic xanthoastrocytoma. In a case report by Sawyer and colleagues ${ }^{237}$ the hyperdiploid karyotype showed a gain of chromosomes 3 and 5 and the loss of chromosomes 20 and 22 as well as the addition of two unbalanced translocations; one involving chromosome 7 and an unknown chromosomal partner and another involving telomeric fusions of chromosomes 15 and 20. Later in 1992, this same group reported the recurrent tumor. ${ }^{239}$ The apparent telomeric fusion between chromosomes 15pter and 20qter, and between an extra copy of the long arm of chromosome 1 and chromosome 22qter, evolved in a stepwise fashion to ring chromosomes 20 and 22 . A report by $\mathrm{Li}$ and associates ${ }^{148}$ described the karyotype from a recurrent pleomorphic xanthoastrocytoma following treatment, showing a near-diploid chromosome count with complex structural abnormalities. Lai, et al., ${ }^{141}$ reported two pleomorphic xanthoastrocytoma karyotypes, of which only one showed an abnormal diploid karyotype with translocation involving chromosomes $1,12,16$, and 19. More recently, Yin and colleagues ${ }^{299}$ conducted CGH experiments on three pleomorphic xanthoastrocytoma tumors. These findings revealed gains on $2 \mathrm{p}$ (one of three), $4 \mathrm{pter}$ (one of three), 7 (two of three), 11qter, 12, 15q, and 19 (each locus with one of three); and losses on 8p (two of three), 9p, 10p, and 13 (one of three in each of these loci).

Oligodendrogliomas, Anaplastic Oligodendrogliomas, and Mixed Oligoastrocytoma. According to their histopathological appearances, diffusely infiltrative gliomas can be divided into astrocytic, pure oligodendroglial, and mixed oligoastrocytic tumors. Based on similarities in clinical features and genetic aberrations, oligodendrogliomas and oligoastrocytic tumors are often grouped together as oligodendroglial tumors. The WHO classifications identify oligodendrogliomas as Grade II, and these lesions behave much like diffuse astrocytomas, whereas anaplastic oligodendrogliomas are characterized as Grade III. An accurate distinction between the two is important, however, because it has prognostic and therapeutic implications (see Jeuken, et al. ${ }^{121}$ ). The CGAP website references 45 cases of oligodendrogliomas. ${ }^{94,117,154,201,207,209,270,298}$ Among these cases, approximately $25 \%$ involve normal karyotypes with only the loss of a sex chromosome. The gain of chromosome 7 and the loss of chromosomes 21 or 22 appear as the sole change in another $25 \%$ of karyotypes. The remaining karyotypes 
show combinations of these changes as well as the addition of translocations and unidentified marker chromosomes as different clones within the same tumor, indicating heterogeneity in the cell population.

The CGAP website also references one case of an oligoastrocytoma, ${ }^{53}$ showing heterogeneity in the karyotypes present in the tumor. In each of the 14 karyotypes identified for this tumor, the gain of chromosome 7 occurred in all clones, and the authors suggest that the largest and most widely distributed clonal population $(47, \mathrm{XY},+7)$ underwent further evolution to give rise to seven additional sidelines. Two karyotypes displayed a tetraploid content, with two more showing 50 chromosomes, and the remaining karyotypes were described as diploid. No apparent translocations or structural changes were identified on G-banding analysis, with all aberrations existing as whole chromosomal gains or losses.

Analysis of the $\mathrm{CGH}$ studies reveals more wide-ranging genomic changes. A current survey of the Progenetix website yields 40 cases of oligodendrogliomas (not otherwise specified), ${ }^{119,127,137,190,191,250}$ with the primary changes including the loss of all or part of $1 \mathrm{p}$ ( $42.5 \%$ of cases), gain or amplification of $7 \mathrm{p}(15 \%)$, gain of part or all of $7 \mathrm{q}(27.5 \%)$, gain or amplification of $8 \mathrm{q}(\sim 12 \%)$, loss of part or all of $9 \mathrm{p}$ (20\%), loss of chromosome $10(10 \%)$, gain of chromosome $11(\sim 12 \%)$, loss of chromosome $13(15 \%)$, gain of $17 \mathrm{q}$ (20\%), the loss of all of chromosome $19(10 \%)$ or the loss of $19 \mathrm{q}(27 \%)$, and the loss of chromosome $22(\sim 17 \%)$. Twelve cases of anaplastic oligodendrogliomas ${ }^{127,137,190}$ were associated with more striking genomic changes, including the loss of all or part of $1 \mathrm{p}$ (41-50\%), loss of part or all of chromosome 2 (16-25\%), loss of part or all of chromosome $4(\sim 40 \%)$, loss of all or part of chromosome $6(\sim 16 \%)$, loss of all of chromosome $9(16 \%)$ or the loss of $9 p(9 \%)$, loss of all of chromosome $10(25 \%)$, loss of chromosome 13 (16\%), loss of chromosomes 14, 15, and 16 (25\% each), loss of $19 q(25 \%)$, and loss of $21(16 \%)$.

Also summarized on the Progenetix site are the findings in 16 anaplastic oligoastrocytomas ${ }^{127,137,160}$ showing similar oligodendroglioma-like changes as well as others, including the predominant loss of $1 p(43 \%), 2 q(12.5 \%), 4 q$ (12.5\%), 9p (18.8\%), 11p (18\%), 12q (6.3\%), $13(43.8 \%)$, $14 q(18 \%), 18 q(6.3 \%)$, and $19 q(18.8 \%)$, and gains of $7 / 7 q$ $(25 \%), 8 \mathrm{q}(12 \%)$, and $10 \mathrm{p}(6.3 \%)$. These findings are consistent with many LOH studies (see Jeuken, et al., ${ }^{121}$ for review) in which losses of $1 p$ and $19 q$ are identified as the hallmark changes characteristic of oligodendrogliomas. Array-based CGH has been used to refine the deletion of $1 \mathrm{p}$ and $19 \mathrm{q}$ in both tumors and cell lines. Law and colleagues ${ }^{145}$ used homozygosity mapping, FISH, and CGH to arrayed BACs to screen 17 glioma cell lines for chromosome 1 and 19 deletions. Array-based CGH and homozygosity mapping of these cell lines defined a 700-kb common deletion region encompassed by a larger deletion region previously known in sporadic gliomas. The common deletion region was localized to 1 p36.31 and included CHD5, a putative tumor suppressor gene.

Other novel changes have been refined and identified with the increased resolution of array-based CGH, including findings by Rossi and associate ${ }^{229}$ showing an approximately 550-kb region in 11q13 and an approximately 300$\mathrm{kb}$ region in 13q12 displaying hemizygous deletion in virtually all the tumors analyzed regardless of their $1 \mathrm{p} / 19 \mathrm{q}$ status. These findings were confirmed by interphase-based FISH analyses of nuclei from the same tumors used for array-based CGH, making this specific change a diagnostic marker for this subgroup of low-grade tumors.

In another array-based CGH study, Kitange, et al., ${ }^{127}$ examined 31 oligodendrogliomas of different grades and histological features and identified the most frequent aberrations, including the loss of $1 p(49 \%)$ and $19 q(43 \%)$, and the combined loss of $1 p / 19 q(37 \%)$ as well as the deletions of $4 \mathrm{q}, 5 \mathrm{p}, 9 \mathrm{p}, 10 \mathrm{q}, 11 \mathrm{p}$, and $13 \mathrm{q}$, and gains of $7 \mathrm{p}, 8 \mathrm{q}, 10 \mathrm{p}$, and 11q. Whole-chromosome losses of 4, 9, and 13 were also detected, with whole-chromosome gains of 7 and 11 . The minimally altered regions were identified at chromosomal bands 1p36.32, 4q33, 5p15, 8q24, 11p15, and 19q13.3. A subsequent univariate analysis of these cases suggested that combined deletion of $1 p$ and $19 q$ was associated with better survival $(p=0.03)$, whereas an $8 q$ gain in oligodendrogliomas was strongly associated with poor outcome $(\mathrm{p}=$ 0.002 ). Also associated with poor disease outcome were alterations that had a low prevalence in the pure oligodendrogliomas, including loss of $3 q, 9 q$, and $12 q$ and gain of $1 \mathrm{p}, 8 \mathrm{p}$, and 10q. The common changes shared by low-grade oligodendroglioma and its high-grade counterparts suggest that the loss of $1 p$ and $19 q$ are early events in oncogenesis, with varying reports on whether the initial change occurs on $1 \mathrm{p}$ or $19 \mathrm{q} .{ }^{121}$ Furthermore, the presence of astrocytic components in the mixed subtypes suggested similar clonal origins, with the tumor microenvironment imposing differentiating influences.

The search for tumor suppressor genes on both $1 \mathrm{p}$ and $19 q$ has led to the identification of minimal regions of interest by an assortment of molecular analyses, including arraybased CGH and FISH methods, and has identified candidate genes, including TP73 (1p36.32), CDKN2C and RAD54 (both 1p32), GLTSCR1 (19q13.3), EDH2 (19q13.3), and GLTSCR2 (19q13.3).

Ependymal Tumors. Ependymomas are well-delineated, moderately cellular gliomas and are the third most common brain tumors in children. ${ }^{267}$ The WHO classification differentiates four major types: ependymoma (WHO Grade II), anaplastic ependymoma (Grade III), myxopapillary ependymoma (Grade I), and subependymoma (Grade I) as well as the ependymal variants (cellular, papillary, epithelial, clear cell, and mixed). Whereas ependymomas occur in both children and adults, subependymomas and myxopapillary ependymomas are more common in adults. ${ }^{267}$

The CGAP website identifies 106 ependymoma karyotypes $^{1,22,50,62,64,83,92,117,161,175,207,209,225,227,257,270,278,281,293,294}$ (also reviewed by Mazewski, et al. ${ }^{161}$ ). The karyotypes described are predominantly normal, and when abnormal are near-diploid, and are characterized by gains and losses of entire chromosomes. Normal karyotypes have been estimated to occur in approximately 34\% of published cases. ${ }^{161}$ The most commonly gained chromosomes include 4, 5, 7, 8, and 9, either as the sole change or in combination. Loss of chromosome 10, 17, and 22 is also a frequent occurrence. Structural chromosomal aberrations often involve chromosomes $2,6,7,12,13,16,17$, and 22 and are frequently simple in nature. No specific translocation has been identified and the only significant breakpoint appears at 22q11-13.

The LOH studies have identified $\mathrm{LOH}$ of $22 \mathrm{q}$ as the most frequent change in approximately $30 \%$ of ependymomas, ${ }^{267}$ contributed partially by the loss or structural abnor- 
malities of chromosome 22 observed in the karyotypes. Clinically, adult ependymomas and the myxopapillary subtype are most likely to have chromosome 22 changes. The $22 \mathrm{q}$ region contains the $N F-2$ tumor suppressor gene, making this a candidate gene for ependymomas (see discussion in a later section). A number of other tumors seen in NF2, including vestibular schwannomas and meningiomas, have also shown chromosomal aberrations involving chromosome $22 \mathrm{q} .{ }^{267} \mathrm{~A}$ SKY analysis has been performed in one case of ependymoma reported by our group, ${ }^{257}$ and showed no additional structural aberrations from the original Gbanded karyotype (http://www.ncbi.nlm.nih.gov/sky/) (Fig. 2). Cytogenetic analysis of subependymomas ${ }^{57,260}$ revealed normal karyotypes and nonclonal changes involving chromosome 17. When multicolor FISH analysis was conducted on an intracranial ependymoma, ${ }^{91}$ the tumor was found to possess chromosomal aberrations including $\mathrm{i}(1 \mathrm{q})$ as well as aberrations involving chromosomes $6 \mathrm{p}$ and $17 \mathrm{p}$.

The Progenetix Database summarizes the CGH findings of 165 ependymomas (not otherwise specified) and 29 cases of anaplastic ependymomas (see for references http:// www.progenetix.net/). The most common genomic changes among the 165 ependymomas summarized included the gain of $1 \mathrm{q}(17 \%), 4(14 \%), 5(15 \%), 7(17 \%), 9(16 \%)$, and $12(10 \%)$, and the loss of chromosomes $3(11.5 \%), 6 \mathrm{p}$ (14.6\%), 6q (20\%), 10 (14\%), 13 (12\%), $16(18.2 \%), 17$ (12\%), 19 (10.9\%), 20q (12.7\%), and 22 (29\%). In the 29 anaplastic cases, ${ }^{118,241,288}$ gains of $1 \mathrm{q}(17.2 \%), 7(10.3 \%), 9 \mathrm{q}$ $(13.8 \%)$, and $15(10 \%)$ were detected as well as amplification at $2 \mathrm{p} 24 .{ }^{241}$ The amplification at $2 \mathrm{p} 24$ was confirmed by FISH to be amplification of MYCN in a spinal ependymoma. Losses were detected on chromosomes $3(6 \%)$, 9p (6.9\%), 10p (10.3\%), 10q (17.2\%), 13q21 (10.3\%), and 22 $(10 \%)$. The LOH studies have confirmed the presence of deletions in these regions, ${ }^{106}$ specifically at chromosomes 6 and 9 as well as at loci 3p14,10q23, and 11q. Moreover, investigation of chromosome 22 using tiling-path arrays by Ammerlaan, et al., ${ }^{6}$ revealed the presence of overlapping interstitial deletions of $2.2 \mathrm{Mb}$ and approximately $510 \mathrm{~kb}$ in two patients. The deletions were also found to be present in the constitutional DNA of these two patients and in some of their unaffected relatives. Microsatellite analysis of these families further refined the commonly deleted segment to a region of $320 \mathrm{~kb}$ between markers RH13801 and D22S419, suggesting the presence of a low-penetrance ependymoma susceptibility locus at 22q11.

The CGH assay has also been used to correlate clinical parameters and outcome. Analysis of 42 primary and 11 recurrent pediatric ependymomas by metaphase-based CGH was correlated to clinical outcome in a study by Dyer, et al. ${ }^{72}$ Hierarchical clustering of the findings identified three distinct genetic patterns. The first group showed few and mainly partial imbalances, which the authors suggested were a result of structural changes. The second "numerical group" showed 13 or more chromosome imbalances with a nonrandom pattern of gains and losses of entire chromosomes. The remaining tumors showed a balanced genetic profile that was significantly associated with a younger age at diagnosis $(\mathrm{p}<0.0001)$, suggesting that ependymomas arising in infants were biologically distinct from those occurring in older children. Multivariate analysis showed that the structural group had a significantly worse outcome compared with tumors in which a numerical $(\mathrm{p}=0.05)$ or balanced profile $(\mathrm{p}=0.02)$ was found.

For the myxopapillary ependymomas, a molecular cytogenetic study by Mahler-Araujo and colleagues ${ }^{156}$ attempted to identify common aberrations within this group of tumors. Seventeen myxopapillary ependymomas were studied by combinations of $\mathrm{CGH}$, microsatellite analysis, and interphase FISH. Of seven tumors analyzed using CGH, a concurrent gain on chromosomes 9 and 18 was the most common finding. Microsatellite and interphase-based FISH analysis revealed results consistent with $\mathrm{CGH}$ findings; these results included the gains of both chromosomes 9 and 18 in 11 of 17 cases, the gain of either chromosomes 9 or 18 and imbalance of the other chromosome in three of 17 tumors, and allelic imbalances of chromosomes 9 or 18 in three and one of 17 tumors, respectively.

The FISH assay has been performed using 1p/1q, 19p/ $19 \mathrm{q}$, centromere $18 / D A L 1$, and bcr/NF2 probe pairs in the analysis of 10 clear cell ependymomas. ${ }^{81}$ No deletions involving $1 \mathrm{p}, 19 \mathrm{q}$, or NF2 were detected. Furthermore, the tumors in five of seven patients, all showing anaplasia, had losses of both centromere 18 and $D A L-1$.

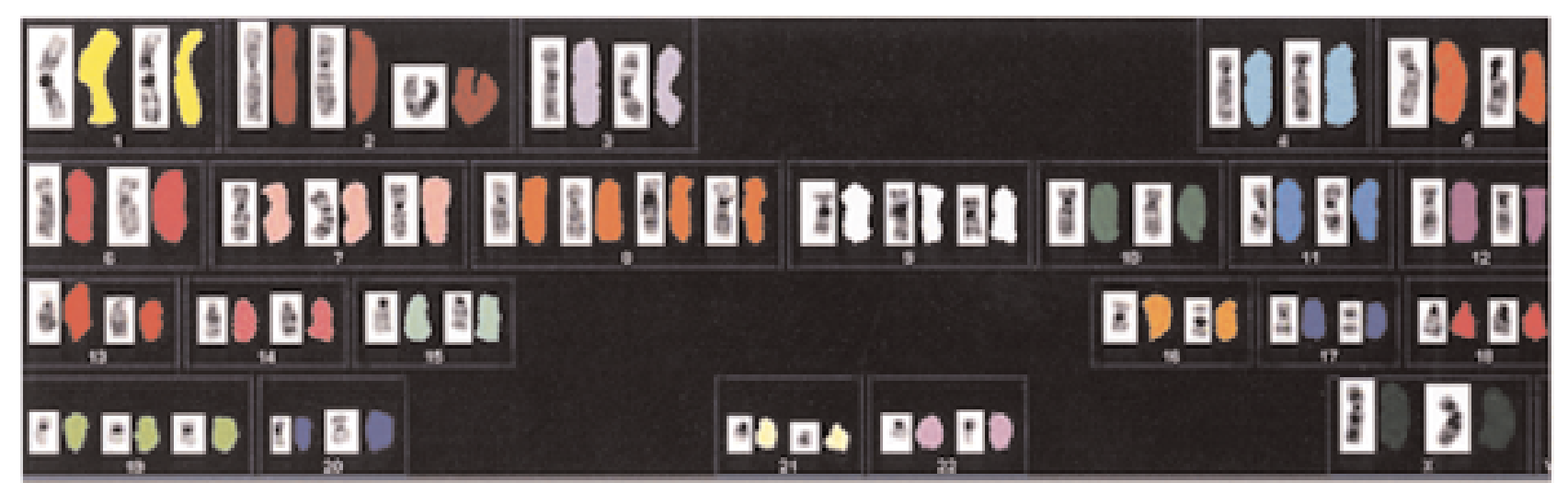

Fig. 2. A SKY analysis of an adult ependymoma. The final SKY karyotype can be seen in which the pseudocolor or "classified colors" are used, along with the inverted DAPI image. Each chromosome is identified by a specific color (for example, chromosome 1 is yellow). No hidden translocations were identified. The gains of chromosomes 2, 7, 8, and 19 were confirmed. Original magnification $\times 60$. 


\section{Neuroepithelial Tumors of Uncertain Origin}

Spongioblastoma. Spongioblastomas are classified by WHO as Grade IV, and are tumors containing spongioblast cells. The CGAP site reports one case of spongioblastoma that had a diploid count with a stemline showing the gain of chromosome 2 and the loss of both chromosomes 7 and 9. Double minute chromosomes, which are indicative of gene amplification, were detected in a cell, along with the presence of marker chromosomes in a hypotetraploid cell. ${ }^{83}$

Gliomatosis. Gliomatosis cerebri (WHO Grade III/IV) is a rare, diffuse glial tumor with extensive brain infiltration that involves more than two lobes, frequently occurs bilaterally, and often extends to the infratentorial structures and spinal cord. The peak incidence appears to occur in patients between 40 and 50 years of age. Unfortunately, the prognosis is typically poor.

The CGAP website reports two cases of gliomatosis, ${ }^{30,99}$ in which the karyotypes are described as near-diploid. Bigner and associates ${ }^{30}$ reported the presence of unidentifiable marker chromosomes and double minutes against an otherwise normal karyotype. The karyotype reported by Hecht, et al., ${ }^{99}$ revealed structural aberrations involving chromosomes 6q, 14q, 15q, 18q, 19p, 20p, and 21q. A tetraploid version of the diploid karyotype was also reported, indicating failure of the cell to undergo cytokinesis.

In a recent $\mathrm{CGH}$ analysis, Kros and colleagues ${ }^{138}$ examined the idea of "field cancerization." Because gliomatosis cerebri is a rare condition in which the brain is infiltrated by a diffusely growing glial cell population involving at least two lobes, and sometimes even affecting infratentorial regions, the neoplastic proliferation may have a monoclonal origin, or alternatively, it may reflect progressive neoplastic change of an entire tissue field, which is known as field cancerization. Thus, the presence of an identical set of genetic aberrations throughout the lesion would point to monoclonality of proliferation, whereas the presence of nonidentical genetic changes in widely separated regions within the neoplasm would support the concept of field cancerization. The CGH analysis revealed losses on $2 \mathrm{q} 11-\mathrm{q} 31$ in 13 of 24 samples and losses on 19q13-qter in 10 of 24 samples from both left and right hemispheres. Other widespread chromosomal aberrations included losses on 3q13qter and 16q22-qter and gains on 7q22-qter, supporting the concept of monoclonal tumor proliferation.

Astroblastoma. Astroblastomas are a rare glial tumor occurring preferentially in young adults. Lesions are characterized by a perivascular pattern of glial fibrillary acidic protein-positive astrocytic cells with broad, nontapering processes radiating toward a central blood vessel. Lowgrade astroblastomas appear to have a better prognosis than those with high-grade histological features.

Four cases of astroblastoma that have been reported at the CGAP site ${ }^{141,232,257,269}$ show karyotypes in the diploid range. Structural aberrations such as translocations are frequent as well as whole chromosomal gains and losses. Chromosomes $7,10,12,21$, and 22 are frequently involved in both numerical and structural changes. The SKY analysis of an astroblastoma case, ${ }^{257}$ previously reported by Jay, et al., ${ }^{113}$ refined the original karyotype, describing the loss of chromosomes 10,21 , and 22 and the presence of two marker chromosomes; the identification of the markers as an unbalanced translocation between chromosomes 10 and 21; and the presence of a chromosome classified as some duplication of chromosome 22 (http://www.ncbi.nlm.nih.gov/sky/). Cytogenetic analysis of a high-grade astroblastoma ${ }^{169}$ revealed a hypodiploid clone showing deletion of $1 \mathrm{p} 36$ and $11 \mathrm{p} 13$ and an unbalanced translocation between chromosomes 14 and 15. Chromosome 22 was found to be rearranged, which was confirmed on FISH analysis, whereby it was determined that a rearrangement of $22 \mathrm{q}$ resulted in a complex translocation with chromosome 11. Results of the FISH assay also confirmed the loss of distal $1 \mathrm{p}$.

Brat and coworkers ${ }^{37}$ conducted CGH studies on seven astroblastomas, identifying genomic changes including gains of chromosome 20q (four of seven) and 19 (three of seven). The combination of these gains occurred in three tumors, including two well-differentiated and one malignant astroblastoma. Other alterations, noted in two tumors each, were losses on 9q, 10, and X.

\section{Neuronal and Mixed Neuronal-Glial Tumors}

Ganglioglioma. Gangliogliomas are rare tumors of the CNS that account for approximately $1 \%$ of all brain tumors and are classified as WHO Grade I. Histologically, gangliogliomas are composed of intimately admixed glial and neuronal components, with pathological origins have are not yet been identified.

The CGAP site lists 10 ganglioglioma cases. ${ }^{22,62,175,257}$ Of the 10 , seven were described as diploid, two were tetraploid, and the remaining case was hyperdiploid. Whole chromosomal gains and losses characterized the cytogenetic descriptions; however, these also included structural aberrations including deletions, additions, and translocations. Gains and structural aberrations involving chromosome 7 occurred frequently. There were also instances of copy number and structural changes involving chromosome 13. Other case reports, ${ }^{116,133,286}$ have described cytogenetic findings consistent with those presented at the CGAP site. A SKY analysis of an adult ganglioglioma by our group $^{257}$ showed no additional chromosomal alterations from those detected on conventional G-banding studies (http://www.ncbi.nlm.nih.gov/sky/). One anaplastic ganglioglioma was reported by Jay, et al. ${ }^{115}$ who described the malignant transformation of a ganglioglioma that showed a complex abnormal karyotype with three sublines containing several structural chromosomal abnormalities.

There are few CGH studies of gangliogliomas. The Progenetix website displays two cases, ${ }^{218}$ one normal and the other whose sole abnormality was a loss of the region of 4q13-q31. Squire, et al., ${ }^{257}$ used CGH to analyze a pediatric ganglioglioma, and the lesion was shown to have no net changes, despite the identification of structural changes involving chromosomes 1, 2, 3, 13, 17, and 22 as well as the detection of some cells with a tetraploid count. The disparity between the CGH results and cytogenetic findings lies in the heterogeneity of abnormal cells, the presence of normal karyotypes, and the possibility of contaminating normal tissue. Two publications by Yin and colleagues ${ }^{300,301}$ described the CGH findings in five gangliogliomas, including the loss of material on $9 p$ in three of five cases. Gains of parts or all of chromosome 7 were also detected and confirmed on FISH analysis. Genomic losses were detected at 2q33-q34, 8q12-q22, 14q21-qter, and 15q26-qter. 
Desmoplastic Infantile Ganglioglioma and Astrocytoma. Desmoplastic infantile gangliogliomas and astrocytomas are classified as WHO Grade I, and are rare tumors. Desmoplastic infantile gangliogliomas are described as having both neuronal and astroglial elements, whereas desmoplastic infantile astrocytomas have primarily astrocytic elements. Although both may have aggressive cellular features, these tumors are often benign and the patient's prognosis is good when the lesion is completely resected.

Cytogenetic analysis by Park and associates ${ }^{189}$ described a case of desmoplastic infantile ganglioglioma with no consistent clonal abnormalities. The majority of cells, however (25 of 40), showed structural rearrangements, specifically telomere associations, resulting in dicentric and other derivative chromosomes. The breakpoints most often observed included 17q25, 19p13.3, 17p13, 14q32, 11q25, 9p24, $5 q 35$, and $22 q 13$. Bhattacharjee, et al., ${ }^{22}$ reported a case in which the lesion showed a hypotetraploid karyotype with both structural and numerical changes. As in other glial tumors, changes involving chromosomes 1, 7, 9, and 10 were identified. Kros, et al., ${ }^{136}$ conducted molecular analysis including $\mathrm{CGH}$ in three typical cases of desmoplastic infantile astrocytoma and ganglioglioma, and revealed loss of $8 \mathrm{p} 22$-pter in one case, whereas in another a gain of $13 \mathrm{q} 21$ was detected. Their findings led them to suggest that the genetic aberrations found in desmoplastic infantile ganglioglioma differ from those encountered in common astrocytomas.

Central Neurocytoma. Central neurocytomas are rare, benign, slow-growing neoplasms that have a favorable prognosis. They compromise 0.25 to $0.5 \%$ of brain tumors. ${ }^{246}$ The mixed histological features of these tumors has prompted studies to determine their cellular origins.

The CGAP website reports one central neurocytoma, showing the sole abnormality as a loss of chromosome $17 .{ }^{49}$ Jay and colleagues ${ }^{112}$ reported a diploid case in which three copies of $1 \mathrm{q}$ were involved with rearrangements of chromosomes 4 and 7. A FISH analysis investigating the copy number status of chromosome 7 has been conducted by Taruscio, et al., ${ }^{264}$ and the chromosome was found to be gained in $33 \%$ of the tumors studied (nine), and in one case it was the sole abnormality. The CGH studies performed in 10 central neurocytomas by Yin, et al., ${ }^{302}$ are summarized at the Progenetix website and show identified gains at $2 \mathrm{p}$ $(40 \%), 10 q(40 \%)$, and $18 q(30 \%)$.

The mixed cellular features of these tumors has led to several studies to identify their similarity with other more defined tumors, including oligodendrogliomas ${ }^{84}$ and neuroblastoma. ${ }^{273}$ Using FISH analysis for markers on $1 \mathrm{p}$ and $19 \mathrm{q}$, which are characteristic of oligodendrogliomas; and probes for $1 \mathrm{p} 26$ and $M Y C N(2 \mathrm{p} 24)$, which are characteristic of neuroblastoma, these studies have shown that central neurocytomas do not share the characteristic changes associated with oligodendrogliomas or neuroblastomas.

Dysembryoplastic Neuroepithelial Tumor. The DNETs (WHO Grade I) are a benign, usually supratentorial, neuronal-glial neoplasm occurring primarily in children and young adults with a long-standing history of partial seizures. These tumors may occasionally occur in patients with NF1, and they carry a good prognosis. Like central neurocytomas, the mixed cellular features of DNETs have prompted investigators to determine whether these lesions possess the changes known to appear in other tumors. ${ }^{84,192,199}$ These FISH investigations have also shown that DNETs do not have loss of $1 \mathrm{p}$ or $19 \mathrm{q}$, as is the case in oligodendrogliomas; nor do they show amplification of $M Y C N$ or $E G F R$, which is typical of neuroblastomas and astrocytomas, respectively.

Olfactory Neuroblastoma (Esthesioneuroblastoma). There are few cytogenetic studies of esthesioneuroblastomas; however, these lesions have been shown to range from diploid to polyploidy, with relatively simple to complex changes. ${ }^{88,123}$ The CGAP website reports a karyotype ${ }^{123}$ showing a diploid tumor with numerous structural aberrations involving chromosomes 1, 3, 7, 8, 10, and 13. The Progenetix site reports three cases analyzed using $\mathrm{CGH},{ }^{215}$ showing gains of $1 \mathrm{p} 32$ pter (two of three), 8q23-qter (all three), 9q31-qter (two of three), and 15q25-qter, 19, and $22 \mathrm{q}$ (all three in each instance). Losses were detected for $4 q$ and $13 q$ in all cases.

More recently, Bockmuhl, et al., ${ }^{32}$ examined 22 esthesioneuroblastomas. They found deletions on chromosomes $3 p$ and overrepresentations on $17 q$ in up to $100 \%$ of cases. In more than $80 \%$ of cases, deletions were detected on $1 \mathrm{p}$, $3 \mathrm{p} / \mathrm{q}$, 9p, and 10p/q, along with gains on 17p13, 20p, and $2 \mathrm{q}$. The most consistent finding was a pattern for involvement of chromosomes $3,10,17 q$, and 20 occurring almost exclusively by deletions or overrepresentations, respectively. High copy gains/amplifications were seen on 1p34, 1q23-q31, 7p21, 7q31, 9p23-p24, 17q11-q22, 17q24-q25, $19,20 \mathrm{p}, 20 \mathrm{q} 13$, and 22q13. The analysis of metastatic/recurrent lesions indicated a higher percentage of pronounced alterations, such as the high-copy DNA gains at 1q34-qter, 7q11, 9p23-p24, 9q34, 13q33-q34, 16p13.3, 16p11, 16q23$\mathrm{q} 24$, and $17 \mathrm{p} 13$. The authors suggested that deletions of chromosome 11 and gains of $1 \mathrm{p}$ may be associated with metastasis formation and/or worse prognosis. These recent findings add to the ongoing debate whether these tumors are similar to the primitive peripheral neuroectodermal tumor (Ewing group) $)^{256}$ or are a distinct group..$^{32,168}$

\section{Nonglial Tumors}

Tumors of the Choroid Plexus. Choroid plexus papilloma is a rare, benign tumor most common in children younger than 2 years of age. The choroid plexus carcinoma is the malignant form of this tumor. The CGAP database describes 15 cases $^{1,22,50,69,71,147,165,175,196,202,203,228}$ of choroid plexus papilloma or carcinoma. The karyotypes are predominantly near-diploid, hypodiploid, or hypotriploid, and are characterized by whole chromosomal gains and losses; these include gains of chromosomes 5, 6, 7, 8, 9, 12, 15, 18, and 20 and losses of chromosomes 1, 3, 10, 16, 17, 21, and 22 . In two cases, ${ }^{50,69}$ diploid karyotypes were characterized by structural changes, including translocations, deletions, inversions, and the presence of markers, which were present as subclones. All other karyotypes showed no structural aberrations.

The Progenetix website summarizes 41 cases of choroid plexus tumors (not otherwise specified) ${ }^{95,222}$ and 15 WHO Grade III carcinomas. ${ }^{222}$ Of the 41 choroid plexus tumors, gains were identified on chromosomes 5 (up to $53 \%$ from loci 5p14-q13), 7 (53\%), 8 (24\%), 9 (34\%), 12p (36\%), 12q $(17-31 \%), 15(24.4 \%), 18(19.5 \%)$, and $20(19.5 \%)$. Losses were restricted to chromosomes $1(9.8 \%), 2(7.3 \%)$, 3 (14.6\%), 10 (43\%), 16 (9.8\%), 17 (12.2\%), 21 (19.5\%), 
and $22(36.6 \%)$. Grade II carcinomas showed a different pattern of change among the 15 cases. All chromosomes showed almost equal instances of gains and losses, with the following exceptions: gains of chromosome 1 in $40 \%$ of cases; loss of chromosome 3 in $26.7 \%$ of cases; loss of chromosome 6 in $26 \%$ of cases; gain of chromosome 12 in $60 \%$; gain of chromosome 14 in $40 \%$; loss of chromosome 15 in 26.7\%; loss of chromosome 16 in 20\%; loss of chromosome 18 in 33\%; gain of chromosome 20 in 53\%; gain of 21 in 33\%; and loss of most or all of chromosome 22 in up to $72 \%$ of cases. Other regions of prominent gain were identified at 7q11-q31 (33\%), 8q11-q23 (46\%), and chromosome 4q (40\%).

In the CGH study conducted by Rickert and colleagues ${ }^{222}$ which investigated the genomic changes between choroid plexus papillomas and choroid plexus carcinomas, chromosomal imbalance differences characteristic of a tumor entity or age group were identified. In choroid plexus papillomas, $+5 \mathrm{q},+6 \mathrm{q},+7 \mathrm{q},+9 \mathrm{q},+15 \mathrm{q},+18 \mathrm{q}$, and $-21 \mathrm{q}$ were found to be significantly more common, whereas choroid plexus carcinomas were characterized by $+1,+4 q,+10,+14 q$, $+20 \mathrm{q},+21 \mathrm{q},-5 \mathrm{q},-9 \mathrm{p},-11,-15 \mathrm{q}$, and $-18 \mathrm{q}$. Among choroid plexus papillomas, the gains $+8 \mathrm{q},+14 \mathrm{q},+12$, and $+20 \mathrm{q}$ occurred more often in children, whereas adults mainly presented with $+5 \mathrm{q},+6 \mathrm{q},+15 \mathrm{q},+18 \mathrm{q}$, and $-22 \mathrm{q}$. On their own, the number of overall aberrations as well as gains and losses had no significant effect on survival among patients with choroid plexus tumors; however, a significantly longer survival duration among patients with choroid plexus carcinomas was associated with $+9 p$ and $-10 q$.

\section{Pineal Parenchymal Tumors}

Pineocytomas, Pineoblastomas, and Mixed Pineocytoma/Pineoblastoma. Pineal parenchymal tumors arise from pineocytes or their precursors, and they are distinct from other pineal gland neoplasms such as astrocytic and germ cell tumors. Pineocytomas (WHO Grade II) are a slowgrowing pineal parenchymal neoplasm that primarily occurs in young adults, accounting for less than $1 \%$ of all brain tumors, and they comprise approximately $45 \%$ of all pineal parenchymal tumors. Adults 25 to 35 years of age are most frequently affected, with a 5-year survival rate of greater than $80 \%$. Pineoblastomas (WHO Grade IV) are a generally rare but highly malignant primitive embryonal tumor of the pineal gland manifesting primarily in children. Tumors similar in appearance to pineoblastomas have been observed in patients with familial (bilateral) retinoblastoma. Outcomes are generally favorable with appropriate treatment. Pineal parenchymal tumors of intermediate differentiation are monomorphous lesions exhibiting moderately high cellularity, mild nuclear atypia, occasional mitosis, and the absence of large pineocytomatous rosettes. They comprise approximately $10 \%$ of all pineal parenchymal tumors and occur in all age groups, with varying clinical outcomes. A comprehensive discussion of the pathogenesis and cytogenetic aspects of pineal region neoplasms is reviewed by Taylor and associates. ${ }^{266}$

The CGAP website reports three cases of pineocytomas, ${ }^{18,60,205}$ with one case in the diploid range, one hypodiploid, and the other hyperdiploid. No specific pattern of chromosomal change is evident, although whole gains, losses, and structural abnormalities can be found. For pineoblastomas, the CGAP site reports four cases, ${ }^{30,225,258}$ which are characterized by near-diploid karyotypes and whole chromosomal gains and losses.

A CGH study conducted by Rickert, et al., ${ }^{221}$ consisted of nine pineal parenchymal tumors, including three pineocytomas (WHO Grade II), three pineal parenchymal tumors of intermediate differentiation (WHO Grade III), and three pineoblastomas (WHO Grade IV). On average, 0 chromosomal changes were detected per pineocytoma, 5.3 per pineal parenchymal tumor of intermediate differentiation (3.3 gains compared with 2.0 losses), and 5.6 per pineoblastoma (2.3 gains compared with 3.3 losses). The most frequent DNA copy number changes among pineal parenchymal tumors of intermediate differentiation and pineoblastomas were gains of $12 q$ (three of six cases) and $4 q, 5 p$, and $5 q$ (two of six each), as well as losses of 22 (four of six), 9q, and 16q (two of six each). Among pineal parenchymal tumors of intermediate differentiation, the most common chromosomal imbalances were $+4 \mathrm{q},+12 \mathrm{q}$, and -22 (two of three cases each), and in pineoblastomas they were -22 (two of three). Five high-level gains were identified, all of them in pineoblastomas; these were found on 1q12-qter, 5p13.2-14, 5q21-qter, 6p12-pter, and 14q21-qter.

Regarding clinical outcome, all patients with pineocytomas and pineal parenchymal tumors of intermediate differentiation were alive after a mean observation time of 142 and 55 months, respectively, whereas all patients with pineoblastomas had died after a mean of 17 months, indicating that pineal parenchymal tumors of intermediate differentiation are cytogenetically more similar to pineoblastomas and prognostically more similar to pineocytomas. Imbalances in higher-grade pineal parenchymal tumors were mainly affected by gains of $12 q$ and losses of chromosome 22 .

An interesting case study published by Sawyer and coworkers ${ }^{238}$ reported on a 6-month-old girl with a PNET of the pineal region. The tumor exhibited a constitutional reciprocal translocation $\mathrm{t}(16 ; 22)(\mathrm{p} 13.3 ; \mathrm{q} 11.2 \sim 2)$, suggesting that the presence of this translocation, specifically the breakpoint at 22q11.2 2, may have predisposed the patient to the development of the tumor.

\section{Tumors With Neuroblastic or Glioblastic Elements (Em- bryonal Tumors)}

Medulloepithelioma. Medulloepitheliomas are a rare type of neuroepithelial tumor affecting young children. These tumors are usually found in the brain or retina, and are composed of primitive neuroepithelial cells lining the tubular spaces. Because of their classification as embryonal tumors and the presence of neuroblastic and glioblastic elements, specific reports are rare; however, the CGAP website reports one case of an ocular medulloepithelioma ${ }^{21}$ with a diploid karyotype showing the loss of chromosome 15 and a balanced translocation between chromosomes 1 and 16. A second line within this tumor identified the same aberrations, in addition to the partial deletion of one of the chromosome 6 homologs.

Multipotent Differentiating PNETs: Medulloblastoma, Supratentorial PNETs, Medullomyoblastomas, Melanocytic Medulloblastoma, Desmoplastic Medulloblastoma, and Large-Cell Medulloblastoma. The major groups of PNETs are medulloblastomas and supratentorial PNETs, with variants including medullomyoblastomas, melanocytic medulloblastomas, and desmoplastic medulloblastomas. Med- 
ulloblastomas (WHO Grade IV) are a malignant, invasive embryonal tumor of the cerebellum that occurs primarily in children, has a predominantly neuronal differentiation, and has a tendency to metastasize through cerebrospinal fluid pathways. In adulthood, $80 \%$ of medulloblastomas occur in people 21 to 40 years of age. Medulloblastomas have been diagnosed in several familial cancer syndromes, including TP53 germ-line mutations, the nevoid basal cell carcinoma syndrome, and Turcot syndrome Type 2. ${ }^{204}$ Supratentorial PNETs (WHO Grade IV) are embryonal tumors in the cerebrum or suprasellar region that are composed of undifferentiated or poorly differentiated neuroepithelial cells, which have the capacity for differentiation along neuronal, astrocytic, ependymal, muscular, or melanocytic lines. These tumors are also known as cerebral medulloblastoma, cerebral neuroblastoma, cerebral ganglioneuroblastoma, "blue tumor," and PNET. These lesions are generally rare and occur in children.

The majority of published studies group medulloblastomas and supratentorial PNETs together, although some make a clear distinction between the two. The CGAP website combines the two major subgroups, yielding 185 cases. $13,22-24,28,30,50,83,92,175,225,232,278,282$ More than $75 \%$ of the karyotypes are diploid or near-diploid, with the remaining $25 \%$ tetraploid and triploid. Whole chromosomal gains and losses are common and include gains of 1, 3, 4, 6, 7, 8, 17, and 18 and losses of $9,10,12,13$, and 19. In 40 of the cases reported, i(17)(q10) was found to be present as either the sole aberration or with other chromosomal abnormalities. Complex translocations involving several chromosomal partners were present, as were double minute chromosomes and unidentifiable marker chromosomes. The SKY studies conducted by our group ${ }^{13}$ and others ${ }^{5,52}$ have identified the frequent involvement of chromosomes 1, 2, 3, 7, 10, 13, 14, 17,18 , and 22 in simple and complex translocations, contributing to copy number changes in those chromosomes (Fig. 3).

The Progenetix website lists 94 medulloblastomas/ PNETs. These can be subdivided into 40 medulloblastomas (not otherwise specified), 18 desmoplastic medulloblastomas, 14 PNETs (not otherwise specified), and 22 largecell medulloblastomas. The cumulative findings in the 94 cases reveal overall gains and amplifications over losses. Gains include 1q (13.3\%), 2p (13.8\%), 2q11-q24 (8.5\%), 3q (11.7\%), 5 (8.5\%), 6 (9.6\%), 7 (24\%), 7q (4\%), 8q (12\%), $13(9.6 \%), 17(17 \%), 17 \mathrm{q}(23 \%), 18(18 \%)$, and $20 \mathrm{q}(8.5 \%)$; whereas losses appear to be restricted to chromosomes 10 (3\%), 10q (11\%), 16q (9.6\%), 17p (11.6\%), 19 (6.4\%), and $\mathrm{X}(7.5 \%)$. Amplifications are present at 2p24-pter (3.2\%), 2q14-q22 (1.1\%), 8q23 (2.1\%), 9p (2.1\%), and 17p11.2 $(1.1 \%)$. Equal frequencies of gains and losses occur on chromosomes $4,8,9,11$, and 12 .

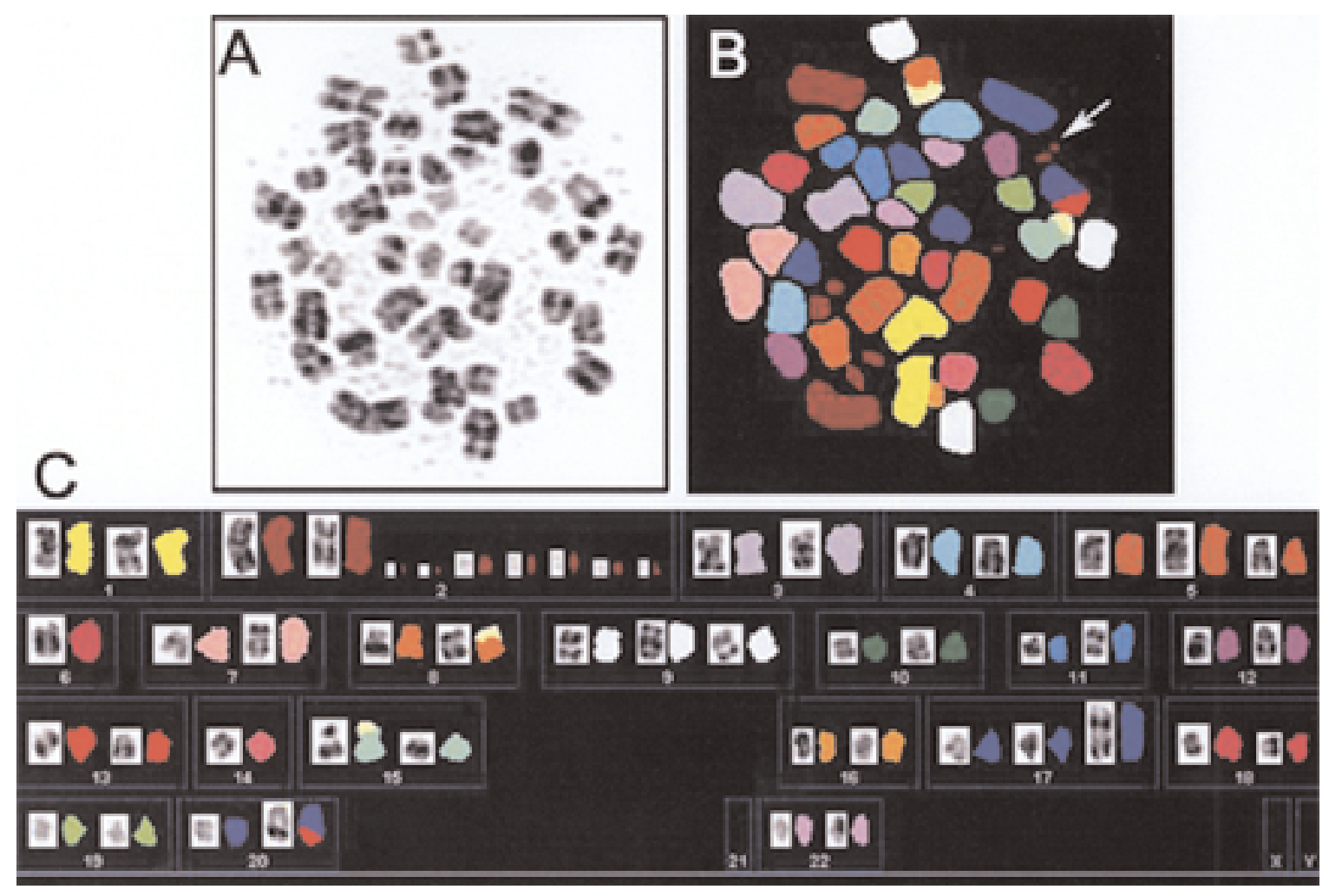

Fig. 3. A SKY analysis of a primary medulloblastoma specimen. A and B: The inverted DAPI image of the metaphase reveals overall poor chromosome morphology (A) as well as the presence of double minute chromosomes (arrow, B). The "classified colors" image following SKY analysis reveals that the origin of the double minute chromosomes is chromosome 2. C: The final SKY karyotype showing the classification of the double minute chromosomes originating from chromosome 2 (later confirmed to be MYCN) as well as the presence of translocations involving chromosomes 8 and 21, 15 and 21, and 20 and 18. Inverted banding and SKY revealed the presence of an i(17)(q10) aberration as well as numerical changes of other chromosomes. Original magnification $\times 60$. 
In the 40 tumors identified as medulloblastomas (NOS), ${ }^{13,73,87,178,250}$ the patterns of gains and losses were similar to the cumulative profile; however, amplifications were not identified in this group. Among the 14 lesions designated as PNETs (not otherwise specified), ${ }^{13,263}$ gains were identified at $1(7.1 \%)$ or $1 \mathrm{q}(14.1 \%), 2 \mathrm{p}(7.1 \%), 3 \mathrm{q}(14.3 \%), 6$ (14.3\%), 6p (6\%), $7(42 \%), 7 \mathrm{q}(15 \%), 8 \mathrm{q}(14.3 \%), 10 \mathrm{p}$ (14.3\%), 14 (14.3\%), 16 (7.1\%), 16q21-qter (21.4\%), 17 (35\%), 18 (24\%), 20q (28\%), and 22 (71\%); and losses were seen at 4q (14\%), 10q23-10qter (7.3\%), $12(28 \%)$, and 19 $(7.1 \%)$. Amplifications were detected in this group at $2 \mathrm{p} 24$ (14.3\%) and 9p (14.3\%). Among the 18 desmoplastic medulloblastomas, ${ }^{13,73,87}$ no amplifications were detected and losses predominated over gains, particularly the losses of chromosomes 6, 10q23-qter, 11, 14, and 19. Gains were detected primarily on chromosomes 7 and 17q. Finally, among the 22 large-cell medulloblastomas, ${ }^{13,73}$ gains predominated over losses, in a pattern similar to the cumulative profile. Amplifications were present at 2p24 and 2q13-q22, 8q23, and $17 \mathrm{p} 11.2$ (Fig. 4). Predominant gains were present at 1q, 2, 5, 6, 7 and 7q, 8 and 8q, 9p, 13, 14, 17 and 17q, and 18q. The most prominent loss occurred on 16q and 17p.

Although they are histologically similar, it is believed that PNETs arising from the cerebellum and cerebrum are biologically distinct which appears to be confirmed by the Progenetix data based on the apparent differences in copy number patterns. In a study by Russo, et al., ${ }^{231} 53$ supratentorial and infratentorial PNETs were examined using CGH to determine whether there was genetic evidence to establish that they were distinct tumors. Although six of the 43 infratentorial PNETs had no copy number aberrations, they were present in all 10 supratentorial PNETs. Gains of 17q occurred in $37 \%$ of cases of infratentorial PNETs, but in no cases of the supratentorial lesions. Moreover, loss of $14 \mathrm{q}$ was observed in supratentorial PNETs and not in infratentorial cases. Finally, loss of $19 \mathrm{q}$ was restricted primarily to supratentorial PNETs.

More recently, Inda and associates ${ }^{111}$ compared the status of homozygous deletion and expression of PTEN and $D M B T 1$ genes in PNET primary tumor samples and cell lines, and found that PTEN homozygous losses were demonstrated in $32 \%$ of medulloblastomas and in none of the supratentorial PNETs, whereas homozygous deletions of DMBT1 appeared in $20 \%$ of supratentorial PNETs and in $33 \%$ of medulloblastomas. No homozygous deletion of PTEN or DMBT1 was detected in any of the PNET cell lines, either by differential PCR or by FISH assays.

The Progenetix database also illustrates the genomic differences between the more anaplastic variants and classic medulloblastomas. Eberhart, et al.. ${ }^{73}$ studied the chromosomal changes in five desmoplastic/nodular, 10 histologically classic, and 18 large-cell/anaplastic medulloblastomas by using CGH and FISH analyses. More copy number changes were identified among the anaplastic subtypes than in nonanaplastic ones. In addition, amplification of $M Y C C$ and $M Y C N$ was identified in four (MYCC) and five (MYCN) large-cell/anaplastic medulloblastomas. High-level gains of other chromosomal loci were also more common among the anaplastic cases. The loss of chromosome $17 \mathrm{p}$ was detected in seven large-cell/anaplastic cases but not in nonanaplastic medulloblastomas. The CGH analysis showed a significant increase in the overall number of chromosomal alterations in large-cell/anaplastic medulloblastomas com-

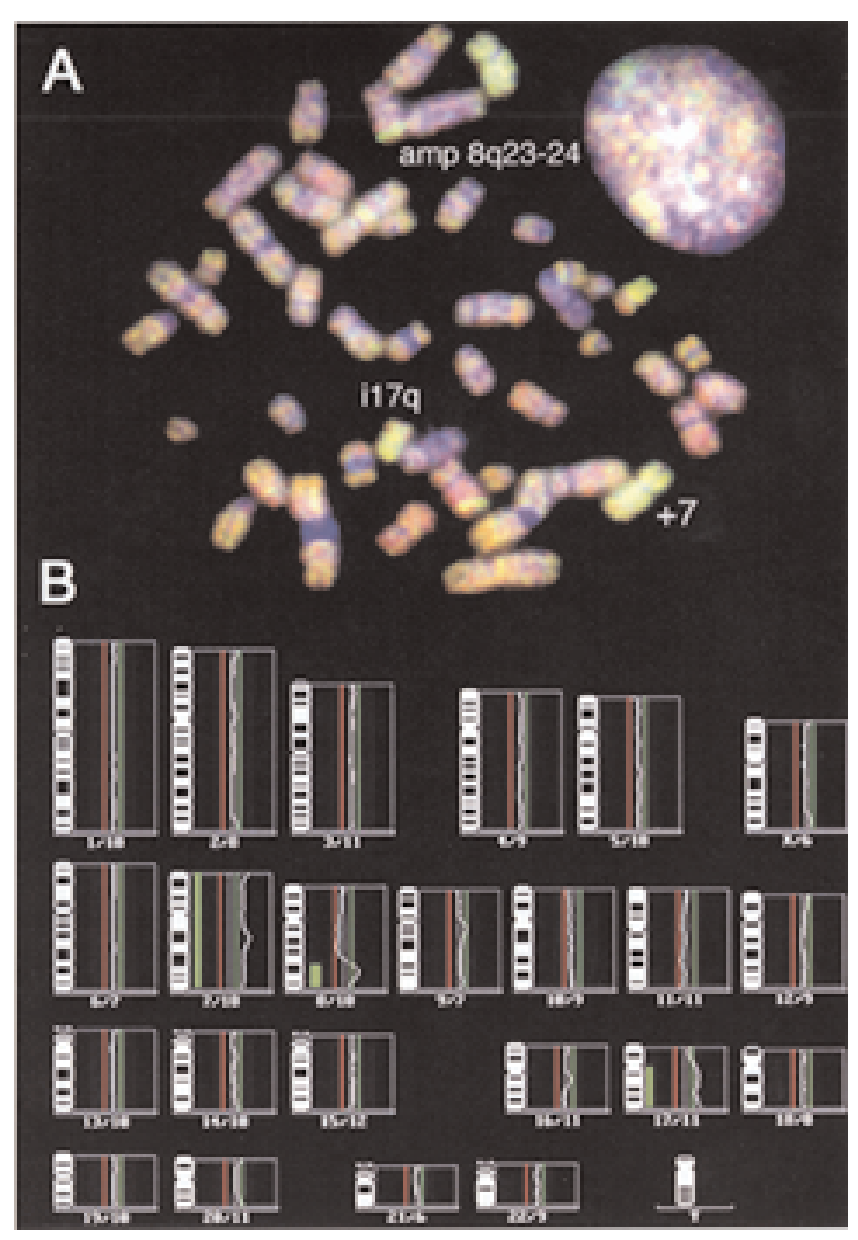

Fig. 4. Metaphase-based CGH and analysis of a primary medulloblastoma. A: Normal metaphase spread after hybridization with tumor and normal DNA. Changes in green/red ratio reveal regions of gain/amplification on chromosomes 7 and 17 as well as at 8q23-q24, which are easily recognized on visual inspection. B: Idiograms of the $\mathrm{CGH}$ analysis showing the previously mentioned changes. Original magnification $\times 60$.

pared with nonanaplastic ones, supporting an association between $M Y C$ oncogene amplification, 17p loss, and the histological features of large-cell/anaplastic tumors. These findings are also supported by classic cytogenetic, FISH, $\mathrm{CGH}$, and SKY studies conducted by our group. ${ }^{13}$ Analysis of medulloblastomas and supratentorial PNETs, including desmoplastic and large-cell subtypes, showed amplification of MYCC or MYCN. Classic cytogenetic analysis identified complex structural changes, double minute chromosomes, and karyotypic heterogeneity as more characteristic of the anaplastic subtypes than classic medulloblastomas or supratentorial PNETs. When correlated with survival, a significant decrease is found among patients with the large-cell/ anaplastic subtypes and is believed to be contributed by MYCC and MYCN amplification. ${ }^{40}$

Lamont and colleagues ${ }^{142}$ demonstrated that stratifying medulloblastomas in children by a combination of refined histopathological classification and FISH evaluation of chromosome 17 abnormalities, losses of 9q22 and 10q24, and amplification of $M Y C C$ and $M Y C N$ helped predict 
prognosis and outcome. It was revealed that the large-cell/ anaplastic phenotype was an independent prognostic indicator. Loss of $17 \mathrm{p} 13.3$ (38\% of medulloblastomas) was found across all of the histopathological variants, whereas MYCC/MYCN amplification (6:8\% of medulloblastomas) was significantly associated with the large-cell/anaplastic phenotype, and was also found to be a prognostic indicator. Loss of $9 q 22$ was associated with the nodular/desmoplastic medulloblastoma variant, whereas loss of $10 \mathrm{q} 24$ was found in all of the variants. Together with metastatic tumor at presentation, the large-cell/anaplastic phenotype, 17 p13.3 loss, or high-frequency $M Y C$ amplification defined a high-risk group of children whose outcome was significantly $(\mathrm{p}=0.0002)$ worse than in a group without these tumor characteristics.

By far the most consistent aberration among medulloblastomas is the loss of $17 \mathrm{p}$ and/or the formation of an isochromosome $17(\mathrm{q})$ in more than $30 \%$ of tumors (Fig. 5). Chromosome 17 aberrations appear to distinguish between infratentorial and supratentorial tumors, ${ }^{43,231}$ and are an indicator of progression. ${ }^{11,184}$ The mapping of TP53 to $17 \mathrm{p} 13$ makes TP53 an ideal candidate for critical tumor suppressor gene involved in pathogenesis; however the role of TP53 has been uncertain, with only 5 to $10 \%$ of tumors showing mutations. Several studies, however, have used advanced molecular cytogenetic and genomic analysis in identifying the role of chromosome 17.

Recently, Pan and colleagues ${ }^{184}$ used CGH and clustering analysis to determine whether copy number changes could help predict prognosis and improve criteria for predicting outcome in a series of 25 medulloblastomas. Isochromosome $17 \mathrm{q}$ was associated with poor overall survival $(\mathrm{p}=$ $0.03)$ and event-free survival $(p=0.04)$ independent of the patient's risk group classification. Patients younger than 3 years of age tend to be associated with fewer than three copy number aberrations $(\mathrm{p}=0.06)$. Unsupervised cluster analysis sorted the patients in the study into four subgroups based on copy number aberrations. Supervised analysis using the program Significance Analysis of Microarrays quantitatively validated those identified by unsupervised clustering that significantly distinguished among the four subgroups. In addition, FISH analysis of breakpoint locations along chromosome 17 in various neoplasms, including medulloblastomas, has identified four different breakpoint cluster regions containing low-copy-number repeat genes that contribute to loss of $17 \mathrm{p}$ or isochromosome 17 formation. ${ }^{242}$ One is located close to or within the centromere of chromosome 17 and a second is in the CharcotMarie-Tooth (CMT1A) region at 17(p11.2). A third breakpoint was found telomeric to the CMT1A region. The fourth and most common breakpoint was bordered by cosmids D14149 and M0140 within the Smith-Magenis syndrome region. These findings complement methylation studies by Fruhwald, et al., ${ }^{82}$ which found that aberrantly hypermethylated CpG islands in 17p11.2 were found in 33\% of medulloblastomas, whereas none of the supratentorial PNETs were methylated, suggesting a potential link between chromosomal instability in $17 \mathrm{p} 11.2$ and hypermethylation. Moreover, Di Marcotullio and associates ${ }^{66}$ recently reported allelic deletion and reduced expression of the human REN (KCTD11), which maps to 17p13.2, in medulloblastomas. The REN (KCTD11) inhibits medulloblastoma cell proliferation and colony formation in vitro and suppresses xenograft tumor growth in vivo, and seems to inhibit medulloblastoma growth by negatively regulating the Hedgehog pathway, which has been implicated in medulloblastoma pathogenesis. ${ }^{265}$

The amplification of the $M Y C N$ and $M Y C C$ genes has been identified in medulloblastomas and PNETs; $4,9,13,114$ however, amplification of EGFR (7p11.2) $)^{181}$ and hTERT $T^{77}$ has also been detected and confirmed using FISH or other molecular assays. Other regions of amplification were recently discovered by Tong, et al., ${ }^{272}$ by using metaphase- and arraybased $\mathrm{CGH}$ in 14 medulloblastoma samples. Metaphasebased CGH detected nonrandom losses at 8p, 17p, 16q, 8q, and $1 p$ and gains on 17q, 12q, 7q, and 1p. Array-based CGH was used to investigate amplification of 58 oncogenes throughout the genome. Novel gene amplifications were identified at PGY1 (7q21.1), MDM2 (12q14.3-q15), and ERBB2 (17q21.2). The highest frequencies of oncogene gain were detected in D17S1670 (61.5\%), and manifested in PIK3CA (46.2\%), PGY1 (38.5\%), MET (38.5\%), ERBB2 (38.5\%), and CSE1L (38.5\%).

Deletion studies have been focused on regions of $10 \mathrm{q},{ }^{111}$ $17 \mathrm{p}$, and more recently at $6 \mathrm{q} 11.1 .{ }^{108} \mathrm{Hui}$, et al., ${ }^{108}$ used highresolution array-based $\mathrm{CGH}$ to detect a novel homozygous deletion at 6q21.1. In this study a 1803 BAC clone array was used to define recurrent chromosomal regions of gains or losses in cell lines and primary tumors and detected chromosomal aberrations consistent with the established genomic patterns for medulloblastomas. A homozygous dele-

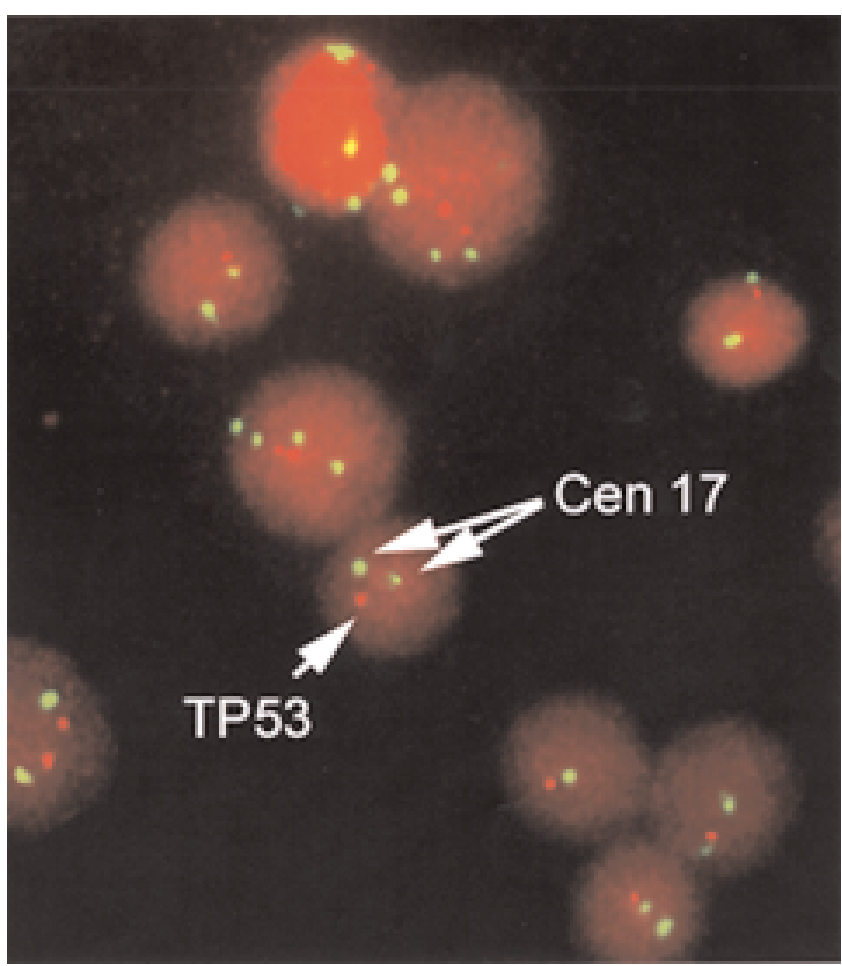

Fig. 5. Photomicrographs of FISH analysis of a primary medulloblastoma. Centromere- and locus-specific FISH analysis using centromere 17 (Cen 17, green) and a probe specific for TP53, located on 17p (red), suggesting the formation of an i(17)(q10) aberration through the loss of one TP53 homolog. Original magnification $\times 60$. 
tion on chromosome $6 \mathrm{q} 23$ was detected in the cell line DAOY, and it was also detected as a single copy loss in $30.3 \%$ of primary tumors. A $0.887-\mathrm{Mb}$ minimal region of homozygous deletion at $6 \mathrm{q} 23.1$ flanked by markers SHGC14149 (6q22.33) and SHGC-110551 (6q23.1) was defined. Quantitative reverse transcription-PCR analysis showed complete loss of expression of two genes located at $6 \mathrm{q} 23.1$ : AK091351 (hypothetical protein FLJ34032) and KIAA 1913, in the cell line DAOY. Subsequent analysis in the remaining cell lines and tumors also showed reduced messenger RNA levels of these genes (in 50 and $70 \%$ of primary tumors, respectively), implicating tumor suppressor function.

Ependymoblastoma. Ependymoblastomas (WHO Grade IV) are rare, malignant, embryonal brain tumors that occur in neonates and young children. They are often large and supratentorial lesions and generally relate to the ventricles; these tumors grow rapidly with craniospinal dissemination. The outcome is grim, with death occurring within 6 to 12 months of diagnosis.

The CGAP website reports three ependymoblastomas, ${ }^{83}$ with diploid karyotypes in two cases and a hypotriploid karyotype in the third. In one diploid case, the sole aberration was the gain of chromosome 22 . In the other, three clonal lines were identified and each was shown to have a chromosomal aberration involving chromosome 17. In the hypotriploid tumor, two lines were identified showing whole chromosomal gains and losses. Aberrations involving chromosome 3 were detected in both lines.

\section{Other CNS Neoplasms}

Meningiomas. Meningiomas are common CNS neoplasms, and although most are benign tumors, as many as $20 \%$ exhibit clinically aggressive features, leading to considerable morbidity and death. ${ }^{194}$ The WHO classification of meningioma includes benign (Grade I), atypical (Grade II), and anaplastic (Grade III) categories. Meningiomas are generally thought to progress from low-grade to high-grade tumors. Pediatric meningiomas and other meningeal tumors are uncommon and are reviewed in detail by Perry, et al. ${ }^{193}$ Pediatric meningiomas appear to share the same cytogenetic changes as their adult counterparts.

The CGAP website reports 811 cases of meningiomas. ${ }^{2,17}$, $19,47,48,63,70,78,93,101,102,146,153,157,210,234,235,279,298,305$ Normal karyotypes, or those missing one sex chromosome, are frequent. The most consistent change reported in benign meningiomas is partial deletion, $\operatorname{del}(22)(\mathrm{q} 12)$, or total deletion of chromosome 22, which occurs most often in Grade I meningiomas. In some karyotypes, the loss/partial deletion of chromosome 22 is the sole abnormality (262 of 811). The loss of chromosome 22 associated with other chromosomal aberrations occurred in 526 of 811 cases. The deletions of part or all of $1 \mathrm{p}, 10$, and 14 are also frequent abnormalities detected in meningiomas. Unstable chromosome alterations, including rings, dicentrics, and telomeric associations, have been observed. ${ }^{235}$ Telomeric associations were observed both as clonal and nonclonal aberrations in $24 \%$ of tumors in a study conducted by Sawyer, et al. ${ }^{235}$ Dicentric chromosome 22 was found in $10 \%$ of tumors, with progressive loss of chromosome 22q material found in two lesions.

The CGH studies referenced at the Progenetix site summarize 45 meningiomas ${ }^{8,224}$ and 46 malignant meningio- mas. $8,45,206,218,224$ The most prominent genomic changes among the 45 meningiomas are the whole or partial loss of $1 \mathrm{p}(22-33 \%)$ and loss of all or part of chromosome 22 (24-51\%). Gains on all chromosomes were also detected, but generally on chromosomes 4q, 5q, 6q, 12q, and 13q. Among the malignant meningiomas, losses of almost all chromosomes are characteristic of this group, but most prominently at $1 \mathrm{p}(26-39 \%), 7 \mathrm{p}(15 \%), 10 \mathrm{q}(17 \%), 14 \mathrm{q}$ (14\%), 18q (17\%), and $22(23 \%)$. Prominent gains were restricted to $12 q(8.7 \%)$, with amplification of $12 q$ in $2.2 \%$ of cases. In addition, gains of $17 \mathrm{q}$ were also detected in $10.9 \%$, with amplification detected in $6.5 \%$ of cases.

The molecular cytogenetic findings have isolated the involvement of $N F 2$ located on $22 \mathrm{q}$ in the pathogenesis of these tumors, and this has led to several studies in which the goal was better identification of its role in tumor initiation, progression, and as a molecular marker. In a recent study to search for microdeletions or/and structural recombinations of chromosome 22, Prowald, et al., ${ }^{200}$ investigated primary cell cultures of 43 meningiomas by using conventional Gbanding (26 without, 17 with loss of chromosome 22). Twenty-seven tumors were analyzed with SKY and 16 with FISH by using DNA probes for the chromosomal regions of 22q11.2, 22q11.23q12.1, 22q12.1, and 22q13.3. The SKY analysis confirmed G-banding data for chromosome 22 and could specify marker chromosomes and translocations containing material from chromosome(s) 22. Locus-specific FISH for regions on $22 \mathrm{q}$ confirmed the deletions in six of eight cytogenetically "normal" cases. These confirmed the authors' assumption that microdeletions on chromosome 22 were present in cytogenetically nonaberrant meningiomas. In addition, two of eight cases showed gains of the 22q13.3, and gains of the 22q12.1 region in another two. These findings suggest complex mechanisms of duplication and translocation, with concomitant genomic deletion in addition to whole losses of chromosome 22; these are reminiscent of mechanisms found in chronic myeloid leukemias discussed by Kolomietz, et al. ${ }^{130}$

Sayagues and colleagues ${ }^{240}$ examined samples obtained in 125 patients after diagnosis of meningioma, using interphase FISH on primary tumor specimens for 11 different chromosomes to establish the intratumoral patterns of clonal evolution associated with chromosomal instability in individual patients. In this way, tumor progression pathways in meningiomas and their relationship with tumor histopathological features and behavior could be established. The FISH assay showed that $56(45 \%)$ of the 125 cases analyzed had a single tumor cell clone, corresponding histologically to benign Grade I tumors. In the remaining 69 cases $(55 \%)$, more than one tumor cell clone was identified: two clones in 45 cases (36\%), three in $19(15 \%)$, and four or more in five cases (4\%). The accompanying flow cytometric analysis showed the presence of DNA aneuploidy in 44 of these cases (35\%), 30\% corresponding to DNA hyperdiploid and 5\% to hypodiploid cases; of the DNA aneuploid cases, 35 (28\%) showed two clones and nine $(7 \%)$ had three or more clones.

Among the cases with chromosomal abnormalities, the earliest tumor cell clone observed was frequently characterized by the loss of one or more chromosomes (64\% of all meningiomas); loss of either a single chromosome 22 or, less frequently, of a sex chromosome (X or Y), and del(1p) was commonly found as the single initial cytogenetic aber- 
ration $(30,5$, and $5 \%$ of the cases, respectively). In addition, an isolated loss of chromosome 22 was found as the initial abnormality in only one of 14 atypical/anaplastic meningiomas, whereas the same cytogenetic pattern was present in the ancestral tumor cell clone in $32 \%$ of the benign tumors. These results demonstrate that meningiomas are genetically heterogeneous tumors that display different patterns of numerical chromosome changes. The presence of more than one tumor cell clone detected in almost half of the cases, including all atypical/anaplastic cases, and the fact that the pathways of clonal evolution observed in the benign tumors were different from those observed in atypical/anaplastic meningiomas, indicate that the latter tumors might not always represent a more advanced stage of histologically benign meningiomas.

The use of FISH for tumor characterization was recently demonstrated by Bannykh and colleagues ${ }^{10}$ who reported a case in which a malignant brain neoplasm with rhabdoid morphological features emerged in the bed of a subtotally resected ganglioglioma. The rhabdoid appearance of the tumor cells indicated either an especially malignant variant of rhabdoid meningioma or an atypical teratoid/rhabdoid tumor with an unusually late onset. The FISH assay identified the loss of one copy of $N F 2$ on 22q, thus classifying this tumor as a malignant rhabdoid meningioma.

Studies of chromosome 14 in which interphase FISH and CGH were used have been correlated with clinical, histopathological, and prognostic features in a series of 124 meningiomas by Tabernero and associates. ${ }^{262}$ Of 124 cases, $40.3 \%$ showed loss $(14.5 \%)$ or gain $(25.8 \%)$ of the $14 \mathrm{q} 32$ chromosome region based on FISH. Most corresponded to numerical abnormalities: monosomy (12.9\%), trisomy $(1.6 \%)$, or tetrasomy $(24.2 \%)$; in only two cases $(1.6 \%)$, chromosome 14 loss did not involve the whole chromosome and was restricted to the 14q31-q32 region, as confirmed on $\mathrm{CGH}$. Cases with gain or monosomy corresponded more frequently to histologically malignant tumors $(\mathrm{p}=0.009)$. Patients with monosomy $14 / 14 q-$, but not those with gain, were more often male $(p=0.04)$, had a greater incidence of recurrence $(p=0.003)$, and a shorter relapsefree survival period $(\mathrm{p}=0.03)$. The two patients with loss limited to $14 \mathrm{q} 31-\mathrm{q} 32$ had histologically benign tumors and no relapse after more than 5 years of follow up. Most meningiomas with chromosome 14 abnormalities have numerical changes, with interstitial deletions of 14q31-q32 present in few cases. Of the abnormalities detected, only monosomy 14 showed an adverse prognostic impact.

The partial or complete loss of chromosome 1 or $1 \mathrm{p}$ has been demonstrated to be an important step in the initiation and/or progression of meningiomas. ${ }^{8}$ Therefore, Buckley, et al. ${ }^{42}$ studied 82 meningiomas by using a chromosome 1 tiling array containing 2118 features. A broad range of aberrations, such as deletions and/or gains of various sizes, were identified. Deletions were the predominant finding and ranged from monosomy to a $3.5-\mathrm{Mb}$ terminal $1 \mathrm{p}$ homozygous deletion. In each case, $1 p$ deletions were detected. The distribution of aberrations supports the existence of at least four candidate loci on chromosome 1 (three on $1 p$ and one on 1q) that are important for meningioma tumorigenesis. These candidate genes included the TP73 and ARHGEF16 (or Rho guanine exchange factor 16) genes. The TP73 gene has been studied previously in meningiomas, but only with a limited number of tumors. ${ }^{152}$ The authors hypothesized that the finding of an anaplastic meningioma with a homozygous deletion encompassing this region may indicate that the inactivation of this gene or of other neighboring genes could be related to the very late stage of meningioma progression. In addition, the observed association between the presence of segmental duplications and deletion breakpoints offers a mechanism in the generation of these tumorspecific aberrations.

\section{Tumors of the Sellar Region}

Craniopharyngioma. Craniopharyngiomas are a rare epithelial neoplasm arising in the hypothalamic and pituitary region, accounting for 6 to $9 \%$ of all primary CNS neoplasms and 56\% of sellar and suprasellar tumors in children. Craniopharyngiomas may exhibit a malignant clinical course, despite their benign nature and the fact that they are composed of well-differentiated tissue classified into two subtypes that are histologically and clinically distinct: adamantinomatous (embryonic remnants) and papillary (squamous papillary).

There are few cytogenetic studies of craniopharyngiomas. The CGAP website reports four craniopharyngioma cases. ${ }^{89,126,175,278}$ These cases were all diploid, with no specific associated chromosomal change. In addition to these, Griffin, et al., ${ }^{94}$ reported normal karyotypes for four cases.

There are also few CGH studies ${ }^{219,223,304}$ and these have not shown consistent chromosomal changes. Rickert and Paulus $^{219}$ examined 20 adamantinomatous and nine papillary craniopharyngiomas and found no DNA copy number changes in any of the 29 primary craniopharyngiomas, regardless of histological subtype. Similar findings were seen in a study by Yoshimoto, et al., ${ }^{304}$ of 10 adamantinomatous craniopharyngiomas that showed no copy number changes. In a CGH study of nine adamantinomatous craniopharyngiomas, however, Rienstein and associates ${ }^{223}$ reported an overall increase of copy number changes in six cases.

Pituitary Adenoma and Pituitary Carcinoma. The CGAP site reports 48 cases of pituitary adenoma. ${ }^{16,20,44,67,79,144,187,226}$ The karyotypes are largely diploid, showing frequent gains of chromosomes $4,7,8,9,12$, and 20 , and losses of chromosomes 10, 14, 19, and 22. Finelli and coworkers ${ }^{79}$ conducted conventional cytogenetic and interphase FISH analyses on 53 specimens. Of the 53 samples (including 17 nonfunctioning pituitary adenomas, 16 PRL-, nine ACTH-, nine GH-, and two TSH-secreting tumors), only eight had abnormal karyotypes (see CGAP website). Interphase FISH assays for centromeres 5, 8, 12, and X were performed in 31 cases, resulting in the detection of 17 cases with copy number changes in one or more of the chromosomes tested. Separate or combined trisomy of chromosomes 5,8 , and 12 were found in all 10 prolactinomas and in four of nine nonfunctioning pituitary adenomas, whereas the combined loss of chromosomes 5 and 8 was observed in one of six ACTHand one of six GH-secreting pituitary adenomas.

The current and previous data on 23 pituitary adenomas showed that the tumors with the highest frequency of abnormal karyotypes revealed by cytogenetic and/or interphase FISH studies were PRL-secreting (78\%), nonfunctioning pituitary adenoma (26\%), and GH-secreting tumors $(18 \%)$. Recurrent structural rearrangements affecting chromosomes 1,3 , and 12 were also identified in prolactino- 
mas, which therefore appear to be the only pituitary adenoma subtype with a defined trend of tumor-specific chromosomal change. Chromosome 11 changes were investigated in 24 pituitary adenomas by Kontogeorgos, et al., ${ }^{132}$ The FISH analysis showed numerical abnormalities in 16 functioning (94\%) and five nonfunctioning (71\%) adenomas. Ten functioning tumors showed aneuploidy, whereas the remaining ones and all nonfunctioning adenomas were diploid. Aberrant chromosome 11 signals were noted mostly in aneuploid adenomas, involving 17 to $100 \%$ of their cell population. These authors' findings suggested that chromosome 11 abnormalities were common in all types of pituitary adenomas, occurring more frequently in functioning tumors. Specific numerical abnormalities, such as monosomy and trisomy, tended to be associated with certain adenoma types, whereas tumors with extra copies of chromosome 11 often exhibit overall aneuploidy.

In the CGH studies reported, ${ }^{56,59,76,97,107,131,167,183,217,261,276}$ no specific copy number changes were detected for this group of tumors. Gains have been identified on chromosomes 3, $4,5,7,8,9,12,14,16,17,19,20,22$, and $\mathrm{X}$, with the highest frequencies for chromosomes 5, 7, 9, 12, 19, and X. Losses seem to be restricted primarily to chromosomes 2 , $10,11,13$, and 18 . The region of $1 \mathrm{p} 32-\mathrm{p} 33$ has been identified as a region of loss, in the presence of gains in the long arm of chromosome 1 . Loss at chromosome 13 showed a region of minimal overlap at $13 \mathrm{q} 21$, the locus to which $R B$ maps. Analysis of $R B$ in pituitary adenomas has revealed LOH in this region (see review by Herrmann, et al. ${ }^{104}$ ).

Cytogenetic reports on pituitary carcinomas are rare, and are reviewed in print by Gollin and Janecka; 88 however, the Progenetix website reports four cases ${ }^{220}$ of pituitary carcinomas showing gains of 1q, 3p, 4, 5, 6q, 7, 8, 9p, 9q, 12, $13,14,16,20,21$, and 22 . Losses were detected primarily at $1 \mathrm{p}, 10,11 \mathrm{q} 22$-qter, and 15. Amplification was detected at 13q31-qter.

\section{Tumors of Cranial and Spinal Nerves}

Schwannoma (Neurinoma, Neurilemoma). The CGAP database reports 79 schwannomas. . $^{15,54,80,90,124,151,164,175,208,212,236 \text {, }}$ $259,268,290$ The karyotypes can be generally characterized as diploid, the partial or complete loss of chromosome 22 being the most common chromosomal aberration, and occurring in approximately half of the cases. Other recurrent abnormalities include the loss of a sex chromosome as well as the losses of chromosomes 17 and 15. Gains of chromosome 7 occur, albeit in low frequencies.

There are few CGH studies of schwannomas, ${ }^{7,128,289}$ and in all three of these, comparisons between sporadic schwannomas and those associated with NF2 were discussed. Warren and colleagues ${ }^{289}$ screened 76 vestibular schwannomas obtained in 76 patients (66 sporadic and 10 NF2-related tumors), and found the most common change was the loss of chromosome 22, which was more frequent in sporadic than in NF2-related tumors. In $10 \%$ of cases, gains of $9 \mathrm{q} 34$ were detected. Other gains were detected on regions of chromosomes 10, 11, 13, 16, 19, 20, X, and Y. Koga, et al., ${ }^{128}$ examined 50 cases of PNSTs; among them were 14 schwannomas, which revealed similar findings. Nevertheless, the authors noted that the schwannomas had losses of chromosomes 17 and 19 in less than 50\% of cases, com- pared with other PNSTs. Finally, Antinheimo and cowork$\mathrm{ers}^{7}$ analyzed 25 schwannomas (12 NF2 and 13 sporadic schwannomas), with some chromosomal regions further studied using $\mathrm{LOH}$ or FISH analysis. The CGH analysis detected genomic abnormalities in $60 \%$ of schwannomas, with the most common alteration being the loss on 22q, which was detected in $32 \%$ of cases. No consistent changes were detected in other chromosomal regions between the sporadic and NF2-associated cases.

Due to the high frequency of chromosome 22 loss in both sporadic and NF2-associated tumors, array-based studies across the genome as well as chromosome 22 have been conducted. Mantripragada, et al. ${ }^{158}$ constructed an array spanning 11 million bp of $22 q$ encompassing the NF2 gene, with $100 \%$ coverage and a mean resolution of $58 \mathrm{~kb}$. Moreover, the 220-kb genomic sequence encompassing the NF2 gene was covered by 13 cosmids to further enhance the resolution of analysis. Using CGH methods, the array was used to map and size chromosome 22q deletions, around $N F 2$, in 47 sporadic schwannomas. Heterozygous deletions were detected in $45 \%$ of the lesions. Of these 21 tumors with deletions, the authors identified three profiles to classify the lesions. The predominant profile (in 12 of 21) was a continuous deletion of the 11-Mb segment, consistent with monosomy 22 . The second profile (five of 21), was also in agreement with a continuous 11-Mb heterozygous deletion, but displayed a distinctly different level of deletion when compared with the first profile. The third profile was composed of four cases displaying interstitial deletions of various sizes. Two did not encompass the NF2 locus, emphasizing the importance of other loci in schwannoma pathogenesis. Similarly, to determine the frequency and extent of deletions, Bruder, et al., ${ }^{41}$ examined a 7-Mb interval in the vicinity of the NF2 gene by using high-resolution array-based CGH in 116 patients with NF2. At least $90 \%$ of this region of $22 \mathrm{q}$, around the NF2 locus, was included on the array. Deletions were detected in eight severe, 10 moderate, and six mild cases. The authors concluded that these findings do not support the correlation between the type of mutation affecting the NF2 gene and the disease phenotype occurring in constitutional or tumorderived DNA.

Cellular schwannomas appear to possess chromosomal ${ }^{124,151,208,259}$ changes similar to classic schwannomas, namely the near-diploid karyotypes and involvement of chromosomal aberrations involving the sex chromosomes and chromosomes 22 and 7. In two published cases by Rao, et al. ${ }^{208}$ one patient displayed whole chromosome losses of one homolog of chromosomes 13 and 22 as well as the presence of a marker chromosome. The other patient, interestingly, was found to have an apparently balanced translocation between chromosomes 1 and $17(\mathrm{t}(1 ; 17)(\mathrm{p} 12 ; \mathrm{q} 11.2))$, with the $17 \mathrm{q}$ breakpoint occurring in the region of the NFI gene. Cytogenetic analysis of a rare variant, the plexiform cellular schwannoma, was recently published by Joste, et al., ${ }^{124}$ and the authors reported the presence of clonal numerical changes consisting of an additional chromosome 17 in one clone and the addition of chromosomes 17 and 18 in the second one.

Perineuriomas. The literature shows few publications on the cytogenetics of perineuriomas; however, the CGAP website reports two perineuriomas ${ }^{75,164}$ showing abnormal diploid karyotypes, with aberrations involving chromo- 
some 22 appearing in both cases. Mott and associates ${ }^{173}$ reported a soft-tissue perineurioma with the sole abnormality of the loss of chromosome 13. A FISH analysis for chromosome 22 showed no apparent deletion or structural abnormalities.

Neurofibroma. The CGAP reports eight cases of neurofibromas ${ }^{50,172,174,177,213,216}$ with diploid karyotypes. Structural aberrations are present, including balanced and unbalanced translocations, additions, and deletions, as well as marker chromosomes. No consistent chromosomal aberration appears among these cases.

The Progenetix website reports 40 cases of neurofibromas, both sporadic and NF1 associated, ${ }^{128,188,243}$ showing fairly well-defined patterns of chromosomal gains and losses, including gains from 1p31-p11, 1q, 2q21-q34, 3, 4, 5p15-qter, 5q14-q21, 6q11-q25, 8p, 8q11-q23, 12q11-q21, $13,13 q 21-q 32$, and 18 . Losses were restricted primarily to chromosomes 9, 14q31-qter, 16, 17p, 17q, 19, 20, 21, and 22 . Within these studies, the differences between sporadic and NF1-associated neurofibromas were assessed. Koga, et al., ${ }^{128}$ examined 27 neurofibromas. Both sporadic and NF1associated neurofibromas exhibited losses at chromosome $22 \mathrm{q}$ in more than $50 \%$ of cases. In NF 1-associated neurofibromas, the most frequent losses were found in chromosomes 17p11.2-p13 (60\% of cases), 17q24-25 (40\%), 19 p13.2 (53\%), and 19q13.2-qter (53\%). Gains were more frequently detected in plexiform neurofibromas (two of three cases) than in other benign tumors included in this study.

These findings were recapitulated in another publication by this group, ${ }^{129}$ in which $12 \mathrm{NF} 1$-associated tumors and 12 sporadic cases were analyzed using CGH. In this study, chromosomal imbalances were more common in NF1-associated tumors than in sporadic neurofibromas, with both groups showing predominantly more losses than gains, and it revealed novel chromosomal imbalances including chromosomes 17, 19, and chromosome arm 22q, which may be related to oncogenes or tumor suppressor genes in neurofibromas. For NF1-associated neurofibromas, the most frequent losses (minimal common regions) were found in chromosomes 17p11.2-p13, 17q24-q25, and 19p13. In addition, both $N F I$-associated and sporadic neurofibromas often exhibited losses at chromosome arms $19 \mathrm{q}$ and $22 \mathrm{q}$, with 19q13.2-qter in NF1 tumors.

Malignant PNSTs. The CGAP website reports 93 malignant PNSTs and triton tumors (with references to large studies $\left.^{80,122,164,166,197,208,244}\right)$. The majority of cases show complex karyotypes, with a near-triploid or tetraploid chromosomal complement. Whole chromosomal gains and losses affecting all chromosomes are apparent, with no specific pattern of genomic change. Plaat and colleagues ${ }^{197}$ used computer analysis to determine recurrent cytogenetic alterations in 51 malignant PNSTs, including 44 from the literature and seven new cases. In addition, direct cytogenetic comparison between NF1-associated and sporadic malignant PNSTs was also performed. Significant losses $(\mathrm{p}<0.05)$ were observed at chromosomal regions $9 \mathrm{p} 2,11 \mathrm{p} 1,11 \mathrm{q} 2$, and 18p1. Also, losses at 1p3, 9p1, 11q1, 12q2, 17p1, 18q1-q2, 19p1, 22q1, $\mathrm{X}$, and $\mathrm{Y}$ were detected. Chromosome 7 was frequently gained, especially at $7 q 1(p<0.05)$. The most frequently involved breakpoints were identified at $1 \mathrm{p} 13,1 \mathrm{q} 21,7 \mathrm{p} 22$, 9p11, 17p11, 17q11, and 22q11.
The cytogenetic differences between NFI-associated and sporadic malignant PNSTs included a relative loss of chromosomal material in NF1-associated malignant PNSTs at $1 \mathrm{p} 3,4 \mathrm{p} 1$, and 21p1-q2 as well as the relative gain in 15p1q1. Differences in breakpoints between NF1-associated and the sporadic malignant PNST group were observed at 1p2122 , comprising $28 \%$ of NF1 compared with $0 \%$ of sporadic malignant PNSTs, 1p32-34 (17 compared with 0\%), 8p1112 (7 compared with 27\%), and 17q10-12 (24 compared with $7 \%$ ). Thus, the authors theorized that losses in $9 \mathrm{p} 2$ and gains in 7q1 could be of oncogenetic importance in malignant PNSTs; and the uncommon loss of 17q1, the NF1 region (17q11.2), in NF-associated malignant PNSTs may reflect a difference in the oncogenic pathway between NF1associated and sporadic malignant PNSTs.

Recently, Bridge and colleagues ${ }^{39}$ used conventional cytogenetics and FISH and SKY analysis to identify recurrent chromosomal aberrations and breakpoints in malignant PNSTs and triton tumors. Twenty-one malignant PNSTs and malignant triton tumors obtained in 17 patients (nine with peripheral neurofibromatosis, also called NF1) were analyzed using standard G-banding and SKY studies for a subset of cases. These findings revealed structural aberrations most frequently occurring at 1p31-36, 4q28-35, 7p22, 11q22-23, 19q13, 20q13, and 22q11-13. Overall, loss of chromosomal material was much more common than gain. Loss of chromosomes or chromosomal regions 1p36 (48\%), 3p21-pter (52\%), 9p23-pter (57\%), 10 (48\%), 11q23-qter $(48 \%), 16 / 16 \mathrm{q} 24(62 \%), 17(43 \%)$, and 22/22q (48\%), and gains of $7 / 7 \mathrm{q}(29 \%)$ and $8 / 8 \mathrm{q}(29 \%)$ were most prominent, with gains and losses distributed equally between malignant PNST and malignant triton tumor.

The Progenetix website reports $70^{128,163,244,245}$ malignant PNSTs showing the frequent gain of $1 \mathrm{q}(7.1$ to $33 \%), 2$ (11.4\%), 2p16-2p23 (11.4 to 20\%), 3 (17\%), 4 (10\%), 5p (35\%), 5q (10\%), 6p (20 to 25\%), 6q (20\%), 7p (37\%), 7q $(25 \%), 8 \mathrm{p}(14 \%), 8 \mathrm{q}(48 \%), 12 \mathrm{p}(21 \%), 12 \mathrm{q}(17 \%), 16 \mathrm{p}$ (14\%), 17q (48\%), 18q (18\%), 20q (24\%), and $21(20 \%)$. Losses are present on all chromosomes at a low frequency; however, predominant losses occur on $1 \mathrm{p}(8.6 \%)$ and $17 \mathrm{p}$ (15.7\%). Amplifications are also present at $5 p, 7 p, 8 q$ (8q21-8qter), 12q21, and 17q24.

Identification of the genomic changes between the malignant and other PNSTs based on CGH was examined by Koga and coworkers ${ }^{128}$ and included 50 cases, consisting of nine malignant PNSTs, 27 neurofibromas (with three plexiform neurofibromas), and 14 schwannomas. These authors' findings were consistent with other CGH studies of the PNSTs, showing gains and amplifications occurring more prominently in the malignant forms, reflecting tumor progression along oncogenic pathways, and losses and deletions were more common in the benign forms, suggesting a pathway involving tumor suppressor genes. In addition, Perry, et al., ${ }^{195}$ used interphase FISH for NF1 (17q), NF2 (22q), p16 (9p), and EGFR (7p) to examine malignant PNST and morphologically similar neoplasms, to determine whether these alterations are involved in malignant PNST tumorigenesis. Twenty-two malignant PNSTs (nine NF1-associated, 13 sporadic), 13 plexiform neurofibromas, five cellular schwannomas, eight synovial sarcomas, six fibrosarcomas, and 13 hemangiopericytomas were analyzed using two-color FISH. The NF1 deletions, often in the form of monosomy 17, were found in malignant PNSTs (76\%), 
neurofibromas $(31 \%)$, hemangiopericytomas (17\%), and fibrosarcomas (17\%), but not in synovial sarcomas or cellular schwannomas. The NF1 losses were encountered more frequently in malignant PNSTs compared with other sarcomas $(\mathrm{p}<0.001)$, as were $\mathrm{p} 16$ homozygous deletions (45 compared with 0\%; $\mathrm{p}<0.001$ ), EGFR amplifications (26 compared with $0 \% ; \mathrm{p}=0.006$ ), and polysomies for either chromosomes 7 (53 compared with $12 \% ; p=0.003$ ) or 22 (50 compared with $4 \% ; \mathrm{p}<0.001$ ). Hemizygous or homozygous p16 deletions were detected in $75 \%$ of malignant PNSTs, but not in benign ones $(\mathrm{p}<0.001)$.

Triton tumors are a rare variant of the malignant PNST group characterized as possessing a mixture of cells with nerve sheath and skeletal muscle differentiation. Karyotypic studies ${ }^{103,162,277,283}$ and three SKY studies ${ }^{39,96,155}$ have revealed that these tumors possess karyotypic characteristics similar to malignant schwannomas. In most cases, structural aberrations involved chromosomes 7, 8, 17, and 22 . Amplification of $M Y C C$ was also identified. Interestingly, both Magrini, et al., ${ }^{155}$ and Hennig, et al., ${ }^{103}$ report the detection of an isochromosome $8 \mathrm{q}$ as one of two aberrations in a diploid karyotype (four copies of isochromosomes $8 \mathrm{q}$ were detected by Magrini, et al., suggesting the formation of the isochromosome 8q (containing MYCC) as an early event of malignancy).

\section{SUMMARY}

The reviews of cytogenetic and molecular cytogenetic findings presented here have shown both common and unique chromosomal changes to the various brain tumor types and are summarized in Table 1 and Fig. 6 . The distribution of genomic alterations shows a general trend of aggressive tumor types possessing changes including $-1 \mathrm{p}$, $+1 \mathrm{q}, 2,-3 \mathrm{p},+3 \mathrm{q},-4,+6,+7,+8 \mathrm{q},-9,-10,+12$, $-17 p$, and $+17 q$ as well as the presence of gene amplification; whereas more benign tumor types are characterized by fewer cytogenetic changes, the prominent alteration being loss of chromosome 22. The integration of genomics and proteomics will facilitate a more comprehensive understanding of the relationship between DNA copy number and gene and protein expression levels in carcinogenesis, and will lead to better diagnosis, novel treatments, and better quality of life.

\section{Other Molecular Cytogenetic Contributions to the Study of Brain Tumors}

Although the greatest contribution of molecular cytogenetic analysis to the study of brain tumors has primarily been the identification of chromosomal changes and imbalances, molecular cytogenetic techniques have also been implemented in other areas of study.

\section{Studying Amplicon/Gene Structure in Double Minute Chromosomes or Homogeneously Staining Regions}

Understanding and revealing patterns of gene amplification within the cell yield important information on gene expression. Several investigations of gene amplification have used molecular cytogenetic analysis. We have examined $E G F R$ amplification in vivo and in vitro, ${ }^{185}$ and have found that although EGFR amplification is observed in one third of GBMs, only one GBM cell line has maintained this amplification in vitro to date. It is interesting that of all the common genetic alterations observed in GBMs, EGFR amplification is the only aberration with a proportionally low incidence in vitro, in comparison with its presence in patient samples. Also, because EGFR mutations in GBM manifest primarily, if not exclusively, in amplified form, few cell lines with mutation of endogenous EGFR are available, suggesting that in vivo environments select for EGFR amplification and mutation, whereas in vitro environments (cell culture), select against this gene alteration. To contrast directly the fates of EGFR amplification in vivo and in vitro, as well as to examine potential relationships between $E G F R$ amplification and mutation, we established and maintained GBM explants as xenografts by serial passaging in nude mice. Analysis of EGFR copy number and EGFR mutation status in 11 patient tumors and their corresponding xenografts, as well as the monitoring of EGFR copy number during the establishment of a GBM cell line from a xenograft with amplified $E G F R$, indicate that selection for EGFR amplification is an in vivo phenomenon. Furthermore, during tumor propagation as a xenograft the EGFR mutation occurs only in tumors with $E G F R$ amplification, and selection of amplified mutant EGFR over amplified wild-type EGFR is rapid and complete.

The genomic structure of EGFR amplification units has also been investigated in detail in brain neoplasms. Double minute chromosomes are extrachromosomal circular DNA that comprise amplicon structures ranging in both size and complexity. Double minute chromosomes have been reported in several brain neoplasms, including GBMs and neuroblastomas. Vogt and colleagues ${ }^{284}$ investigated the genetic content and organization of the repeat elements in the double minute chromosomes of seven gliomas. A FISH analysis showed that the EGFR locus was never deleted from its expected location on chromosome 7 in the cells of all analyzed tumors; furthermore, the chromosome regions corresponding to each breakpoint were sequenced after PCR amplification, compared with the normal sequence, and shown to be normal. A FISH study with a probe spanning a deletion region in a subset of cases revealed that the deletion was specific to the double minute chromosomes and not the resident site on chromosome 7 . These molecular and FISH findings led to the conclusion that the observed double minute chromosomes originated from a single founding extrachromosomal body. In each of the gliomas, the founding molecule was generated by a simple event that circularized a chromosome fragment overlapping $E G F R$. The authors hypothesized that this likely occurs from the postreplicative excision of a chromosomal fragment, whereby the two ends are ligated by microhomologybased nonhomologous end-joining.

The FISH assay has also been used in identifying other genes that may be coamplified within double minute chromosomes as well as homogeneously staining regions. Methods have been introduced for releasing chromatin fibers from interphase nuclei in preparation for FISH analysis. ${ }^{100,303}$ With these approaches, the map order, orientation, and distance between closely linked genes can readily be determined by analysis of the linear arrangement of probes on released free chromatin fibers. Chromatin FISH mapping techniques conveniently bridge the resolution gap between pulsed-field gel electrophoresis and FISH metaphase mapping, so that molecular contigs generated by conven- 
TABLE 1

Summary of cytogenetic findings in brain tumors*

\begin{tabular}{|c|c|c|c|c|c|c|}
\hline \multirow[b]{2}{*}{ Tumor Type } & \multicolumn{2}{|r|}{ Karyotype } & \multicolumn{3}{|c|}{ CGH Findings } & \multirow[b]{2}{*}{ Comments } \\
\hline & Ploidy & Changes & Losses & Gains & Amp & \\
\hline astrocytoma & $\begin{array}{l}2 \mathrm{n}+1- \\
4 \mathrm{n}+1-\end{array}$ & $\begin{array}{l}+\mathbf{7},-\mathbf{9},-\mathbf{1 0} \\
\quad+\mathbf{1 9},-\mathbf{2 2} ; \mathrm{ExCh} \\
\quad \text { structures present }\end{array}$ & $\begin{array}{l}1 \mathrm{p}, 2,3 \mathrm{p}, 4,9 \mathrm{p} \\
10 \mathrm{q}, 13 \mathrm{q} 21 \\
18,19 \mathrm{q}, \mathrm{X}\end{array}$ & $\begin{array}{l}5,7,7 q, 8 q \\
9,10 p, 12 p, 19 p\end{array}$ & $8 \mathrm{q} 21$-qter & $\begin{array}{l}\text { candidate oncogenes (loci): } M Y C C \\
\text { (8q23), EGFR (7p12.3-p12.1), } \\
C D K 4(12 \mathrm{q} 14), M D M 2(12 \mathrm{q} 13)\end{array}$ \\
\hline $\begin{array}{l}\text { anaplastic } \\
\text { astrocytoma }\end{array}$ & $\begin{array}{c}2 n+l- \\
4 n+1- \\
3 n+1-\end{array}$ & $\begin{array}{l}+7,-\mathbf{9},-\mathbf{1 0} \\
+\mathbf{1 9},-\mathbf{2 2} ; \text { complex } \\
\text { structural changes; } \\
\text { ExCh structures } \\
\text { present }\end{array}$ & $\begin{array}{l}1 \mathrm{p}, 3,8 \mathrm{p}, 9 \mathrm{p}, 10 \\
12 \mathrm{q} 21-\mathrm{qter} \\
13 \mathrm{q} 11-\mathrm{q} 32 \\
14,17 \mathrm{p}, 19 \mathrm{q} \\
22\end{array}$ & $\begin{array}{l}1 \mathrm{q}, 2 \mathrm{q}, 5,5 \mathrm{q} 11-\mathrm{q} 23 \\
7,8 \mathrm{q}, 12 \mathrm{q} 11-\mathrm{q} 21 \\
17 \mathrm{q}, 20\end{array}$ & $\begin{array}{l}1 \mathrm{p} 31,1 \mathrm{p} 32,7 \mathrm{p} 11.2 \\
7 \mathrm{q} 21,7 \mathrm{q} 22-\mathrm{q} 33 \\
8 \mathrm{q} 13-\mathrm{q} 22.3 \\
12 \mathrm{q} 13-\mathrm{q} 21 \\
18 \mathrm{q} 26,20 \mathrm{p} 12\end{array}$ & \\
\hline GBM & $\begin{array}{c}2 n+1- \\
4 n+1- \\
3 n+1-\end{array}$ & $\begin{array}{l}+\mathbf{7},-\mathbf{9},-\mathbf{1 0},+\mathbf{1 9} \\
\mathbf{- 2 2} ; \text { complex } \\
\text { structural changes; } \\
\text { ExCh structures } \\
\text { present }\end{array}$ & $\begin{array}{l}1 \mathrm{p}, 3,8 \mathrm{p}, 9 \mathrm{p}, 10 \\
12 \mathrm{q} 21 \text {-qter, } \\
13 \mathrm{q} 11-\mathrm{q} 32,14 \\
17 \mathrm{p}, 19 \mathrm{q}, 22\end{array}$ & $\begin{array}{l}1 \mathrm{q}, 2 \mathrm{q}, 5,5 \mathrm{q} 11-\mathrm{q} 23 \\
7,8 \mathrm{q}, 12 \mathrm{q} 11-\mathrm{q} 21 \\
17 \mathrm{q}, 20\end{array}$ & $\begin{array}{l}1 \mathrm{p} 31,1 \mathrm{p} 32,7 \mathrm{p} 11.2 \\
7 \mathrm{q} 21,7 \mathrm{q} 22-\mathrm{q} 33 \\
8 \mathrm{q} 13-\mathrm{q} 22.3 \\
12 \mathrm{q} 13-\mathrm{q} 21,18 \mathrm{q} 26 \\
20 \mathrm{p} 12\end{array}$ & $\begin{array}{l}\text { candidate tumor suppressors (loci): } \\
\text { TP53 (17p13.1), CDKN2A (9p21), } \\
\text { PTEN (10q23.31), RB } \\
\text { (13q14.1), TOP3B (22q), TAF } \\
\text { (22q) }\end{array}$ \\
\hline $\begin{array}{l}\text { pilocytic } \\
\text { astrocytoma }\end{array}$ & $2 n+1-$ & $+7,-10,-22$ & $\begin{array}{l}1 \mathrm{p}, 1 \mathrm{p} 31-\mathrm{p} 36,3 \\
14 \mathrm{q} 11-\mathrm{q} 24,15 \\
19,20,21,22\end{array}$ & $\begin{array}{l}\text { 4, 4q21-q32, } \\
5 q 14-q 31, \\
6 q 13-q 23,7,7 q 31 \\
10,11,11 q 24-q t e r \\
13 q 21-q 31\end{array}$ & none to date & \\
\hline $\begin{array}{l}\text { subependymal } \\
\text { giant cell } \\
\text { astrocytoma }\end{array}$ & $2 n+1-$ & $\begin{array}{l}\text { no specific changes; } \\
\quad \mathbf{P}-\mathbf{2 2} \text { ? }\end{array}$ & none to date & none to date & none to date & $\begin{array}{l}\text { occurs almost exclusively in patients } \\
\text { w/ TSC; linkage studies involving } \\
\text { 9q34 (TSC1), 16q13.3 (TSC2) }\end{array}$ \\
\hline $\begin{array}{l}\text { pleomorphic } \\
\text { xantho- } \\
\text { astrocytoma }\end{array}$ & $2 \mathrm{n}+1-$ & $\begin{array}{l}\text { no specific changes; } \\
\quad \mathbf{?},-20,-\mathbf{2 2} ?\end{array}$ & $\begin{array}{c}\text { no specific } \\
\text { changes }\end{array}$ & $\begin{array}{c}\text { no specific } \\
\text { changes }\end{array}$ & $\begin{array}{c}\text { no specific } \\
\text { changes }\end{array}$ & \\
\hline $\begin{array}{l}\text { oligodendro- } \\
\text { glioma }\end{array}$ & $2 n+1-$ & $\begin{array}{l}+\mathbf{7},-\mathbf{2 1},-\mathbf{2 2} ; \mathrm{ExCh} \\
\quad \text { structures present }\end{array}$ & $\underset{22}{\mathbf{1 p}, 9 p, 13, \mathbf{1 9 q}}$ & $7,7 q, 8 q, 11,17 q$ & $7 q, 8 q$ & candidate oncogenes/loci: \\
\hline $\begin{array}{l}\text { oligoastro- } \\
\text { cytoma }\end{array}$ & $2 n+1-$ & +7 & & none to date & $7 q, 8 q$ & $\begin{array}{l}\text { GNI }(8 \mathrm{q}) \text {, associated w/ poor out- } \\
\text { come }\end{array}$ \\
\hline $\begin{array}{l}\text { anaplastic } \\
\text { oligoden- } \\
\text { droglioma }\end{array}$ & & none reported & $\begin{array}{l}\mathbf{1 p}, 2 \mathrm{q}, 4 \mathrm{q}, 9 \mathrm{p}, 11 \mathrm{p} \\
12 \mathrm{q}, 13,14 \mathrm{q} \\
18 \mathrm{q}, \mathbf{1 9 q}\end{array}$ & $7,7 q, 8 q, 10 p$ & $7 q, 8 q$ & $\begin{array}{l}\text { candidate tumor suppressors (loci): } \\
\text { TP73 (1p36.32), CDKN2C (1p32), } \\
\text { RAD54 (1p32), GLTSCR1 } \\
\text { (19q13.3), EDH2 (19q13.3), } \\
\text { GLTSCR2 (19q13.3), GNI } \\
\text { (11q13) }\end{array}$ \\
\hline ependymoma & $2 n+1-$ & $\begin{array}{l}\text { normal: }+4,+5,+7, \\
\quad+8,+9,-10,-17, \\
\text {-22; breakpoint: } \\
\text { 22q11 }\end{array}$ & $\begin{array}{l}3,6 \mathrm{p}, 6 \mathrm{q}, 10,13 \\
16,17,19,20 \mathrm{q} \\
22\end{array}$ & $1 \mathrm{q}, 4,5,7,9,12$ & none to date & $\begin{array}{l}\text { candidate oncogenes (loci): } M Y C N \\
\quad(2 \mathrm{p} 24)\end{array}$ \\
\hline $\begin{array}{l}\text { anaplastic } \\
\text { ependy- } \\
\text { moma }\end{array}$ & & none reported & $\begin{array}{l}\text { 3, 9p, 10p, 10q, } \\
13 \mathrm{q} 21,-\mathbf{2 2}\end{array}$ & $1 \mathrm{q}, 7,9 \mathrm{q}, 15$ & $2 \mathrm{p} 24$ & $\begin{array}{l}\text { candidate tumor suppressors (loci): } \\
\text { GNI (3p14, 10q23, } \\
11 \mathrm{q}), N F 2(2 \mathrm{q} 11)\end{array}$ \\
\hline $\begin{array}{l}\text { subependy- } \\
\text { moma }\end{array}$ & $2 n$ & $\begin{array}{l}\text { no specific } \\
\text { changes; ?17? }\end{array}$ & none to date & none to date & none to date & \\
\hline $\begin{array}{l}\text { myxopapil- } \\
\text { lary epen- } \\
\text { dymoma }\end{array}$ & & none reported & 9,18 & 9,18 & 9,18 & \\
\hline $\begin{array}{l}\text { clear cell } \\
\text { ependy- } \\
\text { moma }\end{array}$ & & none reported & none to date & none to date & none to date & $\begin{array}{l}\text { FISH findings: }-18 \text {, no } 1 \mathrm{p} \text { deletion, } \\
\text { no } 19 \mathrm{q} \text { deletion, no } N F 2 \text { deletion }\end{array}$ \\
\hline $\begin{array}{l}\text { spongio- } \\
\text { blastoma }\end{array}$ & $2 n, 4 n$ & $\begin{array}{l}\text { no specific changes; } \\
\text { ExCh structures } \\
\text { \& markers }\end{array}$ & none to date & none to date & none to date & \\
\hline gliomatosis & $2 n+1-$ & $\begin{array}{l}\text { no specific changes; } \\
\text { ExCh structures }\end{array}$ & $\begin{array}{l}\text { 2q11-q31, } \\
\text { 3q13-qter, } \\
\text { 16q22-qter, } \\
\text { 19q13-qter }\end{array}$ & 7q22-qter & none to date & \\
\hline astroblastoma & $2 n+1-$ & $\begin{array}{l}+7,-10,-12,-21 \\
\quad-22\end{array}$ & $9 q, 10$ & $20 q, 19$ & none to date & \\
\hline $\begin{array}{l}\text { ganglio- } \\
\text { glioma }\end{array}$ & $\begin{array}{l}2 \mathrm{n}+/- \\
4 \mathrm{n}+1-\end{array}$ & $\begin{array}{l}\text { normal: }+7,+/-13 \text {, } \\
\quad \mathrm{t}(13)\end{array}$ & $\begin{array}{l}\text { majority normal } \\
4 \mathrm{q} 13-\mathrm{q} 31,9 \mathrm{p} \\
14,15\end{array}$ & majority normal, 7 & majority normal & \\
\hline $\begin{array}{l}\text { desmoplastic } \\
\text { infantile } \\
\text { ganglio- } \\
\text { glioma/ } \\
\text { astrocytoma }\end{array}$ & $\begin{array}{l}2 \mathrm{n}+1- \\
4 \mathrm{n}+1-\end{array}$ & $\begin{array}{l}\text { structural changes } \\
\text { affecting } 5 \mathrm{q} 35, \\
9 \mathrm{p} 24,11 \mathrm{q} 25,14 \mathrm{q} 32, \\
17 \mathrm{p} 13,17 \mathrm{q} 25, \\
\& 22 \mathrm{q} 13\end{array}$ & $\begin{array}{l}\text { no specific } \\
\text { changes }\end{array}$ & $\begin{array}{c}\text { no specific } \\
\text { changes }\end{array}$ & $\begin{array}{c}\text { no specific } \\
\text { changes }\end{array}$ & \\
\hline
\end{tabular}


TABLE 1 (continued)

Summary of cytogenetic findings in brain tumors*

\begin{tabular}{|c|c|c|c|c|c|c|}
\hline \multirow[b]{2}{*}{ Tumor Type } & \multicolumn{2}{|r|}{ Karyotype } & \multicolumn{3}{|c|}{ CGH Findings } & \multirow[b]{2}{*}{ Comments } \\
\hline & Ploidy & Changes & Losses & Gains & Amp & \\
\hline $\begin{array}{l}\text { central } \\
\text { neuro- } \\
\text { cytoma }\end{array}$ & & $\begin{array}{l}\text { no specific changes, } \\
-17\end{array}$ & & $2 \mathrm{p}, 10 \mathrm{q}, 18 \mathrm{q}$ & none to date & $\begin{array}{l}\text { FISH findings: }+7 \text {, no } 1 \mathrm{p} \text { deletion, } \\
\text { no } 19 \mathrm{q} \text { deletion, no EGFR amp, } \\
\text { no MYCN amp }\end{array}$ \\
\hline DNET & & none reported & none reported & none reported & none reported & $\begin{array}{l}\text { FISH findings: no } 1 \mathrm{p} \text { deletion, no } \\
19 \mathrm{q} \text { deletion, no MYCN amp, no } \\
\text { EGFR amp }\end{array}$ \\
\hline $\begin{array}{l}\text { olfactory } \\
\text { neuroblas- } \\
\text { toma }\end{array}$ & $\begin{array}{l}2 n+l- \\
4 n+1- \\
3 n\end{array}$ & $\begin{array}{l}\text { no specific changes; } \\
\text { structural changes } \\
\text { involving } 1,3,7,8, \\
10,13\end{array}$ & $3 p, 4 q, 13 q$ & $\begin{array}{l}\text { 1p32-pter, 8q23-qter, } \\
9 \mathrm{q} 31-\mathrm{qter}, 15,17 \mathrm{q} \\
19,22 \mathrm{q}\end{array}$ & $\begin{array}{l}\text { 1p34, 1q23-q31, 7p21, } \\
\text { 7q31, 9p23-p24, } \\
\text { 17q11-q22, 17q24- } \\
\text { q25, 19, 20p, 20q13, } \\
\text { 22q13; ??metastatic } \\
\text { lesions: 1q34-qter, } \\
\text { 7q11, 9p23-p24, 9q34 } \\
\text { 13q33-q34, 16p13.3, } \\
16 \mathrm{p} 11,16 \mathrm{q} 23-\mathrm{q} 24, \\
17 \mathrm{p} 13\end{array}$ & \\
\hline $\begin{array}{l}\text { choroid } \\
\text { plexus } \\
\text { papilloma }\end{array}$ & $\begin{array}{l}2 \mathrm{n}+1- \\
\quad 3 \mathrm{n}\end{array}$ & $\begin{array}{l}-1,-3,+5,+6,+7 \\
\quad+8,+9,-10,+12 \\
\quad+15,-16,-17 \\
\quad+18,+20,-21 \\
\quad-22\end{array}$ & $\begin{array}{l}1,2,3,1-10, \\
16,17,21,22\end{array}$ & $\begin{array}{l}5,5 \mathrm{p} 14-\mathrm{q} 13,7,8,9, \\
\quad 12 \mathrm{p}, 12 \mathrm{q}, 15,18,20\end{array}$ & none to date & \\
\hline $\begin{array}{l}\text { choroid } \\
\text { plexus } \\
\text { carcinoma }\end{array}$ & $\begin{array}{l}\text { similar } t \\
\text { papill }\end{array}$ & $\begin{array}{l}\text { to choroid plexus } \\
\text { loma }\end{array}$ & $\begin{array}{l}3,6,16,18,22 \\
20,21\end{array}$ & $\begin{array}{l}1,4 \mathrm{q}, 7 \mathrm{q} 11-\mathrm{q} 31 \\
8 \mathrm{q} 11-\mathrm{q} 23,12,13\end{array}$ & none to date & $\begin{array}{l}\text { longer survival associated } w /+9 p \& \\
-10 q\end{array}$ \\
\hline $\begin{array}{l}\text { pineocytoma/ } \\
\text { mixed }\end{array}$ & $2 n+1-$ & no specific changes & $22,9 q, 16 q$ & $4 q, 5 q, 5 p, 12 q$ & & \\
\hline pineoblastoma & & & $22,9 q, 16 q$ & $4 q, 5 q, 5 p, 12 q$ & $\begin{array}{l}\text { 1q12-qter, 5p13.2-p14, } \\
\text { 5q21-qter, 6p12-pter, } \\
\text { 14q21-qter }\end{array}$ & \\
\hline $\begin{array}{l}\text { medulloepi- } \\
\text { thelioma }\end{array}$ & $2 n+1-$ & no specific changes & none to date & none to date & none to date & \\
\hline $\begin{array}{l}\text { medullo- } \\
\text { blastoma }\end{array}$ & $\begin{array}{l}2 n+1- \\
\quad 4 n, 3 n\end{array}$ & $\begin{array}{l}+1,+3,+4,+6,+7, \\
\quad+8,-9,-10,-12, \\
\quad-13,+17, \mathbf{i}(\mathbf{1 7}) \\
\quad(\mathbf{q 1 0}),+18,-19 ; \\
\text { complex structural } \\
\text { changes; ExCh } \\
\text { structures present }\end{array}$ & $10,10 q, 16 q, 17 p$ & $\begin{array}{l}1 \mathrm{q}, 2 \mathrm{p}, 2 \mathrm{q} 11-2 \mathrm{q} 24 \\
3 \mathrm{q}, 5,6,7,7 \mathrm{q}, 8 \mathrm{q} \\
13,17,17 \mathrm{q}, 18 \\
20 \mathrm{q}\end{array}$ & $\begin{array}{l}2 \mathrm{p} 24-2 \text { pter, } 2 \mathrm{q} 14- \\
2 \mathrm{q} 22,8 \mathrm{q} 23,9 \mathrm{p} \\
17 \mathrm{p} 11.2\end{array}$ & $\begin{array}{l}\text { candidate oncogenes (loci): PGY1 } \\
\text { (7q21.1), MDM2 (12q14.3-q15), } \\
\text { ERBB2 (17q21.2), MYCN (2p24), } \\
\text { MYCC (8q23), PIK3CA (3q26), } \\
\text { MET (7q31), CSE1L (20q13), } \\
\text { EGFR (7p12.3-p12.1), hTERT } \\
\text { (5p15.33) }\end{array}$ \\
\hline $\begin{array}{l}\text { supratentorial } \\
\text { PNET }\end{array}$ & $\begin{array}{l}2 n+/- \\
\quad 4 n, 3 n\end{array}$ & $\begin{array}{l}+1,+3,+4,+6 \\
\quad+7,+8,-9,-10 \\
\quad-12,-13,+17 \\
\quad+18,-19 ; \text { com- } \\
\text { plex structural } \\
\text { changes; ExCh } \\
\text { structures present }\end{array}$ & $\begin{array}{r}4 \mathrm{q}, 10 \mathrm{q} 23 \text {-qter, } \\
12,14 \mathrm{q}, \mathbf{1 9 q}\end{array}$ & $\begin{array}{l}1,1 \mathrm{q}, 2 \mathrm{p}, 3 \mathrm{q}, 6,5 \mathrm{p}, 7 \\
7 \mathrm{q}, 8 \mathrm{q}, 10 \mathrm{p}, 14,16 \\
16 \mathrm{q} 21-\mathrm{qter}, 17,18 \\
20,20 \mathrm{q}, 22\end{array}$ & $2 \mathrm{p} 24,9 \mathrm{p}$ & $\begin{array}{l}\text { candidate tumor suppressors (loci): } \\
\text { REN (KCTD11) (17p13.2), TP53 } \\
(17 \mathrm{p} 13), P T E N(10 \mathrm{q} 23.31), \\
D M B T 1(10 \mathrm{q} 25.3-\mathrm{q} 26.1), S U F U \\
(10 \mathrm{q} 24-\mathrm{q} 25), \text { GNI }(6 \mathrm{q}, 10 \mathrm{q})\end{array}$ \\
\hline $\begin{array}{l}\text { desmoplastic } \\
\text { medullo- } \\
\text { blastoma }\end{array}$ & $\begin{array}{l}2 n+/- \\
\quad 4 n, 3 n\end{array}$ & $\begin{array}{l}\text { all chromosomes in- } \\
\text { volved in copy } \\
\text { number changes; } \\
\text { complex structural } \\
\text { changes; ExCh } \\
\text { structures present }\end{array}$ & $\begin{array}{l}6,9 q 22,10 q 23- \\
\quad \text { qter, } 11,14,19\end{array}$ & $7,17 q$ & $2 \mathrm{p} 24$ & \\
\hline $\begin{array}{l}\text { large cell me- } \\
\text { dulloblas- } \\
\text { toma }\end{array}$ & $\begin{array}{l}2 n+1- \\
\quad 4 n, 3 n\end{array}$ & $\begin{array}{l}\text { all chromosomes in- } \\
\text { volved in copy } \\
\text { number changes; } \\
\text { complex structural } \\
\text { changes; ExCh } \\
\text { structures present }\end{array}$ & $10 q 24,16 q, 17 p$ & $\begin{array}{l}1 \mathrm{q}, 2,5,6,7,8,8 \mathrm{q} \\
9 \mathrm{p}, 13,14,17 \\
18 \mathrm{q}\end{array}$ & $\begin{array}{l}\text { 2p24, 2q13-2q22, } \\
\quad \mathbf{8 q 2 3}, 17 \mathrm{p} 11\end{array}$ & $\begin{array}{l}\text { breakpoint regions: Charcot-Marie- } \\
\text { Tooth (CMT1A) 17(p11.2), SMS } \\
\text { region }\end{array}$ \\
\hline $\begin{array}{l}\text { ependymo- } \\
\text { blastoma }\end{array}$ & $\begin{array}{l}2 n+1- \\
\quad 3 n\end{array}$ & no specific changes & none to date & none to date & none to date & \\
\hline meningioma & $2 n+1-$ & $\begin{array}{l}-1 \mathrm{p},-20,-14, \\
\quad-22 ; \text { del }(\mathbf{2 2})(\mathbf{q} 12)\end{array}$ & $1,1 \mathrm{p}, 22,14 \mathrm{q} 32$ & $4 q, 5 q, 6,13 q$ & none to date & $\begin{array}{l}\text { NF2 deletions investigated using } \\
\text { FISH; chromosome } 14 \\
\text { FISH/CGH studies indicate mono- } \\
\text { somy } 14 \text { associated w/ adverse } \\
\text { prognostic impact }\end{array}$ \\
\hline
\end{tabular}


TABLE 1 (continued)

Summary of cytogenetic findings in brain tumors*

\begin{tabular}{|c|c|c|c|c|c|c|}
\hline Tumor Type & \multicolumn{2}{|r|}{ Karyotype } & \multicolumn{3}{|c|}{ CGH Findings } & Comments \\
\hline $\begin{array}{l}\text { malignant me- } \\
\text { ningioma }\end{array}$ & & & $\begin{array}{l}1 \mathrm{p}, 7 \mathrm{p}, 10 \mathrm{q}, 14 \mathrm{q} \\
18 \mathrm{q}, 22\end{array}$ & $12 \mathrm{q}, 17$ & $12 q, 17 q$ & $\begin{array}{l}\text { candidate genes on } 1 \mathrm{p}: \text { TP73, } \\
\text { ARHGEF16 }\end{array}$ \\
\hline $\begin{array}{l}\text { craniopharyn- } \\
\text { gioma }\end{array}$ & $2 \mathrm{n}$ & $\begin{array}{l}\text { normal; no specific } \\
\text { changes }\end{array}$ & CGH findings are ty & ypically normal profiles & & \\
\hline $\begin{array}{l}\text { pituitary } \\
\text { adenoma }\end{array}$ & $2 n+1-$ & $\begin{array}{l}+4,+7,+8,+9 \\
\quad-10,+12,-14 \\
\quad-19,+20,-22 \\
\text { prolactinomas: re- } \\
\text { current rearrange- } \\
\text { ments of } 1,3, \& 12\end{array}$ & $\begin{array}{l}1 \mathrm{p} 32-\mathrm{p} 33,2,10 \\
11,13,13 \mathrm{q} 21 \\
18\end{array}$ & $\begin{array}{l}3,4,5,7,8,9,12 \\
\quad 13,16,17,19,20 \\
22\end{array}$ & none to date & $\begin{array}{l}\text { no specific CGH changes, all chro- } \\
\text { mosomes affected by copy number } \\
\text { changes; chromosome } 11 \text { changes } \\
\text { on FISH analysis generally associ- } \\
\text { ated w/ aneuploidy \& functioning } \\
\text { tumors }\end{array}$ \\
\hline $\begin{array}{l}\text { pituitary } \\
\text { carcinoma }\end{array}$ & & & $\begin{array}{l}1 \mathrm{p}, 10,11 \mathrm{q} 22 \text {-qter, } \\
15\end{array}$ & $\begin{array}{l}1 \mathrm{q}, 3 \mathrm{p}, 5,6,7,8,9 \mathrm{p} \\
\quad 9 \mathrm{q}, 12,13,14,16 \\
20,21,22\end{array}$ & 13q31-qter & $\begin{array}{l}\text { no specific CGH changes, all chro- } \\
\text { mosomes affected by copy number } \\
\text { changes }\end{array}$ \\
\hline schwannoma & $2 n+/-$ & $+7,-15,17,-22$ & $\begin{array}{l}-\mathbf{2 2} \text { (most com- } \\
\text { mon in sporadic) }\end{array}$ & $\begin{array}{l}9 \mathrm{q} 34,10,11,13,16 \\
\quad 19,20\end{array}$ & none to date & NF2-associated \& sporadic cases \\
\hline neurofibroma & $2 n$ & $\begin{array}{l}\text { no specific changes; } \\
\text { markers, trans- } \\
\text { locations, additions, } \\
\& \text { deletions }\end{array}$ & $\begin{array}{l}9,14 \mathrm{q} 31-14 \mathrm{qter}, \\
\text { 16, 17p, 17q, } 19, \\
\text { 20, 21, 22; NF1- } \\
\text { associated: } \\
\text { 17p11.2-p13, } \\
\text { 17q24-25, } \\
\text { 19p13.2, } \\
\text { 19q13.2-qter, } \\
\text { 22q }\end{array}$ & $\begin{array}{l}\text { 1p31-1p11, 1q, 2q21- } \\
\text { 2q34, 3, 4, } \\
\text { 5p15-5qter, 5q14- } \\
5 \mathrm{q} 21,6 \mathrm{q} 11-6 \mathrm{q} 25 \\
\text { 8p, 8q11-8q23, } \\
12 \mathrm{q} 11-12 \mathrm{q} 21,13 \\
13 \mathrm{q} 21-\mathrm{q} 32,18\end{array}$ & none to date & NF1-associated \& sporadic cases \\
\hline $\begin{array}{l}\text { malignant } \\
\text { PNSTs }\end{array}$ & $\begin{array}{c}4 n+1- \\
3 n+1-\end{array}$ & $\begin{array}{l}\text { whole chromosomal } \\
\text { gains \& losses af- } \\
\text { fecting all chromo- } \\
\text { somes; complex } \\
\text { structural changes; } \\
\text { breakpoints affected: } \\
\text { 1p13, 1p31-36, 1q21, } \\
\text { 4q28-35, 7p22, 9p11, } \\
\text { 11q22-23, 17p1, } \\
\text { 17q11, 19q13, 20q13, } \\
\text { 22q11-13; NF1- } \\
\text { associated: 1p21-22, } \\
\text { 1p32-34, 17q10-12 }\end{array}$ & $\begin{array}{l}1 \mathrm{p}, 17 \mathrm{p} \\
: \\
1, \\
3,\end{array}$ & $\begin{array}{l}1 \mathrm{q}, 2,2 \mathrm{p} 16-2 \mathrm{p} 23,3 \\
45 \mathrm{p}, 5 \mathrm{q}, 6 \mathrm{p}, 6 \mathrm{q} \\
7 \mathrm{p}, 7 \mathrm{q}, 8 \mathrm{p}, 8 \mathrm{q} \\
12 \mathrm{p}, 12 \mathrm{q}, 16 \mathrm{p}, 17 \mathrm{q} \\
18 \mathrm{q}, 20 \mathrm{q}, 21\end{array}$ & $\begin{array}{l}5 \mathrm{p}, 7 \mathrm{p}, 8 \mathrm{q} \\
8 \mathrm{q} 21-8 \mathrm{qter}, 12 \mathrm{q} 21 \\
17 \mathrm{q} 24\end{array}$ & $\begin{array}{l}\text { NF1-associated \& sporadic cases; } \\
\text { EGFR amp positive in some cases } \\
\text { on FISH analysis; NF1 deleted in } \\
\text { NF1-associated \& sporadic cases } \\
\text { on FISH analysis; p16 also deleted } \\
\text { on FISH analysis in some cases }\end{array}$ \\
\hline
\end{tabular}

* Bold type designates the characteristic changes in the tumor group. Abbreviations: amp = amplification; ExCh = extrachromosomal; GNI = gene not identified; SMS = Smith-Magenis syndrome; TSC = tuberous sclerosis complex.

tional molecular hybridization methodology can be oriented with respect to chromosomal landmarks and established genetic markers for each chromosomal region. We have used free chromatin to study the complex structures of amplified genes within the amplicons in homogeneously staining regions and double minute chromosomes in neuroblastoma (Fig. 7). ${ }^{186}$ No regular reiterated amplicon repeat unit was present in the homogeneously staining regions, but detailed analysis of the configurations of the amplified genes within each array indicated that multiple rearrangements generated a complex homogeneously staining region amplicon structure.

Similarly, analysis of a cell line bearing double minute chromosomes demonstrated that a composite amplicon structure involving deletions and/or duplications of the amplified genes is a feature of double minute chromosome formation. These data are consistent with a molecular mechanism involving many rearrangements during the evolution of gene amplification, resulting in complex amplicon structures with distinct changes in relative gene copy number and considerable variation in intragenic distances between coamplified genes. ${ }^{186}$ Studies performed by investigators in the James group at the Mayo Clinic have mapped the EGFR amplicon, indicating coamplification of genes besides EGFR. ${ }^{74,287}$ Free chromatin studies on the EGFR amplicon in GBMs would also be of interest for better understanding of the complexity and structure of this common aberration.

\section{Mouse Models and Xenograft Fidelity}

Animal models for studying brain tumors have important 


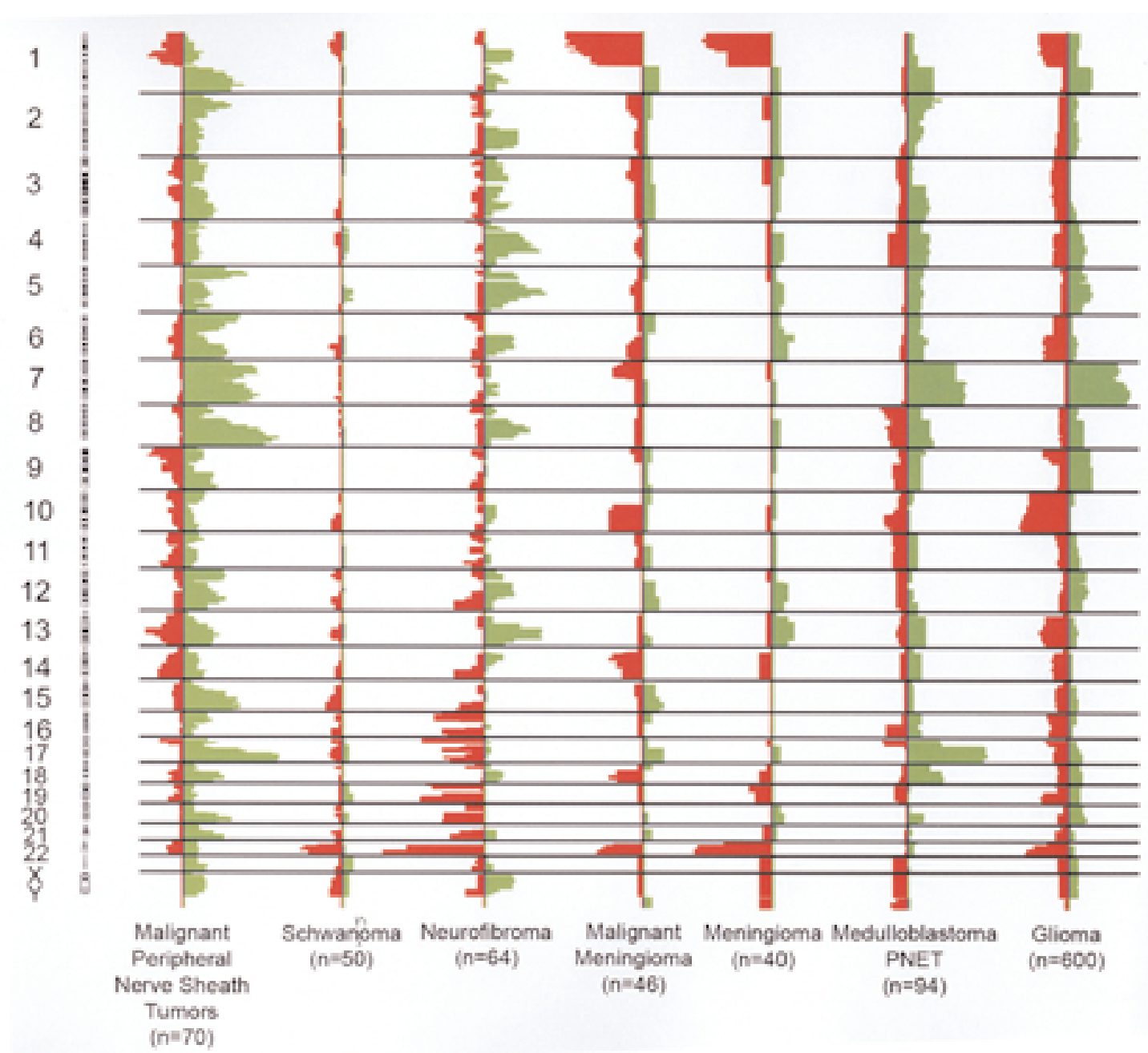

Fig. 6. Idiogram showing a summary of distribution of chromosomal changes in the major brain tumor groups. The distribution of chromosomal changes is as identified on the Progenetix website. Gains and losses of chromosomal material are denoted by green and red, respectively, for each chromosome. Note that all tumors considered to be gliomas (regardless of grade, type, adult, or pediatric) are grouped together, but possess distinct genomic changes, as described in the text and in Table 1. The same occurs for tumors grouped as medulloblastomas and PNETs.

implications for understanding tumor initiation, pathogenesis, progression, and treatment strategies. Molecular cytogenetic techniques have enabled investigators to probe the murine genome with considerable ease as a result of advancements in cloning techniques and the sequencing of the mouse genome. The most common use of cytogenetic analysis is to identify chromosomal aberrations in the mouse genome and to determine whether the chromosomal abnormalities detected in mouse tumors are comparable to those in humans.

Ding and associates ${ }^{68}$ generated a transgenic mouse astrocytoma model by using the glial fibrillary acidic protein promoter to express oncogenic V(12)Ha-ras, specifically in astrocytes. The chimeras expressing high levels of $\mathrm{V}(12)$ Ha-ras in astrocytes died of multifocal malignant astrocytomas within 2 weeks, with $95 \%$ of the mice dying of solitary or multifocal low- and high-grade astrocytomas within 2 to 6 months. The astrocytomas derived from these mice were pathologically similar to human astrocytomas. Banding, FISH, and SKY analyses revealed consistent clonal aneuploidies of chromosomal regions that were syntenic with comparable loci altered in human astrocytomas. Extra copies of mouse chromosome 10 were identified as a major clonal abnormality on SKY as well as FISH analyses. Mouse chromosome 10 harbors regions that are syntenic with a large portion of human chromosome 12q; 12q13-q14 contains $C D K 4$ and $M D M 2$, which are amplified and overexpressed in approximately $10 \%$ of human GBMs. This was reflected by the overexpression of both CDK4 and MDM2 by both mouse astrocytoma cells compared with normal mouse astrocytes.

The occurrence of a trisomy for mouse chromosome 8 and an extra copy of chromosome 3 translocated to chromosome 18 were also detected at relatively high clonal frequency, with no obvious syntenic relationship to any human astrocytoma-specific genetic alterations reported to date. A 
mouse model for oligodendroglioma described by Weiss and associates ${ }^{292}$ used the $\mathrm{S} 100$ beta promoter to generate transgenic mice expressing $v$-erb $B$, a transforming allele of $E G F R$, resulting in the development of low-grade oligodendrogliomas. Transgenic animals that were heterozygous for ink4a/arf or p53 developed high-grade tumors. The $\mathrm{CGH}$ assay was used and revealed loss of distal mouse chromosome 4 , which is syntenic to the human chromosome $1 \mathrm{p}$ region that is commonly lost in oligodendroglioma.

A mouse model for medulloblastoma described by Tong, et al., ${ }^{274}$ was identified through the disruption of poly(adenosine $5^{\prime}$-diphosphate-ribose) polymerase (termed PARP$1)$, via the construction of PARP-1/p53 double null mice. The resulting tumors were found to be typical of cerebellar medulloblastomas and possessed chromosomal aberrations including dicentric chromosomes, Robertsonian-like fusions, and triradial and quadriradial chromosomes, which are indicative of errors in DNA repair. Mouse SKY analysis has been used by our group to study a medulloblastoma derived from a $\mathrm{ptch}^{+-}$mouse (provided by MD Taylor and JT Rutka, unpublished data), showing only a change of ploidy ( $4 n$ ) and the absence of translocations (Fig. 8).

Finally, animal models have also been used to test treatment strategies. Branle and coworkers ${ }^{36}$ used CGH to monitor tumor profiles, particularly the loss of $1 \mathrm{p}$ and $19 \mathrm{q}$, during the implantation and tumor development of glioma cell lines injected into mouse and rat brains. Moreover, Brad- ford and colleagues ${ }^{35}$ used six characterized clonal cell lines derived from the VM spontaneous murine astrocytoma for drug sensitivity testing. Various drugs, including the Vinca alkaloids, nitrosoureas, adriamycin, and cis-platinum were used, and it was found that there was a relationship between chromosome number and sensitivity of a wide variety of cytotoxic drugs, including the aforementioned nitrosoureas, Vinca alkaloids, and cis-platinum as well as procarbazine and bleomycin, but not adriamycin or fluorouracil. Clones with small numbers of chromosomes were more resistant than were clones with gross polyploidy.

Xenografts have been an invaluable method for regenerating precious fresh tissue specimens and understanding tumor biology in an in vivo setting; however, a xenograft's value lies in its ability to reflect the original tumor. Many of the studies referenced in this review have resulted from cell lines or primary tissues engrafted into animals. Monitoring by FISH, SKY, or CGH techniques has shown that most engraftments maintain the integrity of the original genome. ${ }^{120}$ Notably, the available model systems, whether at the cellular, tissue, or animal level, do not accurately represent the biology of human brain tumors. This is particularly true for $E G F R$ amplification/mutation in glioblastoma.

There have been multiple attempts at developing a model to investigate the effects of $E G F R$ mutation in GBMs. These include the introduction of altered EGFR complementary DNAs into cultured brain tumor cells, developing

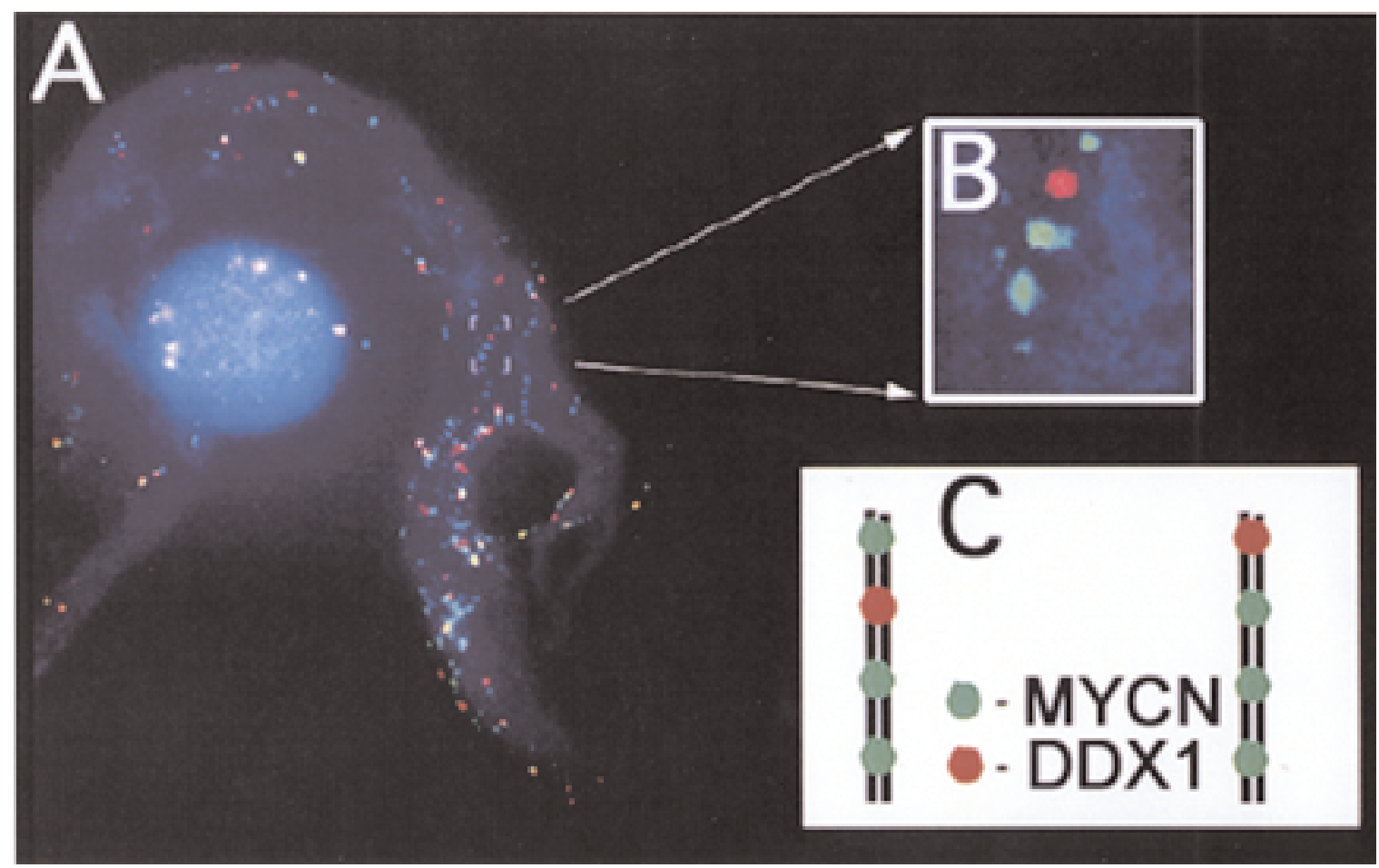

Fig. 7. Free chromatin FISH assay used to study gene structure and arrangement, illustrating the use of FISH-based free chromatin analysis for further study of the structure and arrangement of genes within an amplicon. A: A free chromatin preparation from a neuroblastoma cell line, LAN-5, illustrates double minute amplicons in extended form. The DNA of the expanded free chromatin cell surrounds a normal interphase nucleus; both are counterstained with DAPI (blue), and MYCN and DDXI are detected with anti-digoxigenin rhodamine (red/orange) and fluorescein isothiocyanate-avidin (green), respectively. B: Enlarged example of a typical double minute in which the organization of each gene within the amplicon is clearly seen. C: A schematic diagram of the double minutes showing the two different amplicon structures seen within double minutes when free chromatin arrays are used in this cell line. 


\section{J. Bayani, A. Pandita, and J. A. Squire}

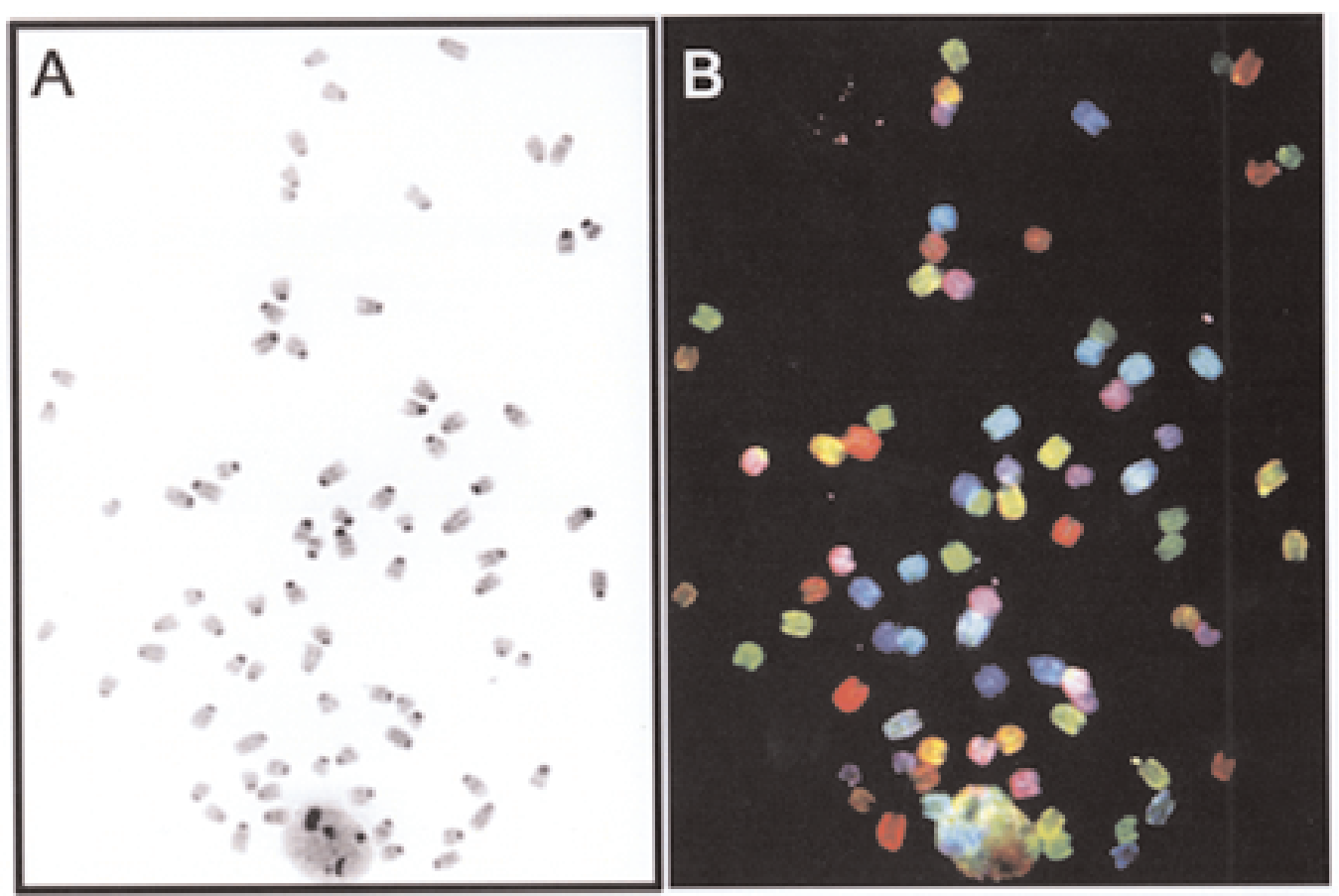

Fig. 8. Mouse SKY studies showing ploidy changes in a mouse medulloblastoma. The SKY assay using the murine paint set was hybridized to a cytogenetic preparation from a medulloblastoma that arose from a ptch $+/-$ mouse. A: Inverted DAPI staining showing the similar-looking mouse chromosomes. B: The red-green-blue image of the fluorescent staining following hybridization with the probe. Normally possessing 40 chromosomes, this tumor revealed only a change in ploidy, $4 \mathrm{n}$ rather than $2 \mathrm{n}$. No translocations were identified. (Murine specimen provided by M. D. Taylor and J. T. Rutka, images courtesy of J. Bayani and J. A. Squire.) Original magnification $\times 60$.

EGFR mutant transgenic mice, and transducing mutant EGFR in vivo by using viral constructs. The latter two approaches reflect a growing interest in the use of genetically engineered mice to study brain tumors. Nevertheless, such models also have limitations, and it seems that none of the approaches developed to date provide as accurate a representation of human GBMs with EGFR amplification/mutation as direct xenograft transplantation and propagation of material resected in patients. Alternative model systems cannot accurately represent the overexpression of EGFR that occurs in primary tumors with EGFR amplification, and it is quite likely that high-level expression is key for obtaining model biological properties that are consistent with those of human glioblastoma. Therefore, the xenograft model represents the most valid system with which to study the molecular biology associated with and to test therapeutic strategies directed against this gene alteration.

The FISH method monitors the amplification of EGFR in this model system very well (Figs. 9 and 10). Also, in the majority of the cell culture model systems developed to describe EGFR mutations, the expression and retention of the exogenous mutant $E G F R$ is imposed on tumor cells. These transfected GBM lines lose their mutant EGFR expression unless they are maintained in media containing a high concentration of selective drugs, which clearly is not the case in vivo. The models currently available have not facilitated the development of a GBM model that is readily accessible for studying the effects of high-level EGFR signaling that results from amplification of EGFR. The lack of such models has hindered a large number of neurooncolo- gy researchers in their efforts to answer straightforward questions regarding the effects and treatment of EGFR amplification in these tumors.

\section{Cancer Stem Cells}

Cancer stem cell investigations in neoplasms other than hematopoietic malignancies have increased over the past few years. In recent years, Singh and colleagues ${ }^{253,254}$ have used molecular cytogenetic analysis as a means of identifying and monitoring cancer stem cells from brain tumors. In their first investigation, identification and purification of brain tumor stem cells was performed using the neural stem cell surface marker CD133 in medulloblastomas and lowgrade gliomas. It was demonstrated that CD133 + cells had the potential for self-renewal, and they differentiated in culture into tumor cells that phenotypically resembled the original tumor obtained in the patient. Cytogenetic and SKY analyses from CD133 + tumor spheres cultured from a medulloblastoma revealed a clonal abnormal karyotype: 45 $\mathrm{XY},-10,-16,+18$. Interphase FISH analysis of another medulloblastoma specimen was performed on unsorted and sorted CD133 + and CD133 - cells. Probes for centromere 17 and the p53 locus were used in all three cell populations (unsorted, CD133+, and CD133-), and in all three FISH analyses revealed the presence of isochromosome 17q. Evaluation of these data indicated that the chromosome 17 abnormality was present in the brain tumor stem cell population, $(\mathrm{CD} 133+)$, both in the unsorted tumor cells and those negative for CD133. This supports the notion that the 

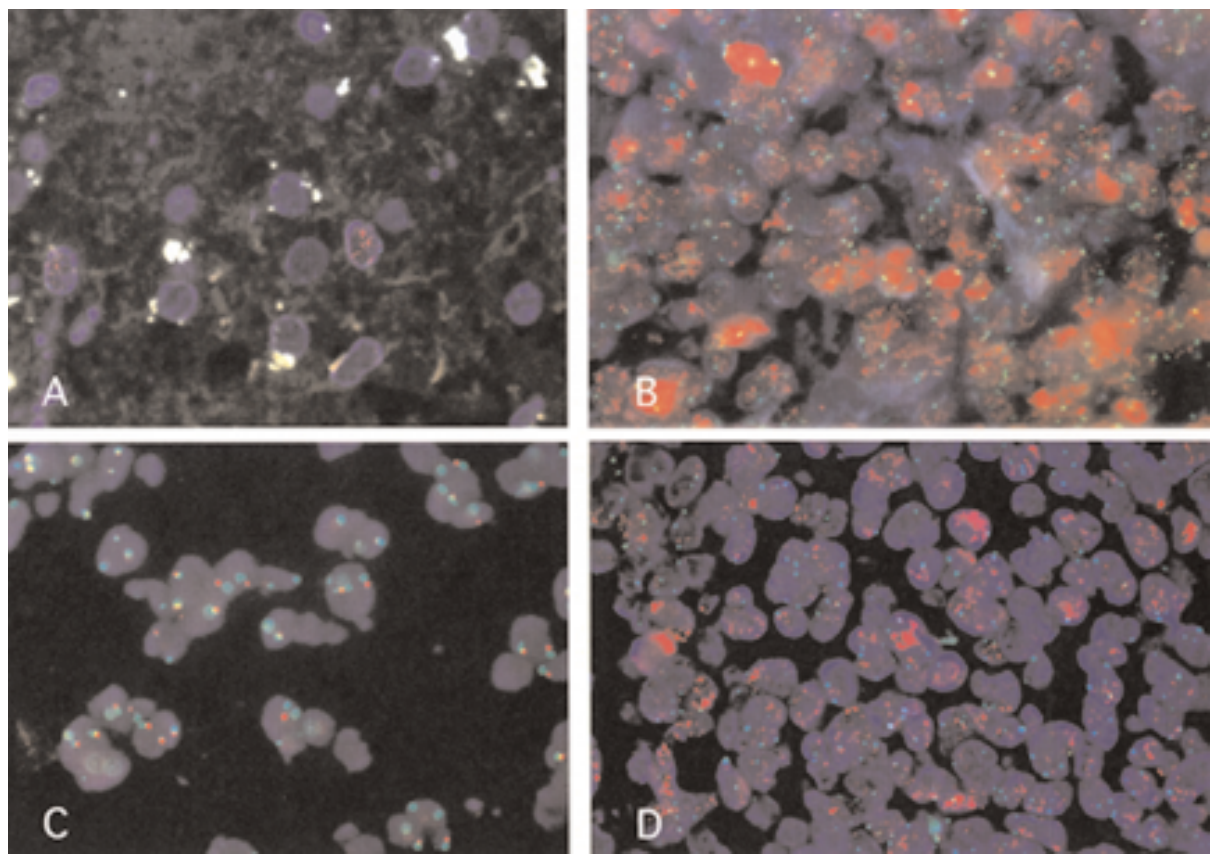

Fig. 9. Studies of GBM xenografts. Photomicrographs showing results of FISH analysis of tumor-xenograft pairs for Xenografts 1 (A and B) and 2 (C and D), revealing the selection for and occurrence of EGFR amplification during initial xenograft establishment. A: Infrequent cellular amplification of EGFR in Tumor 1 (a GBM resected in a patient). B: Ubiquitous cellular amplification in the first-generation xenograft from this tumor. C: Tumor 2 (another GBM obtained in a different patient), for which there was no evidence of amplification in the primary lesion. D: A first-generation xenograft in which the majority of cells displayed amplified EGFR. (Images courtesy of A. Pandita and C. D. James.) Original magnification $\times 60$.
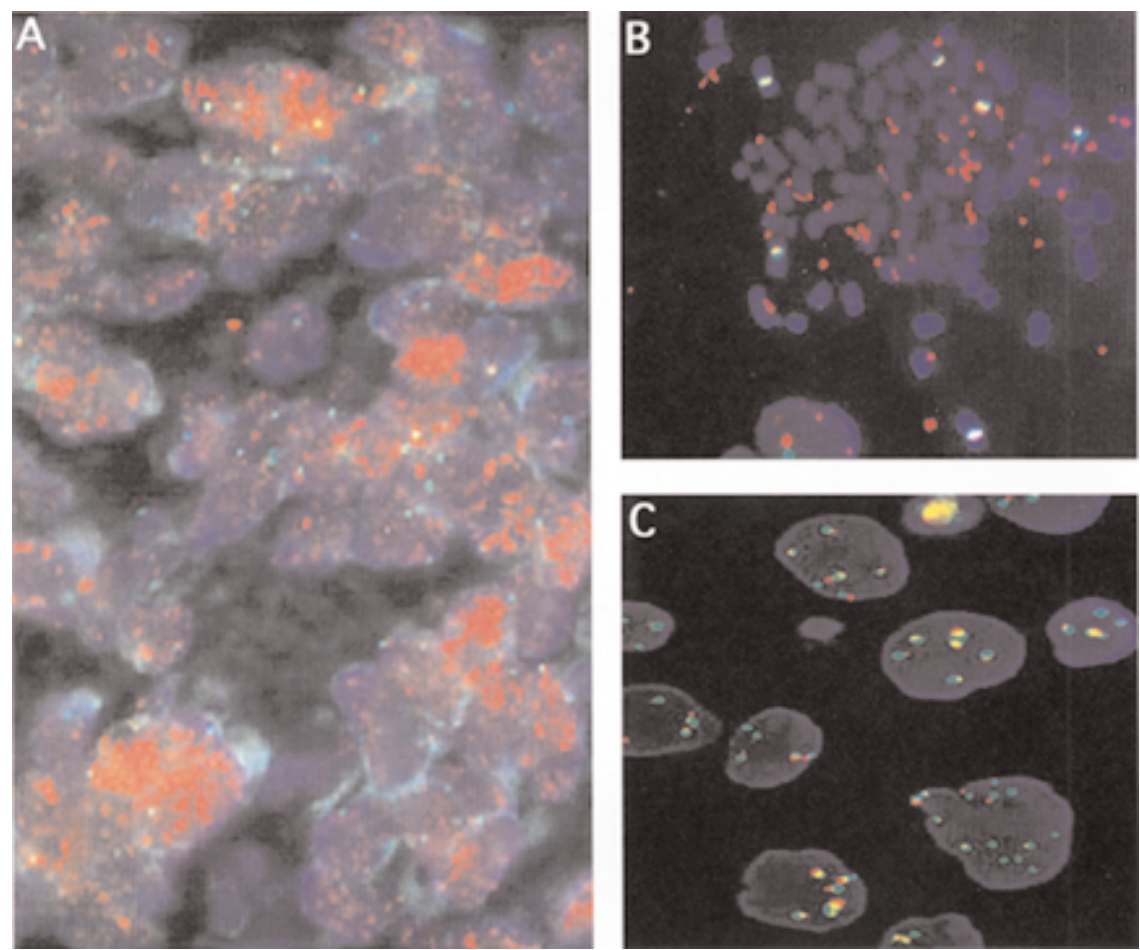

Fig. 10. Studies of EGFR amplification in GBM xenografts; photomicrographs confirm loss of amplified EGFR in cells cultured from Xenograft 1. The Xenograft 1 tumor (A) and metaphase FISH (B) results were obtained in a Xenograft 1-derived short-term culture and depicted the amplification of EGFR as extrachromosomal (double minutes). C: Latepassage cell culture ( 3 months) of Xenograft 1, demonstrating a lack of cells with amplified EGFR in addition to the abnormal ploidy for chromosome 7 that is revealed by the chromosome 7 centromeric probe. (Images courtesy of A. Pandita and C. D. James.) Original magnification $\times 60$. 
tumor-derived sphere cells do not contaminate normal neural stem cells, but instead undergo a transformation event, acquiring the enhanced self-renewal and proliferation properties observed in vitro.

In a follow-up study conducted by the same group, ${ }^{254}$ CD133+ cells were isolated from primary GBM and medulloblastoma tumors to determine the true capacity of cancer stem cells for self-renewal and exact recapitulation of the original tumor in vivo. The CD133 + cells, in some cases as few as 100 of them, were injected into the brains of NOD-SCID mice. The CD133 - cells were also injected as a parallel study. It was observed that the mice injected with CD133 + cells produced tumors identical to the original one, whereas injection of $10^{5} \mathrm{CD} 133$ - cells engrafted into the mouse, but did not produce a tumor. To ensure that the injected human cells were in fact engrafted, FISH assays for human- and mouse-specific centromere were used on paraffin-embedded sections of the xenografts for the CD133+ and CD133 - xenografts (Fig. 11).

In a subset of patients, SKY and interphase-based FISH analyses were conducted to determine the karyotypic abnormalities before engraftment. For a GBM specimen, SKY analysis revealed copy number changes for chromosome 7 , from briefly cultured CD133+ and CD133 - sorted tumor cells. Subsequent interphase FISH analysis in which centromere 7 was used indicated that nearly $80 \%$ of both CD133+ and CD133 - cells exhibited copy number changes for chromosome 7, which was consistent with SKY findings. In a medulloblastoma case, interphase-based FISH analysis in which centromere 17 and the $p 53(17 \mathrm{p} 13.1)$ gene were used on briefly cultured CD133 + and CD133 - tumor cells prior to engraftment, the findings indicated the formation of an i(17)(q10) aberration. Less than $4 \%$ of the $\mathrm{CD} 133^{+/-}$cells showed a normal signal pattern, suggesting a low rate of potential normal cell contamination.

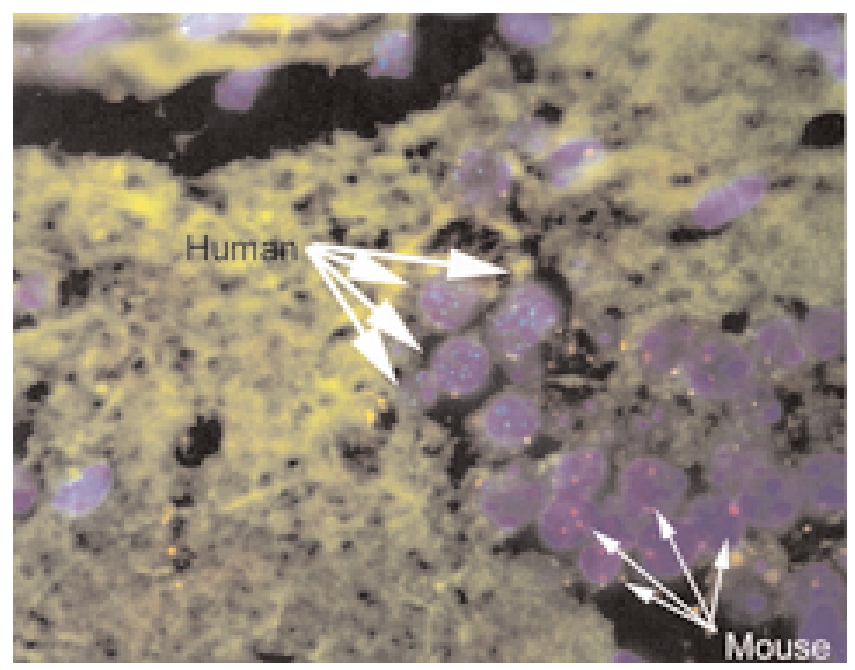

Fig. 11. Photomicrograph showing human CD133+ GBM cells injected into the mouse brain. Sections of paraffin-embedded brain obtained in a mouse injected with human CD133+ GBM cells were hybridized using both human (green) and mouse (red) pancentromeric probes. A FISH assay confirmed that human cells were successfully engrafted into the mouse brain. Original magnification $\times 60$.
The FISH studies performed on paraffin-embedded CD133 + and CD133 - xenografts obtained in an adult GBM also indicated that the majority of cells bore evidence of transformation, with amplification of the EGFR gene identical to that in the patient's tumor (Fig. 12). These cytogenetic data indicate that the transplanted cells, whether CD133 + or CD133-, have an abnormal karyotype and aneusomy pattern inconsistent with significant contamination by normal cells. Moreover, the CD133 - and CD133+ cells have the same cytogenetic alterations, suggesting that they are clonally derived.

In a similar study by Galli and colleagues ${ }^{86} \mathrm{GBM}$-derived neural stem cells, the glioblastoma U87 cell line, and human fetal neural stem cells were either subcutaneously or orthotopically injected into SCID/bg mice. Standard chromosome analysis was used to identify chromosomal changes in the engraftments, which were present in the tumor lines and U87 cell lines; however, no cytogenetic changes were identified in the human fetal neural stem cell engraftments. The apparent predominant chromosomal changes of monosomy 1 , trisomy 7 and 22, and disomy $\mathrm{X}$ in three of the tumor neural stem cell lines showing the highest expansion potential suggests that these aberrations may confer a proliferative advantage to tumor neural stem cells.

\section{Tissue Microarrays}

The TMAs provide a rapid means of assaying tissue sec-
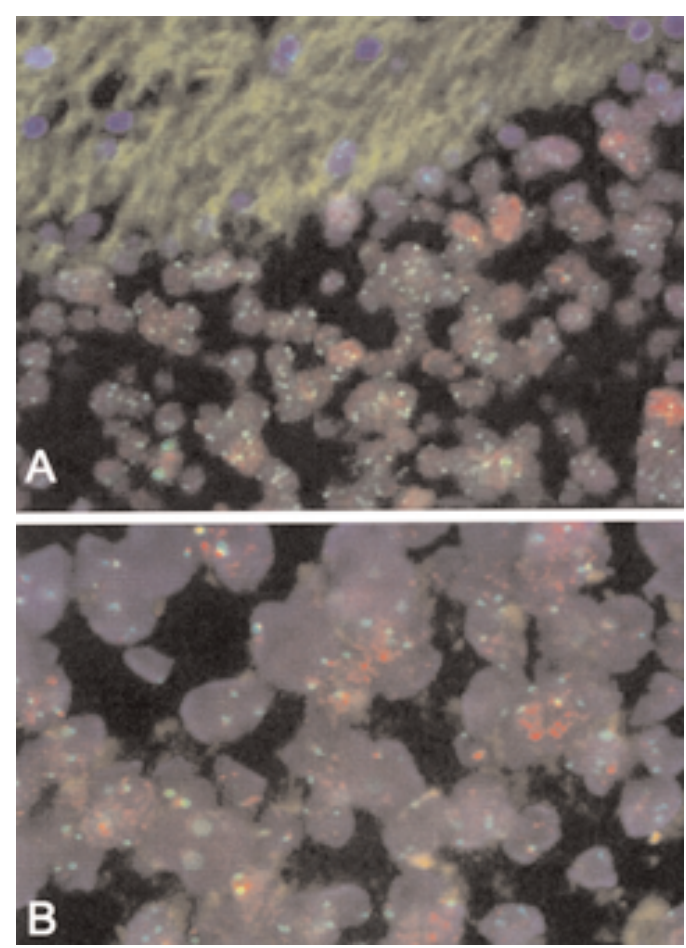

Fig. 12. Paraffin-embedded brain sections in which FISH analysis verified EGFR amplification. A FISH analysis conducted using centromere 7 (green) and EGFR-specific (red) probes confirms the successful engraftment of human CD133+ GBM cells into the mouse brain, showing EGFR amplification (A) and the same pattern of amplification in the original tumor before sorting and injection (B). Original magnification $\times 60$. 
tions. ${ }^{85}$ Ranging from a handful to several hundred tissue cores (Fig. 13), TMAs and associated analytical software have been useful for uniform histological, immunological, and FISH-based analyses. Few studies exist in which TMAs and molecular cytogenetic techniques were used for the investigation of brain tumors. Fuller, et al., ${ }^{85}$ investigated the utility of high-throughput molecular analysis with FISH for the assessment of glioma TMAs. In their study, 65 WHO Grades III and IV astrocytomas were sampled in duplicate with 0.6-mm-diameter punch cores onto a master microarray block. A FISH assay was used to detect common alterations including EGFR amplification; aneusomies of chromosomes 7, 9, and 10; and deletions of 1p, 19q, PTEN, DMBT1, and p16. Of 585 hybridization sets, $508(87 \%)$ yielded interpretable data, with hybridization failure in $33(5.5 \%)$ and dislodged tissue in 44 sets $(7.5 \%)$.

Interpretation of the TMA findings showed that glioblastomas harbored significantly more alterations than anaplastic astrocytomas, and these findings were consistent with the overall frequency of alterations reported using other

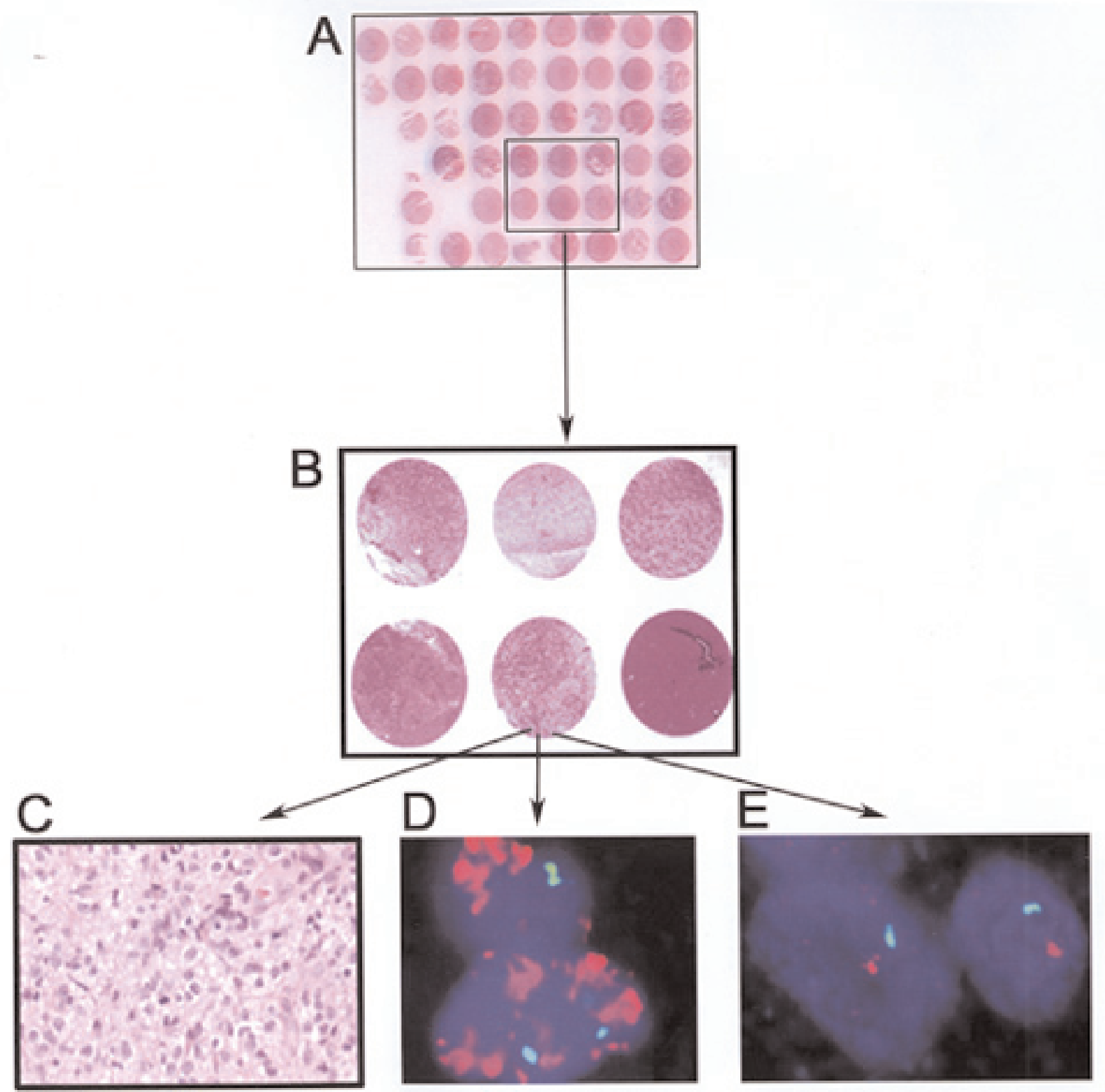

Fig. 13. Photomicrographs obtained for FISH analysis on TMAs. This figure illustrates the use of TMAs to screen for various genetic alterations. Using this method, many tumors can be screened for DNA content (FISH) and protein expression (immunohistochemical analysis) in a single experiment. In this figure, A and B show a microarray for GBM, and the tumor pathology is shown in C. A FISH analysis for EGFR amplification is shown in D and PTEN loss is depicted in E. The EGFR (red) probe in D has multiple copies per cell and is amplified; the chromosome 7 is diploid (green). In the same tumor, as seen in E, there is only one copy of PTEN (red) and chromosome 10 (green). (Images courtesy of A. Pandita and C. D. James.) Original magnification $\times 10(\mathrm{~A}), \times 40(\mathrm{C})$, and $\times 60(\mathrm{~B}, \mathrm{D}$, and E). 
techniques, making FISH studies performed on TMAs a reliable method of analysis. Brat and coworkers ${ }^{38}$ investigated whether genetic losses from chromosomes $1 \mathrm{p}, 19 \mathrm{q}$, $9 \mathrm{p}$, or $10 \mathrm{q}$ were associated with survival in 89 high-grade astrocytomas; these investigators used TMAs. Cases included 15 anaplastic astrocytomas and 74 GBMs selected based on survival times significantly shorter or longer than the expected median. The FISH data for eight DNA probes, including those for 1p32,19q13.4, 9p21 (p16/CDKN2A), and $10 \mathrm{q}$ (PTEN and DMBT1) were used. These results were correlated with patient survival and analyzed using the Fisher exact test of association. Using TMAs to assay for these chromosomal loci proved to be an efficient and rapid means of determining the genetic makeup of these tumors, and the findings were consistent with previous findings determined using traditional methods.

\section{Telomere Length}

Telomeres are unique structures located at the terminal ends of chromosomes that function as a cap protecting the ends of the DNA double helix from being exposed and identified as DNA breaks. At each cell division, a portion of the telomere sequence is lost, with continued telomere shortening resulting in cellular senescence. Telomerase activity is normally found only in stem cells and not in most normal somatic cells; however, telomerase becomes activated and highly expressed in many cancers. In recent years, FISH probes for the telomere sequence have been made available based on the development of FISH-based technologies to quantify telomere length on metaphase or interphase cells. ${ }^{143}$ In various neoplasms, it has been shown that telomere length in neoplastic cells is different from its normal counterpart, and this phenomenon has been associated with genomic instability. ${ }^{285}$

There are few FISH-based telomere studies for brain tumors. Using telomere-specific probes, Miracco and colleagues ${ }^{170}$ examined the interphase nuclei of 31 GBM specimens in which preexisting astrocytomas were not identified. Other aspects include telomerase activity, p53 mutations, and expressions of genes (p53, EGFR, MYCC, $M I G-1$, and Topoisomerase II $\alpha$ ). Although no correlative difference was found between the fluorescence and gene expression, cases positive for telomerase activity did show lower telomere signals per nuclear area.

Carroll and associates ${ }^{46}$ investigated whether there was a relationship between absence of telomerase activity and presence of dicentric chromosomes in meningiomas, and these authors determined the expression of telomerase activity in gliomas. Among the gliomas were 25 GBMs, with $28 \%$ exhibiting telomerase activity. The 25 meningiomas tested demonstrated no telomerase activity, leading the authors to support the hypothesis that meningiomas are benign; transformed, but precrisis. The findings among the GBMs suggest an alternate mechanism for telomere maintenance, such that the therapeutic benefits of telomerase inhibitors may not apply to this tumor group.

Finally, Tabori, et al., (personal communication) examined 56 pediatric low-grade gliomas for telomerase activity and alternative lengthening of telomeres. Telomere FISH was applied to tumors resected in eight patients whose indolent pediatric low-grade gliomas underwent two metachronous biopsy procedures over a period of several years.
Telomere shortening was observed in the second biopsy sample in all eight tumors but not in a control sample of normal brain ( $p<0.0001)$, suggesting that a lack of telomere maintenance was associated with continuous telomere erosion, supporting the role of cell senescence in carcinogenesis, and providing a plausible mechanism for the tendency of pediatric low-grade gliomas to exhibit growth arrest and spontaneous regression (Fig. 14).

\section{Radiosensitivity Studies}

Radiosensitivity studies have been used in the past to determine the genome's response to forms of radiation associated with therapeutic treatment as well as occupational hazards, industrial accidents, and warfare. Characteristic chromosomal features associated with exposure to carcinogens include translocations, chromatid breaks, and radial formations, which can be assayed by classic cytogenetic techniques (Fig. 15) as well as FISH studies. The risk factors to brain tumors are still largely unknown, and therefore investigations into individual sensitivity to environmental carcinogens have been conducted.

Bondy and associates ${ }^{33}$ conducted a pilot study, which indicated that genetically determined sensitivity to environmental carcinogens may play a role in the pathogenesis of brain tumors. Short-term lymphocyte cultures obtained in 45 adults with malignant gliomas and 117 age-, sex-, and ethnicity-matched healthy control volunteers were studied for mutagen-induced chromatid breaks. These findings were correlated to family history of cancer, smoking, and demographic variables and revealed an association between
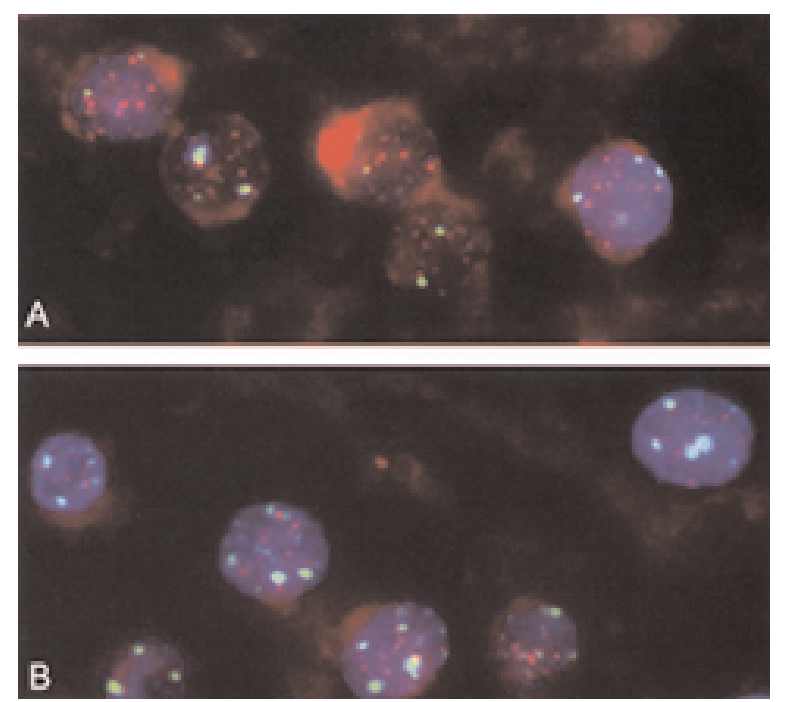

Fig. 14. Photomicrographs showing FISH results in paraffinembedded brain sections by using centromere (green) and telomere (red) probes for a glioma specimen in a quantitative FISH assay to determine telomere length. A: A quantitative FISH assay performed in a specimen obtained in the patient at the first surgery. B: A quantitative FISH assay performed in a recurrent tumor obtained in the same patient at the second surgery 4 years later. Signal intensity analysis revealed an overall decrease in signal in the second specimen, which was easily identified on visual inspection. (Images courtesy of Tabori, et al. [personal communication].) Original magnification $\times 60$. 
mutagen sensitivity and risk of brain tumors. After gamma radiation exposure, the mean number of induced breaks per cell was $0.72 \pm 0.45$ (mean \pm SD) for the patients and 0.45 \pm 0.35 (mean $\pm \mathrm{SD}$ ) for the controls $(\mathrm{p}<0.0001)$. Using the median number of induced breaks per cell in the controls as the breakpoint for defining mutagen sensitivity, an unadjusted odds ratio of 5.36 (95\% CI 2.12-13.69) for mutagen sensitivity and brain tumor risk and an adjusted odds ratio of 5.79 (95\% CI 2.26-14.83) was observed when controlled for epidemiological risk factors, including smoking status, race, income, and education.

In a larger follow-up study conducted by the same group ${ }^{34}$ gamma radiation sensitivity was once again assayed in the lymphocytes of glioma (219 samples) and control specimens (238 samples). There was a statistically significant higher frequency of chromatid breaks per cell from glioma patients (mean 0.55 ; 95\% CI $0.50-0.59$ ) than from control volunteers (mean 0.44; 95\% CI 0.41-0.48) (p < 0.001 ); and that mutagen sensitivity was associated with a statistically significant increased risk for glioma (odds ratio 2.09; 95\% CI 1.43-3.06). These findings are similar to those in a previous study by Sigurdson and colleagues ${ }^{252}$ in which the lymphocytes obtained in 76 patients with malignant gliomas were exposed to gamma radiation. Kaplan-Meier and Cox proportional hazards modeling revealed that gamma-ray mutagen-sensitive patients had worse survival rates than the nonsensitive patients, and after adjustment for age, tumor histological features, and extent of resection, gamma-ray mutagen sensitivity was found to be a prognostic indicator of survival in patients with glioma.

\section{References}

1. Agamanolis DP, Malone JM: Chromosomal abnormalities in 47 pediatric brain tumors. Cancer Genet Cytogenet 81:125-134, 1995

2. Al Saadi A, Latimer F, Madercic M, et al: Cytogenetic studies of human brain tumors and their clinical significance. II. Meningioma. Cancer Genet Cytogenet 26:127-141, 1987

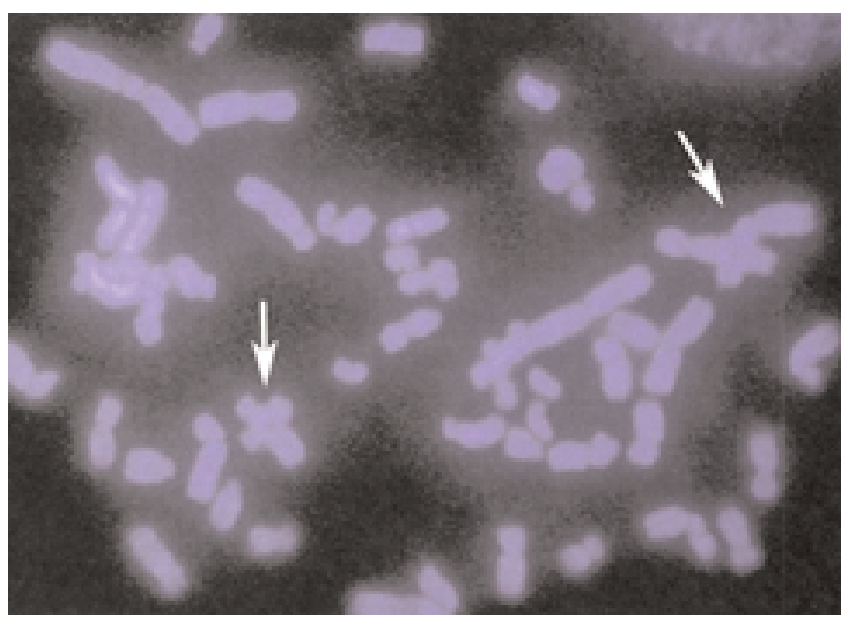

Fig. 15. Photomicrograph showing DAPI-stained human lymphocytes after exposure to gamma radiation. Complex structural changes including translocations and radial formation (arrows) and their frequencies are indicators of radiosensitivity. (Image courtesy of the Squire Lab.) Original magnification $\times 60$.
3. Albertson DG, Pinkel D: Genomic microarrays in human genetic disease and cancer. Hum Mol Genet 12 (Spec 2):R145-R152, 2003

4. Aldosari N, Bigner SH, Burger PC, et al: MYCC and MYCN oncogene amplification in medulloblastoma. A fluorescence in situ hybridization study on paraffin sections from the Children's Oncology Group. Arch Pathol Lab Med 126:540-544, 2002

5. Aldosari N, Wiltshire RN, Dutra A, et al: Comprehensive molecular cytogenetic investigation of chromosomal abnormalities in human medulloblastoma cell lines and xenograft. Neuro-oncol 4:75-85, 2002

6. Ammerlaan AC, de Bustos C, Ararou A, et al: Localization of a putative low-penetrance ependymoma susceptibility locus to 22q11 using a chromosome 22 tiling-path genomic microarray. Genes Chromosomes Cancer 43:329-338, 2005

7. Antinheimo J, Sallinen SL, Sallinen P, et al: Genetic aberrations in sporadic and neurofibromatosis 2 (NF2)-associated schwannomas studied by comparative genomic hybridization (CGH). Acta Neurochir 142:1099-1105, 2000

8. Arslantas A, Artan S, Oner U, et al: Comparative genomic hybridization analysis of genomic alterations in benign, atypical and anaplastic meningiomas. Acta Neurol Belg 102:53-62, 2002

9. Badiali M, Pession A, Basso G, et al: N-myc and c-myc oncogenes amplification in medulloblastomas. Evidence of particularly aggressive behavior of a tumor with c-myc amplification. Tumori 77:118-121, 1991

10. Bannykh SI, Perry A, Powell HC, et al: Malignant rhabdoid meningioma arising in the setting of preexisting ganglioglioma: a diagnosis supported by fluorescence in situ hybridization. Case report. J Neurosurg 97:1450-1455, 2002

11. Batra SK, McLendon RE, Koo JS, et al: Prognostic implications of chromosome 17 p deletions in human medulloblastomas. J Neurooncol 24:39-45, 1995

12. Bayani J, Squire JA: Advances in the detection of chromosomal aberrations using spectral karyotyping. Clin Genet 59:65-73, 2001

13. Bayani J, Zielenska M, Marrano P, et al: Molecular cytogenetic analysis of medulloblastomas and supratentorial primitive neuroectodermal tumors by using conventional banding, comparative genomic hybridization, and spectral karyotyping. J Neurosurg 93:437-448, 2000

14. Bayani JM, Squire JA: Applications of SKY in cancer cytogenetics. Cancer Invest 20:373-386, 2002

15. Bello MJ, de Campos JM, Kusak ME, et al: Chromosomal abnormalities in pituitary adenomas. Cancer Genet Cytogenet 124: 76-79, 2001

16. Bello MJ, de Campos JM, Kusak ME, et al: Clonal chromosome aberrations in neurinomas. Genes Chromosomes Cancer 6: 206-211, 1993

17. Bello MJ, de Campos JM, Vaquero J, et al: Chromosome 22 heterozygosity is retained in most hyperdiploid and pseudodiploid meningiomas. Cancer Genet Cytogenet 66:117-119, 1993

18. Bello MJ, Rey JA, de Campos JM, et al: Chromosomal abnormalities in a pineocytoma. Cancer Genet Cytogenet 71:185-186, 1993

19. Berra B, Papi L, Bigozzi U, et al: Correlation between cytogenetic data and ganglioside pattern in human meningiomas. Int J Cancer 47:329-333, 1991

20. Bettio D, Rizzi N, Giardino D, et al: Cytogenetic study of pituitary adenomas. Cancer Genet Cytogenet 98:131-136, 1997

21. Betts DR, Leibundgut KE, Niggli FK: Cytogenetic analysis in a case of intraocular medulloepithelioma. Cancer Genet Cytogenet 92:144-146, 1996

22. Bhattacharjee MB, Armstrong DD, Vogel H, et al: Cytogenetic analysis of 120 primary pediatric brain tumors and literature review. Cancer Genet Cytogenet 97:39-53, 1997

23. Biegel JA, Rorke LB, Janss AJ, et al: Isochromosome 17q demonstrated by interphase fluorescence in situ hybridization in primitive neuroectodermal tumors of the central nervous system. Genes Chromosomes Cancer 14:85-96, 1995 
24. Biegel JA, Rorke LB, Packer RJ, et al: Isochromosome 17q in primitive neuroectodermal tumors of the central nervous system. Genes Chromosomes Cancer 1:139-147, 1989

25. Bigner SH, Bjerkvig R, Laerum OD: DNA content and chromosomal composition of malignant human gliomas. Neurol Clin 3:769-784, 1985

26. Bigner SH, Mark J, Bullard DE, et al: Chromosomal evolution in malignant human gliomas starts with specific and usually numerical deviations. Cancer Genet Cytogenet 22:121-135, 1986

27. Bigner SH, Mark J, Burger PC, et al: Specific chromosomal abnormalities in malignant human gliomas. Cancer Res 48: 405-411, 1988

28. Bigner SH, Mark J, Friedman HS, et al: Structural chromosomal abnormalities in human medulloblastoma. Cancer Genet Cytogenet 30:91-101, 1988

29. Bigner SH, Mark J, Mahaley MS, et al: Patterns of the early, gross chromosomal changes in malignant human gliomas. Hereditas 101:103-113, 1984

30. Bigner SH, McLendon RE, Fuchs H, et al: Chromosomal characteristics of childhood brain tumors. Cancer Genet Cytogenet 97:125-134, 1997

31. Bigner SH, Schrock E: Molecular cytogenetics of brain tumors. J Neuropathol Exp Neurol 56:1173-1181, 1997

32. Bockmuhl U, You X, Pacyna-Gengelbach M, et al: CGH pattern of esthesioneuroblastoma and their metastases. Brain Pathol 14: 158-163, 2004

33. Bondy ML, Kyritsis AP, Gu J, et al: Mutagen sensitivity and risk of gliomas: a case-control analysis. Cancer Res 56:1484-1486, 1996

34. Bondy ML, Wang LE, El-Zein R, et al: Gamma-radiation sensitivity and risk of glioma. J Natl Cancer Inst 93:1553-1557, 2001

35. Bradford R, Koppel H, Pilkington GJ, et al: Heterogeneity of chemosensitivity in six clonal cell lines derived from a spontaneous murine astrocytoma and its relationship to genotypic and phenotypic characteristics. J Neurooncol 34:247-261, 1997

36. Branle F, Lefranc F, Camby I, et al: Evaluation of the efficiency of chemotherapy in in vivo orthotopic models of human glioma cells with and without $1 \mathrm{p} 19 \mathrm{q}$ deletions and in C6 rat orthotopic allografts serving for the evaluation of surgery combined with chemotherapy. Cancer 95:641-655, 2002

37. Brat DJ, Hirose Y, Cohen KJ, et al: Astroblastoma: clinicopathologic features and chromosomal abnormalities defined by comparative genomic hybridization. Brain Pathol 10:342-352, 2000

38. Brat DJ, Seiferheld WF, Perry A, et al: Analysis of 1p, 19q, 9p, and $10 \mathrm{q}$ as prognostic markers for high-grade astrocytomas using fluorescence in situ hybridization on tissue microarrays from Radiation Therapy Oncology Group trials. Neuro-oncol 6:96-103, 2004

39. Bridge RS Jr, Bridge JA, Neff JR, et al: Recurrent chromosomal imbalances and structurally abnormal breakpoints within complex karyotypes of malignant peripheral nerve sheath tumour and malignant triton tumour: a cytogenetic and molecular cytogenetic study. J Clin Pathol 57:1172-1178, 2004

40. Brown HG, Kepner JL, Perlman EJ, et al: "Large cell/anaplastic" medulloblastomas: a Pediatric Oncology Group Study. J Neuropathol Exp Neurol 59:857-865, 2000

41. Bruder CE, Hirvela C, Tapia-Paez I, et al: High resolution deletion analysis of constitutional DNA from neurofibromatosis type 2 (NF2) patients using microarray-CGH. Hum Mol Genet 10:271-282, 2001

42. Buckley PG, Jarbo C, Menzel U, et al: Comprehensive DNA copy number profiling of meningioma using a chromosome 1 tiling path microarray identifies novel candidate tumor suppressor loci. Cancer Res 65:2653-2661, 2005

43. Burnett ME, White EC, Sih S, et al: Chromosome arm 17p deletion analysis reveals molecular genetic heterogeneity in supratentorial and infratentorial primitive neuroectodermal tumors of
J. Bayani, A. Pandita, and J. A. Squire

the central nervous system. Cancer Genet Cytogenet 97:25-31, 1997

44. Capra E, Scappaticci S, Spina MP: Chromosomal abnormalities in tumor and lymphocyte cultures from patients with pituitary adenomas. Cancer Genet Cytogenet 84:89, 1995

45. Carlson KM, Bruder C, Nordenskjold M, et al: $1 \mathrm{p}$ and $3 \mathrm{p}$ deletions in meningiomas without detectable aberrations of chromosome 22 identified by comparative genomic hybridization. Genes Chromosomes Cancer 20:419-424, 1997

46. Carroll T, Maltby E, Brock I, et al: Meningiomas, dicentric chromosomes, gliomas, and telomerase activity. J Pathol 188: 395-399, 1999

47. Casalone R, Simi P, Granata P, et al: Correlation between cytogenetic and histopathological findings in 65 human meningiomas. Cancer Genet Cytogenet 45:237-243, 1990

48. Cerda-Nicolas M, Lopez-Gines C, Perez-Bacete M, et al: Histopathological and cytogenetic findings in benign, atypical and anaplastic human meningiomas: a study of 60 tumors. Clin Neuropathol 19:259-267, 2000

49. Cerda-Nicolas M, Lopez-Gines C, Peydro-Olaya A, et al: Central neurocytoma: a cytogenetic case study. Cancer Genet Cytogenet 65:173-174, 1993

50. Chadduck WM, Boop FA, Sawyer JR: Cytogenetic studies of pediatric brain and spinal cord tumors. Pediatr Neurosurg 17: 57-65, 1991

51. Chio CC, Lin SJ, Yang SH, et al: Cytogenetic study of twenty-two intracranial tumors. J Formos Med Assoc 90:504-508, 1991

52. Cohen N, Betts DR, Tavori U, et al: Karyotypic evolution pathways in medulloblastoma/primitive neuroectodermal tumor determined with a combination of spectral karyotyping, G-banding, and fluorescence in situ hybridization. Cancer Genet Cytogenet 149:44-52, 2004

53. Coons SW, Johnson PC, Shapiro JR: Cytogenetic and flow cytometry DNA analysis of regional heterogeneity in a low grade human glioma. Cancer Res 55:1569-1577, 1995

54. Couturier J, Delattre O, Kujas M, et al: Assessment of chromosome 22 anomalies in neurinomas by combined karyotype and RFLP analyses. Cancer Genet Cytogenet 45:55-62, 1990

55. Cowell JK, Matsui S, Wang YD, et al: Application of bacterial artificial chromosome array-based comparative genomic hybridization and spectral karyotyping to the analysis of glioblastoma multiforme. Cancer Genet Cytogenet 151:36-51, 2004

56. Crabtree JS, Scacheri PC, Ward JM, et al: Of mice and MEN1: insulinomas in a conditional mouse knockout. Mol Cell Biol 23:6075-6085, 2003

57. Dal Cin P, Van den Berghe H, Buonamici L, et al: Cytogenetic investigation in subependymoma. Cancer Genet Cytogenet 108:84, 1999

58. Dam A, Fock JM, Hayes VM, et al: Recurrent astrocytoma in a child: a report of cytogenetics and TP53 gene mutation screening. Neuro-oncol 2:184-189, 2000

59. Daniely M, Aviram A, Adams EF, et al: Comparative genomic hybridization analysis of nonfunctioning pituitary tumors. $\mathbf{J}$ Clin Endocrinol Metab 83:1801-1805, 1998

60. Dario A, Cerati M, Taborelli M, et al: Cytogenetic and ultrastructural study of a pineocytoma case report. J Neurooncol 48:131-134, 2000

61. de Stahl TD, Hartmann C, de Bustos C, et al: Chromosome 22 tiling-path array-CGH analysis identifies germ-line-and tumorspecific aberrations in patients with glioblastoma multiforme. Genes Chromosomes Cancer 44:161-169, 2005

62. Debiec-Rychter M, Alwasiak J, Liberski PP, et al: Accumulation of chromosomal changes in human glioma progression. A cytogenetic study of 50 cases. Cancer Genet Cytogenet 85:61-67, 1995

63. Debiec-Rychter M, Biernat W, Limon J, et al: Cytogenetic and proliferative potentials in meningiomas. Pol J Pathol 50: 243-248, 1999

64. Debiec-Rychter M, Biernat W, Zakrzewski K, et al: Loss of 
chromosome 22 and proliferative potential in ependymomas. Folia Neuropathol 41:191-195, 2003

65. Debiec-Rychter M, Jesionek-Kupnicka D, Zakrzewski K, et al: Cytogenetic changes in two cases of subependymal giant-cell astrocytoma. Cancer Genet Cytogenet 109:29-33, 1999

66. Di Marcotullio L, Ferretti E, De Smaele E, et al: REN(KCTD11) is a suppressor of Hedgehog signaling and is deleted in human medulloblastoma. Proc Natl Acad Sci U S A 101:10833-10838, 2004

67. Dietrich CU, Pandis N, Bjerre P, et al: Simple numerical chromosome aberrations in two pituitary adenomas. Cancer Genet Cytogenet 69:118-121, 1993

68. Ding H, Roncari L, Shannon P, et al: Astrocyte-specific expression of activated p21-ras results in malignant astrocytoma formation in a transgenic mouse model of human gliomas. Cancer Res 61:3826-3836, 2001

69. Dobin SM, Donner LR: Pigmented choroid plexus carcinoma: a cytogenetic and ultrastructural study. Cancer Genet Cytogenet 96:37-41, 1997

70. Doco-Fenzy M, Cornillet P, Scherpereel B, et al: Cytogenetic changes in 67 cranial and spinal meningiomas: relation to histopathological and clinical pattern. Anticancer Res 13:845-850, 1993

71. Donovan MJ, Yunis EJ, DeGirolami U, et al: Chromosome aberrations in choroid plexus papillomas. Genes Chromosomes Cancer 11:267-270, 1994

72. Dyer S, Prebble E, Davison V, et al: Genomic imbalances in pediatric intracranial ependymomas define clinically relevant groups. Am J Pathol 161:2133-2141, 2002

73. Eberhart CG, Kratz JE, Schuster A, et al: Comparative genomic hybridization detects an increased number of chromosomal alterations in large cell/anaplastic medulloblastomas. Brain Pathol 12:36-44, 2002

74. Eley GD, Reiter JL, Pandita A, et al: A chromosomal region 7p11.2 transcript map: its development and application to the study of EGFR amplicons in glioblastoma. Neuro-oncol 4:86-94, 2002

75. Emory TS, Scheithauer BW, Hirose T, et al: Intraneural perineurioma. A clonal neoplasm associated with abnormalities of chromosome 22. Am J Clin Pathol 103:696-704, 1995

76. Fan X, Paetau A, Aalto Y, et al: Gain of chromosome 3 and loss of $13 \mathrm{q}$ are frequent alterations in pituitary adenomas. Cancer Genet Cytogenet 128:97-103, 2001

77. Fan X, Wang Y, Kratz J, et al: hTERT gene amplification and increased mRNA expression in central nervous system embryonal tumors. Am J Pathol 162:1763-1769, 2003

78. Figarella-Branger D, Vagner-Capodano AM, Bouillot P, et al: Platelet-derived growth factor (PDGF) and receptor (PDGFR) expression in human meningiomas: correlations with clinicopathological features and cytogenetic analysis. Neuropathol Appl Neurobiol 20:439-447, 1994

79. Finelli P, Giardino D, Rizzi N, et al: Non-random trisomies of chromosomes 5, 8 and 12 in the prolactinoma sub-type of pituitary adenomas: conventional cytogenetics and interphase FISH study. Int J Cancer 86:344-350, 2000

80. Fletcher JA, Kozakewich HP, Hoffer FA, et al: Diagnostic relevance of clonal cytogenetic aberrations in malignant soft-tissue tumors. N Engl J Med 324:436-442, 1991

81. Fouladi M, Helton K, Dalton J, et al: Clear cell ependymoma: a clinicopathologic and radiographic analysis of 10 patients. Cancer 98:2232-2244, 2003

82. Fruhwald MC, O'Dorisio MS, Dai Z, et al: Aberrant hypermethylation of the major breakpoint cluster region in $17 \mathrm{p} 11.2$ in medulloblastomas but not supratentorial PNETs. Genes Chromosomes Cancer 30:38-47, 2001

83. Fujii Y, Hongo T, Hayashi Y: Chromosome analysis of brain tumors in childhood. Genes Chromosomes Cancer 11:205-215, 1994

84. Fujisawa H, Marukawa K, Hasegawa M, et al: Genetic differ- ences between neurocytoma and dysembryoplastic neuroepithelial tumor and oligodendroglial tumors. J Neurosurg 97: 1350-1355, 2002

85. Fuller CE, Wang H, Zhang W, et al: High-throughput molecular profiling of high-grade astrocytomas: the utility of fluorescence in situ hybridization on tissue microarrays (TMAFISH). J Neuropathol Exp Neurol 61:1078-1084, 2002

86. Galli R, Binda E, Orfanelli U, et al: Isolation and characterization of tumorigenic, stem-like neural precursors from human glioblastoma. Cancer Res 64:7011-7021, 2004

87. Gilhuis HJ, Anderl KL, Boerman RH, et al: Comparative genomic hybridization of medulloblastomas and clinical relevance: eleven new cases and a review of the literature. Clin Neurol Neurosurg 102:203-209, 2000

88. Gollin SM, Janecka IP: Cytogenetics of cranial base tumors. J Neurooncol 20:241-254, 1994

89. Gorski GK, McMorrow LE, Donaldson MH, et al: Multiple chromosomal abnormalities in a case of craniopharyngioma. Cancer Genet Cytogenet 60:212-213, 1992

90. Gorunova L, Dawiskiba S, Andren-Sandberg A, et al: Extensive cytogenetic heterogeneity in a benign retroperitoneal schwannoma. Cancer Genet Cytogenet 127:148-154, 2001

91. Granzow M, Popp S, Weber S, et al: Isochromosome 1q as an early genetic event in a child with intracranial ependymoma characterized by molecular cytogenetics. Cancer Genet Cytogenet 130:79-83, 2001

92. Griffin CA, Hawkins AL, Packer RJ, et al: Chromosome abnormalities in pediatric brain tumors. Cancer Res 48: 175-180, 1988

93. Griffin CA, Hruban RH, Long PP, et al: Chromosome abnormalities in meningeal neoplasms: do they correlate with histology? Cancer Genet Cytogenet 78:46-52, 1994

94. Griffin CA, Long PP, Carson BS, et al: Chromosome abnormalities in low-grade central nervous system tumors. Cancer Genet Cytogenet 60:67-73, 1992

95. Grill J, Avet-Loiseau H, Lellouch-Tubiana A, et al: Comparative genomic hybridization detects specific cytogenetic abnormalities in pediatric ependymomas and choroid plexus papillomas. Cancer Genet Cytogenet 136:121-125, 2002

96. Haddadin MH, Hawkins AL, Long P, et al: Cytogenetic study of malignant triton tumor: a case report. Cancer Genet Cytogenet 144:100-105, 2003

97. Harada K, Nishizaki T, Ozaki S, et al: Cytogenetic alterations in pituitary adenomas detected by comparative genomic hybridization. Cancer Genet Cytogenet 112:38-41, 1999

98. Harrison KJ, Neumann E, Kalousek DK, et al: Astrocytoma with a unique telomere association. Cancer Genet Cytogenet 76:33-35, 1994

99. Hecht BK, Turc-Carel C, Chatel M, et al: Chromosomes in gliomatosis cerebri. Genes Chromosomes Cancer 14:149-153, 1995

100. Heng HH, Squire J, Tsui LC: High-resolution mapping of mammalian genes by in situ hybridization to free chromatin. Proc Natl Acad Sci U S A 89:9509-9513, 1992

101. Henn W, Cremerius U, Heide G, et al: Monosomy 1p is correlated with enhanced in vivo glucose metabolism in meningiomas. Cancer Genet Cytogenet 79:144-148, 1995

102. Henn W, Niedermayer I, Ketter R, et al: Monosomy $7 \mathrm{p}$ in meningiomas: a rare constituent of tumor progression. Cancer Genet Cytogenet 144:65-68, 2003

103. Hennig Y, Loschke S, Katenkamp D, et al: A malignant triton tumor with an unbalanced translocation $(1 ; 13)(q 10 ; q 10)$ and an isochromosome (8)(q10) as the sole karyotypic abnormalities. Cancer Genet Cytogenet 118:80-82, 2000

104. Herrmann M: Standard and molecular cytogenetics of endocrine tumors. Am J Clin Pathol 119 Suppl:S17-S38, 2003

105. Hirose Y, Aldape KD, Chang S, et al: Grade II astrocytomas are subgrouped by chromosome aberrations. Cancer Genet Cytogenet 142:1-7, 2003

106. Huang B, Starostik P, Schraut H, et al: Human ependymomas 
reveal frequent deletions on chromosomes 6 and 9. Acta Neuropathol (Berl) 106:357-362, 2003

107. Hui AB, Pang JC, Ko CW, et al: Detection of chromosomal imbalances in growth hormone-secreting pituitary tumors by comparative genomic hybridization. Hum Pathol 30:1019-1023, 1999

108. Hui AB, Takano H, Lo KW, et al: Identification of a novel homozygous deletion region at $6 \mathrm{q} 23.1$ in medulloblastomas using high-resolution array comparative genomic hybridization analysis. Clin Cancer Res 11:4707-4716, 2005

109. Hungerford DA, Donnelly AJ, Nowell PC, et al: The chromosome constitution of a human phenotypic intersex. Am J Hum Genet 11:215-236, 1959

110. Ichimura K, Ohgaki H, Kleihues P, et al: Molecular pathogenesis of astrocytic tumours. J Neurooncol 70:137-160, 2004

111. Inda MM, Mercapide J, Munoz J, et al: PTEN and DMBT1 homozygous deletion and expression in medulloblastomas and supratentorial primitive neuroectodermal tumors. Oncol Rep 12:1341-1347, 2004

112. Jay V, Edwards V, Hoving E, et al: Central neurocytoma: morphological, flow cytometric, polymerase chain reaction, fluorescence in situ hybridization, and karyotypic analyses. Case report. J Neurosurg 90:348-354, 1999

113. Jay V, Edwards V, Squire J, et al: Astroblastoma: report of a case with ultrastructural, cell kinetic, and cytogenetic analysis. Pediatr Pathol 13:323-332, 1993

114. Jay V, Squire J, Bayani J, et al: Oncogene amplification in medulloblastoma: analysis of a case by comparative genomic hybridization and fluorescence in situ hybridization. Pathology 31:337-344, 1999

115. Jay V, Squire J, Becker LE, et al: Malignant transformation in a ganglioglioma with anaplastic neuronal and astrocytic components. Report of a case with flow cytometric and cytogenetic analysis. Cancer 73:2862-2868, 1994

116. Jay V, Squire J, Blaser S, et al: Intracranial and spinal metastases from a ganglioglioma with unusual cytogenetic abnormalities in a patient with complex partial seizures. Childs Nerv Syst 13:550-555, 1997

117. Jenkins RB, Kimmel DW, Moertel CA, et al: A cytogenetic study of 53 human gliomas. Cancer Genet Cytogenet 39:253-279, 1989

118. Jeuken JW, Sprenger SH, Gilhuis J, et al: Correlation between localization, age, and chromosomal imbalances in ependymal tumours as detected by CGH. J Pathol 197:238-244, 2002

119. Jeuken JW, Sprenger SH, Vermeer H, et al: Chromosomal imbalances in primary oligodendroglial tumors and their recurrences: clues about malignant progression detected using comparative genomic hybridization. J Neurosurg 96:559-564, 2002

120. Jeuken JW, Sprenger SH, Wesseling P, et al: Genetic reflection of glioblastoma biopsy material in xenografts: characterization of 11 glioblastoma xenograft lines by comparative genomic hybridization. J Neurosurg 92:652-658, 2000

121. Jeuken JW, von Deimling A, Wesseling P: Molecular pathogenesis of oligodendroglial tumors. J Neurooncol 70:161-181, 2004

122. Jhanwar SC, Chen Q, Li FP, et al: Cytogenetic analysis of soft tissue sarcomas. Recurrent chromosome abnormalities in malignant peripheral nerve sheath tumors (MPNST). Cancer Genet Cytogenet 78:138-144, 1994

123. Jin Y, Mertens F, Arheden K, et al: Karyotypic features of malignant tumors of the nasal cavity and paranasal sinuses. Int J Cancer 60:637-641, 1995

124. Joste NE, Racz MI, Montgomery KD, et al: Clonal chromosome abnormalities in a plexiform cellular schwannoma. Cancer Genet Cytogenet 150:73-77, 2004

125. Kallioniemi A, Kallioniemi OP, Sudar D, et al: Comparative genomic hybridization for molecular cytogenetic analysis of solid tumors. Science 258:818-821, 1992
J. Bayani, A. Pandita, and J. A. Squire

126. Karnes PS, Tran TN, Cui MY, et al: Cytogenetic analysis of 39 pediatric central nervous system tumors. Cancer Genet $\mathbf{C y -}$ togenet 59:12-19, 1992

127. Kitange G, Misra A, Law M, et al: Chromosomal imbalances detected by array comparative genomic hybridization in human oligodendrogliomas and mixed oligoastrocytomas. Genes Chromosomes Cancer 42:68-77, 2005

128. Koga $\mathrm{T}$, Iwasaki $\mathrm{H}$, Ishiguro $\mathrm{M}$, et al: Frequent genomic imbalances in chromosomes 17,19 , and $22 \mathrm{q}$ in peripheral nerve sheath tumours detected by comparative genomic hybridization analysis. J Pathol 197:98-107, 2002

129. Koga T, Iwasaki H, Ishiguro M, et al: Losses in chromosomes 17,19 , and $22 q$ in neurofibromatosis type 1 and sporadic neurofibromas: a comparative genomic hybridization analysis. Cancer Genet Cytogenet 136:113-120, 2002

130. Kolomietz E, Meyn MS, Pandita A, et al: The role of Alu repeat clusters as mediators of recurrent chromosomal aberrations in tumors. Genes Chromosomes Cancer 35:97-112, 2002

131. Kontogeorgos G: Molecular cytogenetics of pituitary adenomas, assessed by FISH technique. Front Horm Res 32:205-216, 2004

132. Kontogeorgos G, Kapranos N, Orphanidis G, et al: Molecular cytogenetics of chromosome 11 in pituitary adenomas: a comparison of fluorescence in situ hybridization and DNA ploidy study. Hum Pathol 30:1377-1382, 1999

133. Kordek R, Klimek A, Karpinska A, et al: The immunohistochemistry and ultrastructure of ganglioglioma with chromosomal alterations: a case report. Pol J Pathol 47:37-39, 1996

134. Koschny R, Koschny T, Froster UG, et al: Comparative genomic hybridization in glioma: a meta-analysis of 509 cases. Cancer Genet Cytogenet 135:147-159, 2002

135. Krex D, Mohr B, Appelt H, et al: Genetic analysis of a multifocal glioblastoma multiforme: a suitable tool to gain new aspects in glioma development. Neurosurgery 53:1377-1384, 2003

136. Kros JM, Delwel EJ, de Jong TH, et al: Desmoplastic infantile astrocytoma and ganglioglioma: a search for genomic characteristics. Acta Neuropathol (Berl) 104:144-148, 2002

137. Kros JM, van Run PR, Alers JC, et al: Genetic aberrations in oligodendroglial tumours: an analysis using comparative genomic hybridization (CGH). J Pathol 188:282-288, 1999

138. Kros JM, Zheng P, Dinjens WN, et al: Genetic aberrations in gliomatosis cerebri support monoclonal tumorigenesis. J Neuropathol Exp Neurol 61:806-814, 2002

139. Krupp W, Geiger K, Schober R, et al: Cytogenetic and molecular cytogenetic analyses in diffuse astrocytomas. Cancer Genet Cytogenet 153:32-38, 2004

140. Kubota H, Nishizaki T, Harada K, et al: Identification of recurrent chromosomal rearrangements and the unique relationship between low-level amplification and translocation in glioblastoma. Genes Chromosomes Cancer 31:125-133, 2001

141. Lai YS, Ramsay DA, Macdonald DR, et al: Therapy-related chromosomal changes and cytogenetic heterogeneity in human gliomas. J Neurooncol 32:7-17, 1997

142. Lamont JM, McManamy CS, Pearson AD, et al: Combined histopathological and molecular cytogenetic stratification of medulloblastoma patients. Clin Cancer Res 10:5482-5493, 2004

143. Lansdorp PM, Verwoerd NP, van de Rijke FM, et al: Heterogeneity in telomere length of human chromosomes. Hum Mol Genet 5:685-691, 1996

144. Larsen JB, Schroder HD, Sorensen AG, et al: Simple numerical chromosome aberrations characterize pituitary adenomas. Cancer Genet Cytogenet 114:144-149, 1999

145. Law ME, Templeton KL, Kitange G, et al: Molecular cytogenetic analysis of chromosomes 1 and 19 in glioma cell lines. Cancer Genet Cytogenet 160:1-14, 2005

146. Lekanne Deprez RH, Riegman PH, van Drunen E, et al: Cytogenetic, molecular genetic and pathological analyses in 126 meningiomas. J Neuropathol Exp Neurol 54:224-235, 1995 
147. Li YS, Fan YS, Armstrong RF: Endoreduplication and telomeric association in a choroid plexus carcinoma. Cancer Genet Cytogenet 87:7-10, 1996

148. Li YS, Ramsay DA, Fan YS, et al: Cytogenetic evidence that a tumor suppressor gene in the long arm of chromosome 1 contributes to glioma growth. Cancer Genet Cytogenet 84:46-50, 1995

149. Lindstrom E, Salford LG, Heim S, et al: Trisomy 7 and sex chromosome loss need not be representative of tumor parenchyma cells in malignant glioma. Genes Chromosomes Cancer 3:474-479, 1991

150. Liu L, Ichimura K, Pettersson EH, et al: Chromosome 7 rearrangements in glioblastomas; loci adjacent to EGFR are independently amplified. J Neuropathol Exp Neurol 57: 1138-1145, 1998

151. Lodding P, Kindblom LG, Angervall L, et al: Cellular schwannoma. A clinicopathologic study of 29 cases. Virchows Arch A Pathol Anat Histopathol 416:237-248, 1990

152. Lomas J, Bello MJ, Arjona D, et al: Analysis of p73 gene in meningiomas with deletion at 1p. Cancer Genet Cytogenet 129:88-91, 2001

153. Lopez-Gines C, Cerda-Nicolas M, Gil-Benso R, et al: Association of loss of $1 p$ and alterations of chromosome 14 in meningioma progression. Cancer Genet Cytogenet 148:123-128, 2004

154. Magnani I, Guerneri S, Pollo B, et al: Increasing complexity of the karyotype in 50 human gliomas. Progressive evolution and de novo occurrence of cytogenetic alterations. Cancer Genet Cytogenet 75:77-89, 1994

155. Magrini E, Pragliola A, Fantasia D, et al: Acquisition of i(8q) as an early event in malignant triton tumors. Cancer Genet Cytogenet 154:150-155, 2004

156. Mahler-Araujo MB, Sanoudou D, Tingby O, et al: Structural genomic abnormalities of chromosomes 9 and 18 in myxopapillary ependymomas. J Neuropathol Exp Neurol 62:927-935, 2003

157. Maltby EL, Ironside JW, Battersby RD: Cytogenetic studies in 50 meningiomas. Cancer Genet Cytogenet 31:199-210, 1988

158. Mantripragada KK, Buckley PG, Benetkiewicz M, et al: Highresolution profiling of an $11 \mathrm{Mb}$ segment of human chromosome 22 in sporadic schwannoma using array-CGH. Int J Oncol 22:615-622, 2003

159. Mao X, Hamoudi RA: Molecular and cytogenetic analysis of glioblastoma multiforme. Cancer Genet Cytogenet 122:87-92, 2000

160. Martinez R, Schackert HK, Kirsch M, et al: Comparative genetic analysis of metachronous anaplastic oligoastrocytomas with extended recurrence-free interval. J Neurooncol 72:95-102, 2005

161. Mazewski C, Soukup S, Ballard E, et al: Karyotype studies in 18 ependymomas with literature review of 107 cases. Cancer Genet Cytogenet 113:1-8, 1999

162. McComb EN, McComb RD, DeBoer JM, et al: Cytogenetic analysis of a malignant triton tumor and a malignant peripheral nerve sheath tumor and a review of the literature. Cancer Genet Cytogenet 91:8-12, 1996

163. Mechtersheimer G, Otano-Joos M, Ohl S, et al: Analysis of chromosomal imbalances in sporadic and NF1-associated peripheral nerve sheath tumors by comparative genomic hybridization. Genes Chromosomes Cancer 25:362-369, 1999

164. Mertens F, Dal Cin P, De Wever I, et al: Cytogenetic characterization of peripheral nerve sheath tumours: a report of the CHAMP study group. J Pathol 190:31-38, 2000

165. Mertens F, Heim S, Mandahl N, et al: Recurrent chromosomal imbalances in choroid plexus tumors. Cancer Genet Cytogenet 80:83-84, 1995

166. Mertens F, Rydholm A, Bauer HF, et al: Cytogenetic findings in malignant peripheral nerve sheath tumors. Int J Cancer 61:793-798, 1995

167. Metzger AK, Mohapatra G, Minn YA, et al: Multiple genetic aberrations including evidence of chromosome 11q13 rearrangement detected in pituitary adenomas by comparative genomic hybridization. J Neurosurg 90:306-314, 1999

168. Mezzelani A, Tornielli S, Minoletti F, et al: Esthesioneuroblastoma is not a member of the primitive peripheral neuroectodermal tumour-Ewing's group. Br J Cancer 81:586-591, 1999

169. Mierau GW, Tyson RW, McGavran L, et al: Astroblastoma: ultrastructural observations on a case of high-grade type. Ultrastruct Pathol 23:325-332, 1999

170. Miracco C, De Santi MM, Luzi P, et al: In situ detection of telomeres by fluorescence in situ hybridization and telomerase activity in glioblastoma multiforme: correlation with p53 status, EGFR, c-myc, MIB1, and Topoisomerase IIalpha protein expression. Int J Oncol 23:1529-1535, 2003

171. Misra A, Pellarin M, Nigro J, et al: Array comparative genomic hybridization identifies genetic subgroups in grade 4 human astrocytoma. Clin Cancer Res 11:2907-2918, 2005

172. Molenaar WM, Dijkhuizen T, van Echten J, et al: Cytogenetic support for early malignant change in a diffuse neurofibroma not associated with neurofibromatosis. Cancer Genet Cytogenet 97:70-72, 1997

173. Mott RT, Goodman BK, Burchette JL, et al: Loss of chromosome 13 in a case of soft tissue perineurioma. Clin Neuropathol 24:69-76, 2005

174. Nandula SV, Borczuk AC, Murty VV: Unbalanced t(2;19) and $\mathrm{t}(2 ; 16)$ in a neurofibroma. Cancer Genet Cytogenet 152: $169-171,2004$

175. Neumann E, Kalousek DK, Norman MG, et al: Cytogenetic analysis of 109 pediatric central nervous system tumors. Cancer Genet Cytogenet 71:40-49, 1993

176. Nigg EA: Centrosome aberrations: cause or consequence of cancer progression? Nat Rev Cancer 2:815-825, 2002

177. Nilsson M, Meza-Zepeda LA, Mertens F, et al: Amplification of chromosome 1 sequences in lipomatous tumors and other sarcomas. Int J Cancer 109:363-369, 2004

178. Nishizaki T, Harada K, Kubota H, et al: Genetic alterations in pediatric medulloblastomas detected by comparative genomic hybridization. Pediatr Neurosurg 31:27-32, 1999

179. Nishizaki T, Ozaki S, Harada K, et al: Investigation of genetic alterations associated with the grade of astrocytic tumor by comparative genomic hybridization. Genes Chromosomes Cancer 21:340-346, 1998

180. Nowell PC, Hungerford DA: Chromosome studies on normal and leukemic human leukocytes. J Natl Cancer Inst 25:85-109, 1960

181. Nurnberg P, Zischler H, Fuhrmann E, et al: Coamplification of simple repetitive DNA fingerprint fragments and the EGFR gene in human gliomas. Genes Chromosomes Cancer 3:79-88, 1991

182. Orr LC, Fleitz J, McGavran L, et al: Cytogenetics in pediatric low-grade astrocytomas. Med Pediatr Oncol 38:173-177, 2002

183. Pack SD, Qin LX, Pak E, et al: Common genetic changes in hereditary and sporadic pituitary adenomas detected by comparative genomic hybridization. Genes Chromosomes Cancer 43: 72-82, 2005

184. Pan E, Pellarin M, Holmes E, et al: Isochromosome $17 \mathrm{q}$ is a negative prognostic factor in poor-risk childhood medulloblastoma patients. Clin Cancer Res 11:4733-4740, 2005

185. Pandita A, Aldape KD, Zadeh G, et al: Contrasting in vivo and in vitro fates of glioblastoma cell subpopulations with amplified EGFR. Genes Chromosomes Cancer 39:29-36, 2004

186. Pandita A, Godbout R, Zielenska M, et al: Relational mapping of MYCN and DDXI in band 2p24 and analysis of amplicon arrays in double minute chromosomes and homogeneously staining regions by use of free chromatin FISH. Genes Chromosomes Cancer 20:243-252, 1997

187. Papi L, Baldassarri G, Montali E, et al: Cytogenetic studies in sporadic and multiple endocrine neoplasia type 1-associated pituitary adenomas. Genes Chromosomes Cancer 7:63-65, 1993 
188. Parente F, Grosgeorge J, Coindre JM, et al: Comparative genomic hybridization reveals novel chromosome deletions in 90 primary soft tissue tumors. Cancer Genet Cytogenet 115: 89-95, 1999

189. Park JP, Dossu JR, Rhodes CH: Telomere associations in desmoplastic infantile ganglioglioma. Cancer Genet Cytogenet 92:4-7, 1996

190. Patel A, van Meyel DJ, Mohapatra G, et al: Gliomas in families: chromosomal analysis by comparative genomic hybridization. Cancer Genet Cytogenet 100:77-83, 1998

191. Paunu N, Sallinen SL, Karhu R, et al: Chromosome imbalances in familial gliomas detected by comparative genomic hybridization. Genes Chromosomes Cancer 29:339-346, 2000

192. Perry A, Fuller CE, Banerjee R, et al: Ancillary FISH analysis for 1p and 19q status: preliminary observations in 287 gliomas and oligodendroglioma mimics. Front Biosci 8:a1-a9, 2003

193. Perry A, Giannini C, Raghavan R, et al: Aggressive phenotypic and genotypic features in pediatric and NF2-associated meningiomas: a clinicopathologic study of 53 cases. J Neuropathol Exp Neurol 60:994-1003, 2001

194. Perry A, Gutmann DH, Reifenberger G: Molecular pathogenesis of meningiomas. J Neurooncol 70:183-202, 2004

195. Perry A, Kunz SN, Fuller CE, et al: Differential NF1, p16, and EGFR patterns by interphase cytogenetics (FISH) in malignant peripheral nerve sheath tumor (MPNST) and morphologically similar spindle cell neoplasms. J Neuropathol Exp Neurol 61:702-709, 2002

196. Petersen SE, Frederiksen P, Friedrich U: Cytogenetic analysis and flow cytometric DNA measurement of a human tumor with pronounced hypodiploidy. Cancer Genet Cytogenet 4:1-9, 1981

197. Plaat BE, Molenaar WM, Mastik MF, et al: Computer-assisted cytogenetic analysis of 51 malignant peripheral-nerve-sheath tumors: sporadic vs. neurofibromatosis-type-1-associated malignant schwannomas. Int J Cancer 83:171-178, 1999

198. Povey S, Burley MW, Attwood J, et al: Two loci for tuberous sclerosis: one on 9q34 and one on 16p13. Ann Hum Genet 58:107-127, 1994

199. Prayson RA, Castilla EA, Hartke M, et al: Chromosome 1p allelic loss by fluorescence in situ hybridization is not observed in dysembryoplastic neuroepithelial tumors. Am J Clin Pathol 118:512-517, 2002

200. Prowald A, Wemmert S, Biehl C, et al: Interstitial loss and gain of sequences on chromosome 22 in meningiomas with normal karyotype. Int J Oncol 26:385-393, 2005

201. Pruchon E, Chauveinc L, Sabatier L, et al: A cytogenetic study of 19 recurrent gliomas. Cancer Genet Cytogenet 76:85-92, 1994

202. Punnett HH, de Chadarevian JP, Tomczak EZ: Consistent aneuploidies in choroid plexus papillomas. Genes Chromosomes Cancer 24:293, 1999

203. Punnett HH, Tomczak EZ, de Chadarevian JP, et al: Cytogenetic analysis of a choroid plexus papilloma. Genes Chromosomes Cancer 10:282-285, 1994

204. Raffel C: Medulloblastoma: molecular genetics and animal models. Neoplasia 6:310-322, 2004

205. Rainho CA, Rogatto SR, de Moraes LC, et al: Cytogenetic study of a pineocytoma. Cancer Genet Cytogenet 64:127-132, 1992

206. Rajcan-Separovic E, Maguire J, Loukianova T, et al: Loss of $1 \mathrm{p}$ and $7 \mathrm{p}$ in radiation-induced meningiomas identified by comparative genomic hybridization. Cancer Genet Cytogenet 144:6-11, 2003

207. Ransom DT, Ritland SR, Moertel CA, et al: Correlation of cytogenetic analysis and loss of heterozygosity studies in human diffuse astrocytomas and mixed oligo-astrocytomas. Genes Chromosomes Cancer 5:357-374, 1992

208. Rao UN, Surti U, Hoffner L, et al: Cytogenetic and histologic correlation of peripheral nerve sheath tumors of soft tissue. Cancer Genet Cytogenet 88:17-25, 1996

\section{J. Bayani, A. Pandita, and J. A. Squire}

209. Rey JA, Bello MJ, de Campos JM, et al: Chromosomal composition of a series of 22 human low-grade gliomas. Cancer Genet Cytogenet 29:223-237, 1987

210. Rey JA, Bello MJ, de Campos JM, et al: Chromosomal involvement secondary to-22 in human meningiomas. Cancer Genet Cytogenet 33:275-290, 1988

211. Rey JA, Bello MJ, de Campos JM, et al: Chromosomal patterns in human malignant astrocytomas. Cancer Genet Cytogenet 29:201-221, 1987

212. Rey JA, Bello MJ, De Campos JM, et al: Cytogenetic analysis in human neurinomas. Cancer Genet Cytogenet 28:187-188, 1987

213. Rey JA, Bello MJ, de Campos JM, et al: Cytogenetic clones in a recurrent neurofibroma. Cancer Genet Cytogenet 26: 157-163, 1987

214. Rey JA, Bello MJ, de Campos JM, et al: Cytogenetic follow-up from direct preparation to advanced in vitro passages of a human malignant glioma. Cancer Genet Cytogenet 41:175-183, 1989

215. Riazimand SH, Brieger J, Jacob R, et al: Analysis of cytogenetic aberrations in esthesioneuroblastomas by comparative genomic hybridization. Cancer Genet Cytogenet 136:53-57, 2002

216. Riccardi VM, Elder DW: Multiple cytogenetic aberrations in neurofibrosarcomas complicating neurofibromatosis. Cancer Genet Cytogenet 23:199-209, 1986

217. Rickert CH, Dockhorn-Dworniczak B, Busch G, et al: Increased chromosomal imbalances in recurrent pituitary adenomas. Acta Neuropathol 102:615-620, 2001

218. Rickert $\mathrm{CH}$, Paulus W: Genetic characterisation of granular cell tumours. Acta Neuropathol 103:309-312, 2002

219. Rickert $\mathrm{CH}$, Paulus W: Lack of chromosomal imbalances in adamantinomatous and papillary craniopharyngiomas. J Neurol Neurosurg Psychiatry 74:260-261, 2003

220. Rickert CH, Scheithauer BW, Paulus W: Chromosomal aberrations in pituitary carcinoma metastases. Acta Neuropathol (Berl) 102:117-120, 2001

221. Rickert $\mathrm{CH}$, Simon R, Bergmann M, et al: Comparative genomic hybridization in pineal parenchymal tumors. Genes Chromosomes Cancer 30:99-104, 2001

222. Rickert CH, Wiestler OD, Paulus W: Chromosomal imbalances in choroid plexus tumors. Am J Pathol 160:1105-1113, 2002

223. Rienstein S, Adams EF, Pilzer D, et al: Comparative genomic hybridization analysis of craniopharyngiomas. J Neurosurg 98: $162-164,2003$

224. Rienstein S, Loven D, Israeli O, et al: Comparative genomic hybridization analysis of radiation-associated and sporadic meningiomas. Cancer Genet Cytogenet 131:135-140, 2001

225. Roberts P, Chumas PD, Picton S, et al: A review of the cytogenetics of 58 pediatric brain tumors. Cancer Genet Cytogenet 131:1-12, 2001

226. Rock JP, Babu VR, Drumheller T, et al: Cytogenetic findings in pituitary adenoma: results of a pilot study. Surg Neurol 40:224-229, 1993

227. Rogatto SR, Casartelli C, Rainho CA, et al: Chromosomes in the genesis and progression of ependymomas. Cancer Genet Cytogenet 69:146-152, 1993

228. Roland B, Pinto A: Hyperdiploid karyotype in a choroid plexus papilloma. Cancer Genet Cytogenet 90:130-131, 1996

229. Rossi MR, Gaile D, Laduca J, et al: Identification of consistent novel submegabase deletions in low-grade oligodendrogliomas using array-based comparative genomic hybridization. Genes Chromosomes Cancer 44:85-96, 2005

230. Rowley JD: Letter: A new consistent chromosomal abnormality in chronic myelogenous leukaemia identified by quinacrine fluorescence and Giemsa staining. Nature 243:290-293, 1973

231. Russo C, Pellarin M, Tingby O, et al: Comparative genomic hybridization in patients with supratentorial and infratentorial primitive neuroectodermal tumors. Cancer 86:331-339, 1999

232. Sainati L, Bolcato S, Montaldi A, et al: Cytogenetics of pedi- 
atric central nervous system tumors. Cancer Genet Cytogenet 91:13-27, 1996

233. Sanoudou D, Tingby O, Ferguson-Smith MA, et al: Analysis of pilocytic astrocytoma by comparative genomic hybridization. Br J Cancer 82: 1218-1222, 2000

234. Sawyer JR, Husain M, Lukacs JL, et al: Telomeric fusion as a mechanism for the loss of $1 \mathrm{p}$ in meningioma. Cancer Genet Cytogenet 145:38-48, 2003

235. Sawyer JR, Husain M, Pravdenkova S, et al: A role for telomeric and centromeric instability in the progression of chromosome aberrations in meningioma patients. Cancer 88:440-453, 2000

236. Sawyer JR, Roloson GJ, Bell JM, et al: Telomeric associations in the progression of chromosome aberrations in pediatric solid tumors. Cancer Genet Cytogenet 90:1-13, 1996

237. Sawyer JR, Roloson GJ, Chadduck WM, et al: Cytogenetic findings in a pleomorphic xanthoastrocytoma. Cancer Genet Cytogenet 55:225-230, 1991

238. Sawyer JR, Sammartino G, Husain M, et al: Constitutional $\mathrm{t}(16 ; 22)(\mathrm{p} 13.3 ; \mathrm{q} 11.2$ approximately 12$)$ in a primitive neuroectodermal tumor of the pineal region. Cancer Genet Cytogenet 142:73-76, 2003

239. Sawyer JR, Thomas EL, Roloson GJ, et al: Telomeric associations evolving to ring chromosomes in a recurrent pleomorphic xanthoastrocytoma. Cancer Genet Cytogenet 60:152-157, 1992

240. Sayagues JM, Tabernero MD, Maillo A, et al: Intratumoral patterns of clonal evolution in meningiomas as defined by multicolor interphase fluorescence in situ hybridization (FISH): is there a relationship between histopathologically benign and atypical/anaplastic lesions? J Mol Diagn 6:316-325, 2004

241. Scheil S, Bruderlein S, Eicker M, et al: Low frequency of chromosomal imbalances in anaplastic ependymomas as detected by comparative genomic hybridization. Brain Pathol 11:133-143, 2001

242. Scheurlen WG, Schwabe GC, Seranski P, et al: Mapping of the breakpoints on the short arm of chromosome 17 in neoplasms with an i(17q). Genes Chromosomes Cancer 25:230-240, 1999

243. Schmidt H, Taubert H, Meye A, et al: Gains in chromosomes 7, $8 q, 15 q$ and $17 q$ are characteristic changes in malignant but not in benign peripheral nerve sheath tumors from patients with Recklinghausen's disease. Cancer Lett 155:181-190, 2000

244. Schmidt H, Taubert H, Wurl P, et al: Cytogenetic characterization of six malignant peripheral nerve sheath tumors: comparison of karyotyping and comparative genomic hybridization. Cancer Genet Cytogenet 128:14-23, 2001

245. Schmidt H, Wurl P, Taubert H, et al: Genomic imbalances of $7 p$ and $17 q$ in malignant peripheral nerve sheath tumors are clinically relevant. Genes Chromosomes Cancer 25:205-211, 1999

246. Schmidt MH, Gottfried ON, von Koch CS, et al: Central neurocytoma: a review. J Neurooncol 66:377-384, 2004

247. Schrock E, du Manoir S, Veldman T, et al: Multicolor spectral karyotyping of human chromosomes. Science 273:494-497, 1996

248. Schrock E, Thiel G, Lozanova T, et al: Comparative genomic hybridization of human malignant gliomas reveals multiple amplification sites and nonrandom chromosomal gains and losses. Am J Pathol 144:1203-1218, 1994

249. Shapiro JR, Pu PY, Mohamed AN, et al: Chromosome number and carmustine sensitivity in human gliomas. Cancer 71: 4007-4021, 1993

250. Shlomit R, Ayala AG, Michal D, et al: Gains and losses of DNA sequences in childhood brain tumors analyzed by comparative genomic hybridization. Cancer Genet Cytogenet 121:67-72, 2000

251. Short MP, Richardson EP Jr, Haines JL, et al: Clinical, neuropathological and genetic aspects of the tuberous sclerosis complex. Brain Pathol 5:173-179, 1995

252. Sigurdson AJ, Bondy ML, Hess KR, et al: Gamma-ray muta- gen sensitivity and survival in patients with glioma. Clin Cancer Res 4:3031-3035, 1998

253. Singh SK, Clarke ID, Terasaki M, et al: Identification of a cancer stem cell in human brain tumors. Cancer Res 63:5821-5828, 2003

254. Singh SK, Hawkins C, Clarke ID, et al: Identification of human brain tumour initiating cells. Nature 432:396-401, 2004

255. Smeets DF: Historical prospective of human cytogenetics: from microscope to microarray. Clin Biochem 37:439-446, 2004

256. Sorensen PH, Wu JK, Berean KW, et al: Olfactory neuroblastoma is a peripheral primitive neuroectodermal tumor related to Ewing sarcoma. Proc Natl Acad Sci U S A 93:1038-1043, 1996

257. Squire JA, Arab S, Marrano P, et al: Molecular cytogenetic analysis of glial tumors using spectral karyotyping and comparative genomic hybridization. Mol Diagn 6:93-108, 2001

258. Sreekantaiah C, Jockin H, Brecher ML, et al: Interstitial deletion of chromosome 11q in a pineoblastoma. Cancer Genet Cytogenet 39:125-131, 1989

259. Stenman G, Kindblom LG, Johansson M, et al: Clonal chromosome abnormalities and in vitro growth characteristics of classical and cellular schwannomas. Cancer Genet Cytogenet 57:121-131, 1991

260. Stratton MR, Darling J, Lantos PL, et al: Cytogenetic abnormalities in human ependymomas. Int J Cancer 44:579-581, 1989

261. Szymas J, Schluens K, Liebert W, et al: Genomic instability in pituitary adenomas. Pituitary 5:211-219, 2002

262. Tabernero MD, Espinosa AB, Maillo A, et al: Characterization of chromosome 14 abnormalities by interphase in situ hybridization and comparative genomic hybridization in 124 meningiomas: correlation with clinical, histopathologic, and prognostic features. Am J Clin Pathol 123:744-751, 2005

263. Tarkkanen M, Kiuru-Kuhlefelt S, Blomqvist C, et al: Clinical correlations of genetic changes by comparative genomic hybridization in Ewing sarcoma and related tumors. Cancer Genet Cytogenet 114:35-41, 1999

264. Taruscio D, Danesi R, Montaldi A, et al: Nonrandom gain of chromosome 7 in central neurocytoma: a chromosomal analysis and fluorescence in situ hybridization study. Virchows Arch 430:47-51, 1997

265. Taylor MD, Liu L, Raffel C, et al: Mutations in SUFU predispose to medulloblastoma. Nat Genet 31:306-310, 2002

266. Taylor MD, Mainprize TG, Squire JA, et al: Molecular genetics of pineal region neoplasms. J Neurooncol 54:219-238, 2001

267. Teo C, Nakaji P, Symons P, et al: Ependymoma. Childs Nerv Syst 19:270-285, 2003

268. Teyssier JR, Ferre D: Frequent clonal chromosomal changes in human non-malignant tumors. Int J Cancer 44:828-832, 1989

269. Thangavelu M, Turina J, Tomita T, et al: Clonal cytogenetic abnormalities in pediatric brain tumors: cytogenetic analysis and clinical correlation. Pediatr Neurosurg 28:15-20, 1998

270. Thiel G, Losanowa T, Kintzel D, et al: Karyotypes in 90 human gliomas. Cancer Genet Cytogenet 58:109-120, 1992

271. Thiel G, Lozanova T, Vogel S, et al: Age-related nonrandom chromosomal abnormalities in human low-grade astrocytomas. Hum Genet 91:547-550, 1993

272. Tong CY, Hui AB, Yin XL, et al: Detection of oncogene amplifications in medulloblastomas by comparative genomic hybridization and array-based comparative genomic hybridization. J Neurosurg 100 (2 Suppl Pediatrics):187-193, 2004

273. Tong CY, Ng HK, Pang JC, et al: Central neurocytomas are genetically distinct from oligodendrogliomas and neuroblastomas. Histopathology 37:160-165, 2000

274. Tong WM, Ohgaki H, Huang H, et al: Null mutation of DNA strand break-binding molecule poly(ADP-ribose) polymerase causes medulloblastomas in p53(-/-) mice. Am J Pathol 162: 343-352, 2003

275. Trask BJ: Human cytogenetics: 46 chromosomes, 46 years and counting. Nat Rev Genet 3:769-778, 2002 
276. Trautmann K, Thakker RV, Ellison DW, et al: Chromosomal aberrations in sporadic pituitary tumors. Int J Cancer 91: 809-814, 2001

277. Travis JA, Sandberg AA, Neff JR, et al: Cytogenetic findings in malignant triton tumor. Genes Chromosomes Cancer 9:1-7, 1994

278. Vagner-Capodano AM, Gentet JC, Gambarelli D, et al: Cytogenetic studies in 45 pediatric brain tumors. Pediatr Hematol Oncol 9:223-235, 1992

279. Vagner-Capodano AM, Grisoli F, Gambarelli D, et al: Correlation between cytogenetic and histopathological findings in 75 human meningiomas. Neurosurgery 32:892-900, 1993

280. Vagner-Capodano AM, Hairion D, Gambarelli D, et al: A new approach of brain tumors: the cytogenetic study. J Neuroradiol 18:107-121, 1991

281. Vagner-Capodano AM, Zattara-Cannoni H, Gambarelli D, et al: Cytogenetic study of 33 ependymomas. Cancer Genet Cytogenet 115:96-99, 1999

282. Vagner-Capodano AM, Zattara-Cannoni H, Gambarelli D, et al: Detection of $\mathrm{i}(17 \mathrm{q})$ chromosome by fluorescent in situ hybridization (FISH) with interphase nuclei in medulloblastoma. Cancer Genet Cytogenet 78:1-6, 1994

283. Velagaleti GV, Miettinen M, Gatalica Z: Malignant peripheral nerve sheath tumor with rhabdomyoblastic differentiation (malignant triton tumor) with balanced $\mathrm{t}(7 ; 9)(\mathrm{q} 11.2 ; \mathrm{p} 24)$ and unbalanced translocation $\operatorname{der}(16) \mathrm{t}(1 ; 16)(\mathrm{q} 23 ; \mathrm{q} 13)$. Cancer Genet Cytogenet 149:23-27, 2004

284. Vogt N, Lefevre SH, Apiou F, et al: Molecular structure of double-minute chromosomes bearing amplified copies of the epidermal growth factor receptor gene in gliomas. Proc Natl Acad Sci U S A 101:11368-11373, 2004

285. Vukovic B, Park PC, Al-Maghrabi J, et al: Evidence of multifocality of telomere erosion in high-grade prostatic intraepithelial neoplasia (HPIN) and concurrent carcinoma. Oncogene 22:1978-1987, 2003

286. Wacker MR, Cogen PH, Etzell JE, et al: Diffuse leptomeningeal involvement by a ganglioglioma in a child. Case report. J Neurosurg 77:302-306, 1992

287. Wang XY, Smith DI, Liu W, et al: GBAS, a novel gene encoding a protein with tyrosine phosphorylation sites and a transmembrane domain, is co-amplified with EGFR. Genomics 49:448-451, 1998

288. Ward S, Harding B, Wilkins P, et al: Gain of $1 \mathrm{q}$ and loss of 22 are the most common changes detected by comparative genomic hybridisation in paediatric ependymoma. Genes Chromosomes Cancer 32:59-66, 2001

289. Warren C, James LA, Ramsden RT, et al: Identification of recurrent regions of chromosome loss and gain in vestibular schwannomas using comparative genomic hybridisation. J Med Genet 40:802-806, 2003

290. Webb HD, Griffin CA: Cytogenetic study of acoustic neuroma. Cancer Genet Cytogenet 56:83-84, 1991

291. Weber RG, Sabel M, Reifenberger J, et al: Characterization of genomic alterations associated with glioma progression by comparative genomic hybridization. Oncogene 13:983-994, 1996

292. Weiss WA, Burns MJ, Hackett C, et al: Genetic determinants of malignancy in a mouse model for oligodendroglioma. Cancer Res 63:1589-1595, 2003

\section{J. Bayani, A. Pandita, and J. A. Squire}

293. Weremowicz S, Kupsky WJ, Morton CC, et al: Cytogenetic evidence for a chromosome 22 tumor suppressor gene in ependymoma. Cancer Genet Cytogenet 61:193-196, 1992

294. Wernicke C, Thiel G, Lozanova T, et al: Involvement of chromosome 22 in ependymomas. Cancer Genet Cytogenet 79: $173-176,1995$

295. Wernicke C, Thiel G, Lozanova T, et al: Numerical aberrations of chromosomes 1, 2, and 7 in astrocytomas studied by interphase cytogenetics. Genes Chromosomes Cancer 19:6-13, 1997

296. White FV, Anthony DC, Yunis EJ, et al: Nonrandom chromosomal gains in pilocytic astrocytomas of childhood. Hum Pathol 26:979-986, 1995

297. Wiltshire RN, Herndon JE II, Lloyd A, et al: Comparative genomic hybridization analysis of astrocytomas: prognostic and diagnostic implications. J Mol Diagn 6:166-179, 2004

298. Yamada K, Kasama M, Kondo T, et al: Chromosome studies in 70 brain tumors with special attention to sex chromosome loss and single autosomal trisomy. Cancer Genet Cytogenet 73:46-52, 1994

299. Yin XL, Hui AB, Liong EC, et al: Genetic imbalances in pleomorphic xanthoastrocytoma detected by comparative genomic hybridization and literature review. Cancer Genet Cytogenet 132:14-19, 2002

300. Yin XL, Hui AB, Pang JC, et al: Genome-wide survey for chromosomal imbalances in ganglioglioma using comparative genomic hybridization. Cancer Genet Cytogenet 134:71-76, 2002

301. Yin XL, Ng HK: [Molecular genetic studies on ganglioglioma.] Zhonghua Bing Li Xue Za Zhi 34:147-149, 2005 (Chi)

302. Yin XL, Pang JC, Hui AB, et al: Detection of chromosomal imbalances in central neurocytomas by using comparative genomic hybridization. J Neurosurg 93:77-81, 2000

303. Yokota H, van den Engh G, Hearst JE, et al: Evidence for the organization of chromatin in megabase pair-sized loops arranged along a random walk path in the human G0/G1 interphase nucleus. J Cell Biol 130:1239-1249, 1995

304. Yoshimoto M, de Toledo SRC, da Silva NS, et al: Comparative genomic hybridization analysis of pediatric adamantinomatous craniopharyngiomas and a review of the literature. J Neurosurg 101 (2 Pediatrics):85-90, 2004

305. Zattara-Cannoni H, Gambarelli D, Dufour H, et al: Contribution of cytogenetics and FISH in the diagnosis of meningiomas. A study of 189 tumors. Ann Genet 41:164-175, 1998

306. Zattara-Cannoni H, Gambarelli D, Lena G, et al: Are juvenile pilocytic astrocytomas benign tumors? A cytogenetic study in 24 cases. Cancer Genet Cytogenet 104:157-160, 1998

307. Zuber MA, Krupp W, Holland H, et al: Characterization of chromosomal aberrations in a case of glioblastoma multiforme combining cytogenetic and molecular cytogenetic techniques. Cancer Genet Cytogenet 138:111-115, 2002

Manuscript received September 15, 2005

Accepted in final form October 19, 2005.

Address reprint requests to: Jane Bayani, B.Sc., M.H.Sc., Ontario Cancer Institute, Princess Margaret Hospital, 610 University Avenue, Room 9-717, Toronto, Ontario, Canada M5G 2M9. email: jane.bayani @utoronto.ca. 